NBER WORKING PAPER SERIES

\title{
ON THE WELFARE COST OF CONSUMPTION FLUCTUATIONS IN THE PRESENCE OF MEMORABLE GOODS
}

\author{
Rong Hai \\ Dirk Krueger \\ Andrew Postlewaite \\ Working Paper 19386 \\ http://www.nber.org/papers/w19386 \\ NATIONAL BUREAU OF ECONOMIC RESEARCH \\ 1050 Massachusetts Avenue \\ Cambridge, MA 02138 \\ August 2013
}

We thank Hanming Fang, Eric Hurst, Nick Souleles and numerous participants of the Macro Lunch Seminar at the Economics Department, University of Pennsylvania for useful comments. We also thank Jeffrey Crilley from the Bureau of Labor Statistics for his help with CEX data. Krueger and Postlewaite thank the National Science Foundation for support. The views expressed herein are those of the authors and do not necessarily reflect the views of the National Bureau of Economic Research.

At least one co-author has disclosed a financial relationship of potential relevance for this research. Further information is available online at http://www.nber.org/papers/w19386.ack

NBER working papers are circulated for discussion and comment purposes. They have not been peerreviewed or been subject to the review by the NBER Board of Directors that accompanies official NBER publications.

(C) 2013 by Rong Hai, Dirk Krueger, and Andrew Postlewaite. All rights reserved. Short sections of text, not to exceed two paragraphs, may be quoted without explicit permission provided that full credit, including $(\subset$ notice, is given to the source. 
On the Welfare Cost of Consumption Fluctuations in the Presence of Memorable Goods

Rong Hai, Dirk Krueger, and Andrew Postlewaite

NBER Working Paper No. 19386

August 2013

JEL No. D11,D12,E21

\begin{abstract}
$\underline{\text { ABSTRACT }}$
We propose a new classification of consumption goods into nondurable goods, durable goods and a new class which we call "memorable" goods. A good is memorable if a consumer can draw current utility from its past consumption experience through memory. We propose a novel consumption-savings model in which a consumer has a well-defined preference ordering over both nondurable goods and memorable goods. Memorable goods consumption differs from nondurable goods consumption in that current memorable goods consumption may also impact future utility through the accumulation process of the stock of memory. In our model, households optimally choose a lumpy profile of memorable goods consumption even in a frictionless world. Using Consumer Expenditure Survey data, we then document levels and volatilities of different groups of consumption goods expenditures, as well as their expenditure patterns, and show that the expenditure patterns on memorable goods indeed differ significantly from those on nondurable and durable goods. Finally, we empirically evaluate our model's predictions with respect to the welfare cost of consumption fluctuations and conduct an excess-sensitivity test of the consumption response to predictable income changes. We find that (i) the welfare cost of household-level consumption fluctuations may be overstated by 1.7 percentage points $(11.9 \%$ points as opposed to $13.6 \%$ points of permanent consumption) if memorable goods are not appropriately accounted for; (ii) the finding of excess sensitivity of consumption documented in important papers of the literature might be entirely due to the presence of memorable goods.
\end{abstract}

\author{
Rong Hai \\ Postdoctoral Scholar \\ Becker Friedman Institute for Research in Economic \\ University of Chicago \\ ronghai@uchicago.edu \\ Dirk Krueger \\ Economics Department \\ University of Pennsylvania \\ 160 McNeil Building \\ 3718 Locust Walk \\ Philadelphia, PA 19104 \\ and NBER \\ dkrueger@econ.upenn.edu
}

Andrew Postlewaite
Department of Economics
University of Pennsylvania
3718 Locust Walk/CR
Philadelphia, PA 19104
apostlew@sas.upenn.edu 
We can entertain ourselves with memories of past pleasures ... [Adam Smith (1759)]

Much of the pleasure and pain we experience in daily life arises not from direct experience - that is, "consumption" - but from contemplation of our own past or future or from a comparison of the present against the past or future. The fact that experiences are carried forward in time through memory enables them to affect welfare at later times. [Quoted from Loewenstein and Elster (1992)]

\section{Introduction}

In this paper we propose to augment the canonical distinction of consumption goods into nondurable and durable goods by a third category which we call memorable goods. Conceptually, a good is memorable if a consumer draws utility from its past consumption experience, that is, through memory.

Based on this idea we construct a novel consumption-savings model of nondurable and memorable goods. Memorable goods consumption impacts future utility through the accumulation of the stock of memory. We demonstrate that in the model households optimally choose a non-smooth consumption profile of memorable goods. Our model predicts that in the presence of a negative income shock households optimally postpone their memorable goods consumption and reduce the size of memorable goods expenditure spikes. We then empirically document significant differences in expenditure patterns among nondurable, durable and memorable goods consumption, using the Consumer Expenditure Survey (CEX).

Finally, we present two applications of the model that demonstrate that the distinction between nondurable and memorable goods matters for applied questions. First, we estimate the welfare cost associated with consumption expenditure fluctuations, and find that relative to a benchmark model in which all consumption is treated as nondurable goods consumption (and which is nested in our framework), an explicit distinction and modeling of memorable goods reduces the estimated welfare cost of idiosyncratic consumption fluctuations from $13.6 \%$ points to $11.9 \%$ points of permanent consumption.

Finally we argue that the rejection of the permanent income hypothesis (PIH) based on the excess sensitivity of consumption to expected tax refund receipts documented in the literature (and concretely, by Souleles (1999)) might be entirely due to the presence of memorable goods, and that our extension of a standard PIH-style model that explicitly incorporates memorable goods is fully 
consistent with the empirical evidence. Specifically, we find that after separating memorable goods from traditionally defined nondurable goods, nondurable goods consumption does not respond to predictable federal income tax refunds.

In our model, households face income risk and choose expenditures on nondurable and memorable goods. ${ }^{1}$ Households obtain current utility from the consumption of nondurable goods, memorable goods and the stock of memory of past memorable goods consumption. The stock of memory depreciates, but can in turn be augmented by expenditures on memorable goods. However, current expenditures on memorable goods only add to the stock of memory if these expenditures exceed the weighted average of past memorable goods consumption (the consumption experience has to be memorable enough). Thus the model captures what we think are the salient features of memorable consumption goods: the timing of the physical act of consumption and the utility this act generates are de-coupled, and both expenditures as well as physical consumption occur infrequently as part of the optimal household consumption plan, and in lumps when they occur. Note that the incidence of lumpy expenditures in our model is not the result of any indivisibility or non-convex adjustment cost, but rather is a deliberate choice to do something out of the ordinary.

It is empirically plausible to explain observed lumpy consumption choices without resorting to indivisibilities in consumption for many nondurable consumption categories. For example, on Christmas in the UK, the average number of presents that children receive is 18 . Traditional consumption theory predicts that parents should have given their children one or two gifts every month instead of giving many gifts at the same time, while our model suggests that households choose lumpy consumption expenditures in order to make this consumption experience memorable: only an extraordinary consumption experience contributes to the stock of memory from Christmas. ${ }^{2}$

An immediate implication of our model is that although expenditures on memorable goods are volatile, the associated utility flow that they generate is not. This implication of the model has direct and profound consequences for the calculation of the welfare cost of consumption expenditure fluctuations because the infrequent and lumpy expenditure profile of memorable goods, as implied by the optimal choices of households, might contribute little, if anything, to the welfare

\footnotetext{
${ }^{1}$ We abstract from durable goods in the model because incorporating them is not needed for the application to the welfare cost calculations of idiosyncratic income risk. It is conceptually straightforward to augment the model to include these goods in exactly the same way the sizable literature on consumer durables has done.

${ }^{2}$ In this paper we do not discuss the possibility of "negative memories", such as the memory from a bad vacation experience. It is possible to model bad memories using regret theory, but this is beyond the scope of this paper.
} 
losses associated with volatile consumption expenditures for risk-averse households. ${ }^{3}$ When we use the model with memorable goods to quantify the welfare losses of consumption fluctuations induced by uninsurable idiosyncratic income risk, we find that the presence of memorable goods overstates this cost by 1.7 percentage points, relative to the benchmark in which memorable goods are lumped together with nondurable goods, as commonly done in the literature. This finding stems directly from the facts that a) memorable goods expenditure constitutes a significant share of the sum of expenditures on both nondurable and memorable goods (about 16\%), b) expenditures on memorable goods are very volatile over time and c) according to our model this volatility in expenditures is not associated with a significant welfare loss, relative to a smooth consumption profile. Indeed, according to our model a smooth consumption expenditure profile of memorable goods is suboptimal.

A household's consumption expenditure encompasses a wide array of goods with vastly different characteristics. In order to make the concept of a memorable good useful, we need an operational definition. Traditionally, consumption goods are differentiated only according to whether or not they have a physically durable component. For a nondurable consumption good, expenditures on the good and the physical, utility-generating consumption act typically occur frequently and coincide. After the act of consumption the good is physically gone. Durable goods are typically purchased infrequently, but their utility-yielding continuous service flow lasts as long as the durable good is physically present. We take the key defining characteristics of a memorable good as its infrequent expenditure and infrequent physical consumption (after which the good is physically fully depreciated), combined with the continued utility flow (via memory) from the physically fully consumed good. See Figure 1 for a representation of our classification. Thus a good is memorable (as opposed to durable) if, even though it is not physically present anymore, the consumer derives utility from its past consumption because she still remembers it. ${ }^{4}$ A memorable good (as opposed to nondurable good) is infrequently purchased and infrequently consumed, while nondurable goods

\footnotetext{
${ }^{3}$ One prominent example is the expenditure on weddings. Web sites dealing with the finances of marriages show that the average budget for a wedding amounts to about $\$ 20,000$, while the average household income of a newly married couple is $\$ 55,000$ annually. Many wedding expenditures, such as the expenditure for the honeymoon, the reception site rental, outlays for photography and video services, rehearsal dinner etc., are commonly categorized as nondurable consumption expenditures. We suggest that due to the (hopefully) memorable component in wedding consumption, there is no significant welfare loss associated with the nonsmoothness of household consumption expenditures due to the incidence of a wedding.

${ }^{4}$ Since a memorable good is not physically present anymore after their consumption they also cannot serve as collateral. Thus, and in stark contrast to durable goods, memorable goods are typically hard to purchase on credit.
} 
are frequently purchased and frequently consumed. For example, a luxurious dinner on a trip occurs infrequently while an ordinary dinner at home happens on a daily basis. A typical set of goods that we classify as memorable goods includes dining out, food for catered affairs, trips and vacations, photographic rental and services, clothes and jewelry, and religious and welfare activities. Note that these goods are typically classified as nondurable goods, see e.g., Cutler and Katz (1991) or Souleles (1999).

Figure 1: Purchase and Consumption Patterns

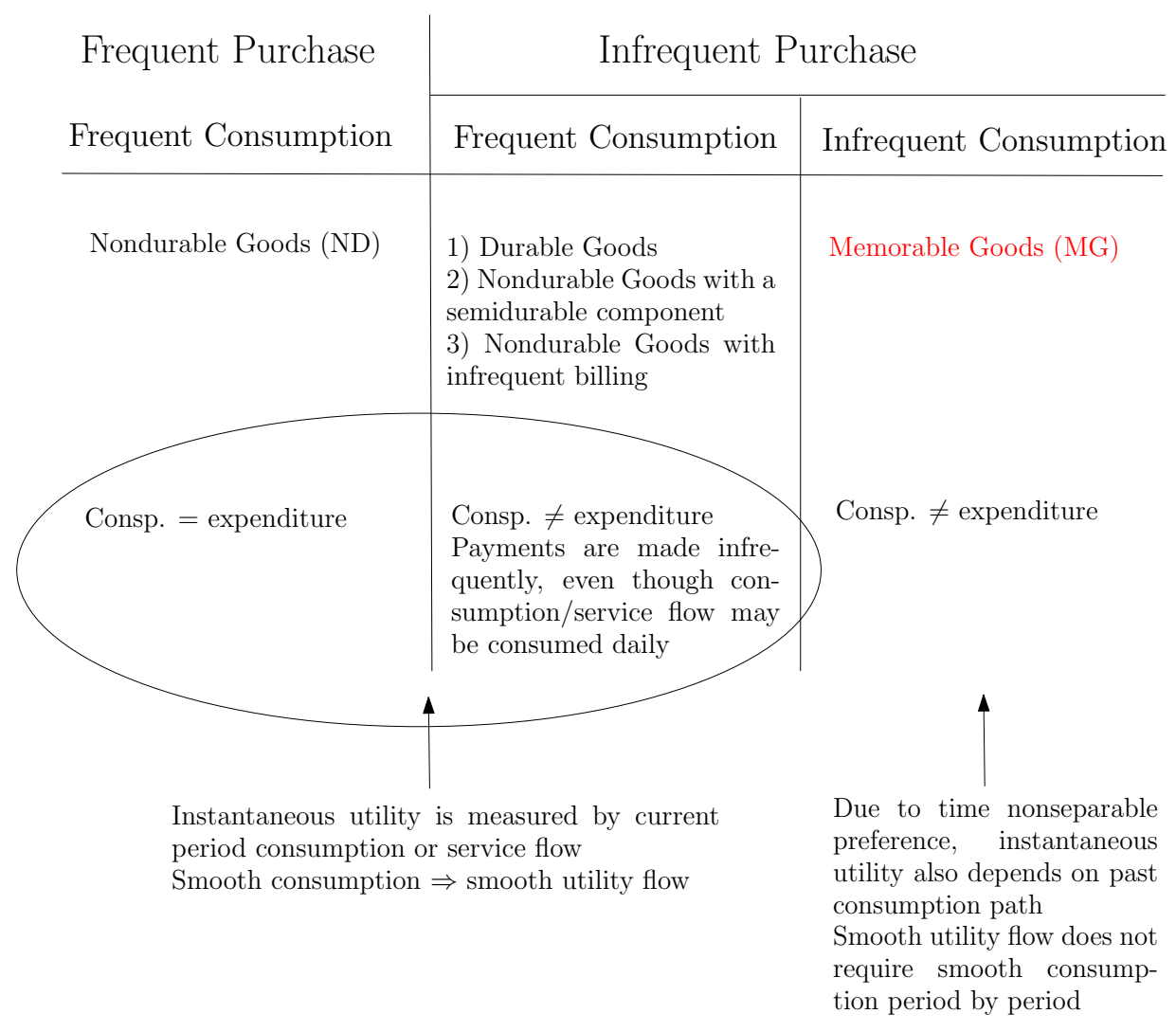

Based on our heuristic definition of memorable goods we turn to the CEX and classify goods into three categories (nondurable goods, durable goods and memorable goods; see Table 9 for a summary and see Tables 10-12 for detailed information) and document salient features of their monthly and quarterly expenditure patterns for individual households over a 12 month time period. We show that memorable goods display more expenditure volatility than nondurable goods, and a higher incidence of zero expenditures over the observed 12 month time period across households (which we 
term inactivity). In contrast, memorable goods expenditures are less volatile and display a lower incidence of zero expenditures than durable goods, both on a monthly basis and on a quarterly basis.

Finally, we show that if one distinguishes expenditures on nondurable and memorable goods in the excess sensitivity test of the permanent income hypothesis using anticipated income tax refunds as in Souleles (1999), the rejection of the PIH is entirely due to the consumption response of expenditures on memorable goods. However, as we argued above, a lumpy change in expenditures on memorable goods in response to an expected income change is fully consistent with our theoretical model, which we view as a natural extension of the standard PIH style consumption-savings model that incorporates memorable goods.

The paper is organized as follows. In the next subsection we briefly relate our work to the existing literature before turning to a description of our model in Section 2. In that section we develop our model of memorable goods and characterize its properties theoretically and numerically via simulations. Section 3 contains the results of a descriptive empirical analysis using CEX consumption data. The purpose of this section is to empirically validate the basic predictions of the theoretical model of Section 2. In the next two sections we turn to two applications of our theory. In Section 4 we analyze the welfare cost of consumption fluctuations in the presence of memorable goods, first using reduced form regressions, and then employing our structural model. In Section 5, we revisit Souleles's (1999) empirical evidence against the permanent income hypothesis when distinguishing between nondurable and memorable goods. Section 6 concludes. Details about the theoretical properties of the model, the numerical solution procedure and the CEX data used in the empirical analysis are relegated to the appendix.

\subsection{Relation to the Literature}

Our paper is related to several strands of the empirical and theoretical literature on household consumption and its response to income shocks. On the empirical side a recent set of papers uses disaggregate household-level data to document stylized facts about the detailed composition of consumption expenditures across different categories. Charles and Stephens (2006) finds that the level and composition of household consumption expenditure change significantly over the business cycle, and that this change depends on their income. Aguiar and Hurst (2008) document that the behavior of total expenditures on nondurable goods over the life cycle masks substantial heterogeneity in the profiles of individual consumption sub-components. 
On the theoretical side, our paper contributes to the literature on modeling household dynamic consumption and savings choices, by proposing and analyzing a novel consumption-savings model with memorable goods. Our paper therefore complements the large literature, starting from Friedman (1957) and Modigliani and Brumberg (1954), that models nondurable consumption choices, as well as the literature on modeling expenditures and consumption on durable goods (see e.g. Mankiw (1982)) and the work that proposes non-time-separable preferences over streams of consumption (see e.g. the habit persistence models of Abel (1990) or Campbell and Cochrane (1999) or models with recursive preferences as in Epstein and Zin (1989)).

It has long been understood that an individual may care about past consumption because of the memories associated with past consumption. See, for example, the quotations of Smith (1759) and Loewenstein and Elster (1992) at the beginning of the introduction. The formal incorporation of utility derived from past consumption dates (at least) back to Strotz's classic paper on dynamic consistency (Strotz (1955)). His formulation incorporated utility from past consumption to allow for "the possibility that a person is not indifferent to his consumption history but enjoys his memories of it". 5

Strotz's model is very general and can easily accommodate the notion of memories that is the focus of this paper, but is overly general for our purposes in some other respects. Strotz puts little structure on the evolution of preferences, that is, the connection between individuals' preferences at different points in his life over life-long consumption paths. This lack of restrictions placed on the evolution of an individual's preferences can lead to time inconsistency, which is what Strotz wanted to point to. Agents' preferences in our model fit into Strotz's framework: an agent will have welldefined preferences over any set of life-long consumption paths, and those preferences will evolve over time. At any given point in time, an agent will have preferences over consumption paths, and the preferences over future consumption will depend on previous consumption. Unlike the general case in Strotz, however, in our formulation preferences are fully time consistent. Thus, we separate the consequences of agents enjoying memories of past consumption from the conceptually different issue of time inconsistency. We view as one advantage of our approach the fact that our model is a straightforward extension of standard consumption-savings models, which allows a clear

\footnotetext{
${ }^{5}$ Strotz began with an individual comparing all possible life-long consumption paths, but at different points in his life. In this framework the individual at some given date $t$ may strictly prefer a consumption path $c$ to path $\hat{c}$, when the paths $c$ and $\hat{c}$ are identical from $t$ onward if consumption path $c$ generated fond memories prior to period $t$ that are absent in path $\hat{c}$.
} 
understanding of the role memories play for optimal dynamic consumption decisions.

We present two applications of the empirical distinction between nondurable and memorable goods. When we revisit Souleles's (1999) empirical test of the permanent income hypothesis using income tax return data, we contribute to the massive body of work that uses household level data to assess the extent to which consumption responds to expected changes in income (starting with Hall (1978)) as well as income shocks. ${ }^{6}$ Hamermesh (1982) notes that if agents cut back on total expenditure there will be a bigger proportional impact on luxuries. Zeldes (1989) tests the permanent income hypothesis and finds that an inability to borrow against future labor income affects the consumption of a significant portion of the population. Nelson (1994) has pointed out that many nondurable goods feature lumpy consumption and infrequent purchases. Parker (1999) finds consumers do not perfectly smooth their consumption expenditure across expected income changes; moreover, the consumption goods that have larger intertemporal elasticity of substitution respond more to predictable income changes. Souleles (1999) produces significant evidence of excess sensitivity in the response of households' nondurable consumption to their income tax refunds even without the presence of liquidity constraints. Browning and Crossley (2000) show that luxuries have a high intertemporal substitution elasticity and thus are easy to postpone. Browning and Crossley (1999) show that liquidity constrained agents cut back on expenditures on small durables during a low income spell much more than would be suggested by the income elasticities of these goods in 'normal' times, while nondurable expenditures flows are much smoother than would be predicted in a model without durables. Charles and Stephens (2006) find that in bad economic times the lower income groups reduced the shares of their total outlays, and these downward adjustments are primarily concentrated among reductions in outlays devoted to entertainment and personal care expenditures.

Finally, our paper contributes to the literature that measures the welfare cost of consumption fluctuations. Using aggregate consumption data, Lucas (1987) calculates that the welfare gains from eliminating all aggregate consumption fluctuations is less than one-hundredth of one percent of consumption when preferences are logarithmic. However, using micro-level consumption data, the welfare losses of idiosyncratic consumption fluctuations are orders of magnitude larger, following the same Lucas (1987) approach. Gorbachev (2011) argues that the welfare losses of household-level nondurable consumption fluctuations equal $4.15 \%$ of annual nondurable consumption, under log

\footnotetext{
${ }^{6}$ See Hall and Mishkin (1982) for a seminal contribution and Jappelli and Pistaferri (2010) for a recent survey of the literature.
} 
preferences and using Panel Study of Income Dynamics (PSID) data on food expenditures. These results are in the same order of magnitude as the ones documented in this paper when we use CEX data and ignore memorable goods.

\section{The Model}

In this section, we present a novel consumption-savings model with memorable goods and discuss its qualitative predictions. Denote by $C_{m t}$ and $C_{n t}$ real contemporaneous consumption expenditures on memorable goods and nondurable goods, respectively. We assume that households have preferences defined over contemporaneous consumption $C_{m t}$ and $C_{n t}$, and in addition, over the stock of memory $M_{t}$ from past memorable consumption expenditures. Specifically, we assume that household preferences can be represented by a period utility function of the following form ${ }^{7}$

$$
U\left(C_{n t}, C_{m t}, M_{t}\right)=\xi \frac{C_{n t}^{1-\gamma}}{1-\gamma}+(1-\xi) \frac{\left(\alpha C_{m t}+(1-\alpha) M_{t}\right)^{1-\gamma}}{1-\gamma} .
$$

The utility from memorable goods consumption is the weighted sum of the direct utility obtained from the act of consumption $C_{m t}$ and the stock of memory $M_{t}$ from past memorable goods consumption, with weight $\alpha$ controlling the importance of immediate memorable goods consumption $C_{m}$ relative to the stock of memory $M_{t}$. When $\alpha=1$, memorable goods become standard nondurable goods. The parameter $\xi$ governs the relative importance of nondurable goods consumption to memorable goods consumption, and $1 / \gamma$ measures the intertemporal elasticity of substitution, assumed to be the same for nondurable and memorable goods.

In addition to specifying how instantaneous utility depends on the stock of memory we need to take a stance on how it is updated over time. In order to capture the idea that only an unusual consumption experience contributes to the stock of memory, we introduce a variable, $N_{t}$, to represent the threshold value for a consumption experience to be indeed memorable. We assume that memorable goods expenditure $C_{m t}$ only adds to the stock of memory $M_{t}$ if it exceeds the threshold value of being memorable $N_{t}$ at time $t$. Specifically, the law of motion of the stock of

\footnotetext{
${ }^{7} \mathrm{~A}$ more general utility specification that relaxes the additive separability between nondurable and memorable goods would be given by

$$
U\left(C_{n t}, C_{m t}, M_{t}\right)=\frac{\left(\xi C_{n t}^{\nu}+(1-\xi)\left(\alpha C_{m t}+(1-\alpha) M_{t}\right)^{\nu}\right)^{\frac{1-\gamma}{\nu}}}{1-\gamma}
$$

with $\nu \neq 1$. The separable formulation leads to qualitative predictions of the model that are more easily interpretable and it turns out to be sufficiently flexible to provide a good fit of the data.
} 
memory $M_{t}$ is characterized by

$$
M_{t+1}=\left(1-\delta_{m}\right) M_{t}+\max \left\{C_{m t}-N_{t}, 0\right\}
$$

where $\delta_{m} \in[0,1]$ measures the speed with which the stock of memory depreciates. ${ }^{8}$

The threshold value $N_{t}$ itself could in principle depend on the individual's complete history of past consumption experience up to time $t$, i.e., $N_{t}=N\left(C_{m 1}, C_{m 2}, \ldots, C_{m t}\right)$. We parameterize the evolution of $N_{t}$ as an $\operatorname{AR}(1)$ process in the following parsimonious way,

$$
N_{t+1}=(1-\rho) N_{t}+\rho C_{m t}
$$

where $\rho \in[0,1]$ controls the weight of current memorable goods consumption on the threshold value. When $\rho=1$, only the most recent immediate memorable goods consumption matters for the past consumption experience, that is, $N_{t}=C_{m, t-1}$. In contrast, when $\rho$ is close to 0 , the impact of $C_{m t}$ on the threshold value of being memorable is small.

To illustrate the conceptual difference in the stock of memories $M$ and the threshold value of being memorable $N$, we take a completely smooth consumption plan, $C_{m, t}=\bar{C}_{m}$ for all $t$, as an example. In this case, the threshold value of being memorable is $N_{t}=\bar{C}_{m}$ while the stock of memories is $M_{t}=0$.

The standard CRRA utility function that does not differentiate between memorable goods and nondurable goods and has no memorable goods stock is a special case of our utility function in equation 1 , with $\xi=1$

$$
U\left(C_{t}\right)=\frac{C_{t}^{1-\gamma}}{1-\gamma}
$$

and $C_{t}=C_{n t}+C_{m t}$.

Given the period utility function, the intertemporal household consumption-savings problem is completely standard. The household faces a stochastic income process $\left\{Y_{t}\right\}$ and aims at maximizing

\footnotetext{
${ }^{8}$ This feature of the model will insure that memorable goods are consumed infrequently even in the absence of nonconvex adjustment costs and indivisibilities. It therefore constitutes an important difference to the standard way consumer durables are modeled.

With memorable goods the way modeled here a consumer who has incurred a large memorable expense this period may well have higher utility if she postponed further expenditures from next period to a later period since there would be a greater increment to the memory stock. The standard treatment of durable goods instead adds the expenditure on a durable good to its stock and specifies a utility flow from that stock, independent of the timing of the expenses that led to this stock.
} 
time zero expected lifetime utility

$$
\mathbb{E}_{0} \sum_{t=0}^{\infty} \beta^{t} U\left(C_{n t}, C_{m t}, M_{t}\right)
$$

subject to a sequence of budget constraints

$$
C_{m t}+C_{n t}+S_{t+1} \leq Y_{t}+(1+r) S_{t}
$$

where $S_{t}$ is the beginning of the period position of riskless assets. The exogenous net return $r$ on these assets is assumed to be nonstochastic and constant. Furthermore, we assume that the household faces a tight borrowing constraint:

$$
S_{t+1} \geq 0
$$

For the stochastic process governing monthly income, we assume that $Y_{t}$ is determined as the sum of a permanent component $\bar{y}$ and an income shock $z_{t}$ that follows an $A R(1)$ process $^{9}$

$$
\begin{aligned}
\ln Y_{t} & =\bar{y}+z_{t} \\
z_{t} & =\rho_{z} z_{t-1}+\epsilon_{t}
\end{aligned}
$$

where $\bar{y}$ is the average log-income of the household, $\rho_{z}$ measures the persistence of the income shock, and the shock itself is distributed normally with variance $\sigma_{\epsilon}^{2}$, that is $\epsilon_{t} \stackrel{i i d}{\sim} N\left(0, \sigma_{\epsilon}^{2}\right)$.

Therefore, the conditional distribution of $z_{t}$ is given by $z_{t} \sim N\left(\rho_{z} z_{t-1}, \sigma_{\epsilon}^{2}\right)$, and the unconditional distribution of $z_{t}$ is given by $z_{t} \sim N\left(0, \frac{\sigma_{\epsilon}^{2}}{1-\rho_{z}^{2}}\right)$. Moreover, the unconditional expected income is given by $\mathbb{E}\left(Y_{t}\right)=\mathbb{E}\left(\exp \left(\bar{y}+z_{t}\right)\right)=\exp \left(\bar{y}+\frac{1}{2} \frac{\sigma_{\epsilon}^{2}}{1-\rho_{z}^{2}}\right)$. In addition, we make the following assumption:

\section{Assumption 1}

$$
(1+r) \beta \leq 1, \quad 0<\rho \leq 1, \quad 0<\delta_{m}<1 .
$$

\footnotetext{
${ }^{9}$ This specification is equivalent to assuming a process of the form: $\ln Y_{t}=\left(1-\rho_{z}\right) \bar{y}+\rho_{z} \ln Y_{t-1}+\epsilon_{t}$.
} 


\subsection{Numerical Model Solution}

The household's maximization problem can be recast as a dynamic programming problem with state variables $(M, N, S, z)$. It is given by

$$
\begin{aligned}
V(M, N, S, z) & =\max _{C_{m}, S^{\prime}}\left\{U\left(C_{n}, C_{m}, M\right)+\beta \mathbb{E}\left[V\left(M^{\prime}, N^{\prime}, S^{\prime}, z^{\prime}\right) \mid z\right]\right\} \\
\text { s.t. } & \\
C_{n} & =Y+(1+r) S-C_{m}-S^{\prime} \\
M^{\prime} & =\left(1-\delta_{m}\right) M+\max \left\{C_{m}-N, 0\right\} \\
N^{\prime} & =(1-\rho) N+\rho C_{m} \\
S^{\prime} & \geq 0 \\
\ln Y & =\bar{y}+z \\
z^{\prime} & =\rho_{z} z+\epsilon .
\end{aligned}
$$

The model with memorable goods consumption in general has no analytical solution, so we need to solve it numerically. The main challenges are that with 4 continuous state variables $(M, N, S, z)$ the state space is large. In addition, our specification of memorable good results in a maximization that is not a convex programming problem, and the resulting policy functions (especially for $C_{m}$ ) will be discontinuous in the state variables, especially the stock of memory $M$ and the threshold of being memorable $N$. To deal with the large state space and the discontinuity in policy function for memorable goods consumption, we use a Smolyak sparse grid collocation algorithm and approximate the value function (but not the policy functions) by a linear combination of polynomials at each grid point. ${ }^{10}$ Further details on the solution algorithm are provided in Appendix B.

\subsection{Qualitative Features}

In order to derive insights into the qualitative features of our model it is instructive to investigate individuals' optimal consumption profile in a "frictionless" case where there is no income risk and no binding borrowing constraints. We then turn to numerical simulation results from a parameterized version of the model.

\footnotetext{
${ }^{10}$ See Smolyak (1963), Barthelmann et al. (2000), Krueger and Kubler (2004), and Malin et al. (2007) for the details of Smolyak's algorithm.
} 


\subsubsection{Theoretical Results}

When there is no income risk, no borrowing constraint and $(1+r) \beta=1$, the standard consumptionsavings model (without memorable goods) predicts that households optimally choose a completely smooth consumption plan. However, in the presence of memorable goods, households don't find it optimal to choose a smooth consumption plan, even in this case. In particular, consider a special case where the threshold value of being memorable depends only on previous memorable goods consumption expenditures, i.e., $\rho=1$. Using the first order conditions of an individual's optimization problem, we can show that a smooth consumption plan is never optimal. The result is summarized in Proposition 1. The details of the proof are provided in Appendix A.

Proposition 1 If there is no income risk and no borrowing constraint and $(1+r) \beta=1$ and $\rho=1$, then a smooth memorable consumption plan is never optimal for any initial memory stock $M_{0}>0$. That is, a consumption plan $C_{m, t}=\bar{C}_{m}$ for all $t$, is never optimal, given $M_{0}>0$.

In general, when $\rho<1$, the dynamics of $C_{m, t}$ and $S_{t+1}$ are more complicated. Therefore, in order to gain some insights into the mechanics of the model we report its key quantitative features, obtained via simulations, in the remainder of this section.

\subsubsection{Simulation Results}

In order to provide further insights into the qualitative predictions of the model we rely on numerical simulations for specific parameter values. The parameters used are the same as in the quantitative welfare analysis in Section 4, and thus their calibration is discussed in detail in that section. We summarize the parameter choices in Table 1. The model is calibrated and solved for a monthly frequency.

In order to characterize the key qualitative features of the model we display simulated consumption and asset time paths for 24 periods (months), for three different realized paths of income shocks. In the benchmark scenario (I) we set the realization of all income shocks to be zero, that is $\epsilon_{t}=0$ for $t=1, \ldots, 24$ and $z_{0}=0$. This thought experiment shows the consumption and savings dynamics of the model in the absence of any shock. ${ }^{11}$ The second scenario (II) explores the response of the household to a negative income shock; 12 months of zero income shocks are followed by a one-time,

\footnotetext{
${ }^{11}$ Of course the policy functions on which these simulations are based fully take into account the stochastic structure of the model.
} 
Table 1: Parameter Values for Simulation

\begin{tabular}{|l||l|c|}
\hline Param. & Interpr. & Value \\
\hline \hline$\rho_{z}$ & Pers. of Income Shock & 0.9900 \\
\hline$\sigma_{\epsilon}$ & Std. of Income Shock & 0.0797 \\
\hline $\bar{y}$ & $\mathbb{E}(y)=1$ & -0.1598 \\
\hline$r$ & Interest Rate & $4 \%$ (p.a.) \\
\hline $1 / \beta-1$ & Time Discount Rate & $7 \%$ (p.a.) \\
\hline$\xi$ & Weight on $C_{n}$ in $U$ & 0.7598 \\
\hline$\alpha$ & Weight on $C_{m}$ in $U$ & 0.8836 \\
\hline$\rho$ & Weight on $C_{m}$ in $N$ & 0.2881 \\
\hline$\delta_{m}$ & Deprec. of Memory & 0.0861 \\
\hline
\end{tabular}

two-standard deviation, negative income shock at period 13, and no subsequent shocks thereafter. ${ }^{12}$ Finally, the third scenario (III) investigates whether the households' consumption-savings response to income shock features asymmetries by simulating a positive income shock symmetric to that of the negative income shock scenario (II). ${ }^{13}$

Further, to assess the importance of binding borrowing constraints we report the simulations for two sets of initial conditions, one in which the endogenously evolving state variables $(M, N, S)$ are set to their long run average, and one in which $M_{0}=N_{0}=0$ and $S_{0}=0$. Last, to understand the role of memories on households' optimal consumption-savings decisions, we report the simulated consumption and savings response in the special case when $\alpha=1$. In this case, the stock of memory does not enter households' utility function, and thus memorable goods become standard nondurable goods.

First, turning to household behavior in the absence of realized income shocks (benchmark scenario), we observe from Figure 2(a) that, for a household with liquid wealth, nondurable consumption is smooth over time (and slightly decreasing, since $\beta(1+r)<1$ ), whereas memorable consumption expenditures exhibit one positive spike in every three months. Although the frequency

\footnotetext{
${ }^{12}$ That is, the sequence of $\left\{\epsilon_{t}\right\}_{t=1}^{24}$ is given by $\epsilon_{t}=0$ for all $t \neq 13$, and $\epsilon_{13}=-2 \sigma_{\epsilon}=-0.16$. Therefore the absolute change in income at period 13 is $\Delta Y_{13}=\exp (\bar{y}-0.16)-\exp (\bar{y})=-0.1260$. Recall that mean income is normalized to one.

${ }^{13}$ To ensure that the increase in income in scenario III is of the same magnitude as the decrease in income in scenario II $\left(\Delta Y_{13}=\exp \left(\bar{y}+\epsilon_{13}\right)-\exp (\bar{y})=0.1260\right)$, we set the one-time positive income shock to be $\epsilon_{13}=0.1379$.
} 
and size of the memorable consumption expenditure spikes depends on the exact values of the parameters of the model (and especially on how fast memories depreciate measured by $\delta_{m}$, and how important current expenditures $C_{m}$ are in refreshing them, measured by $\rho$ ), the existence of spikes and periods of inactivity does not.

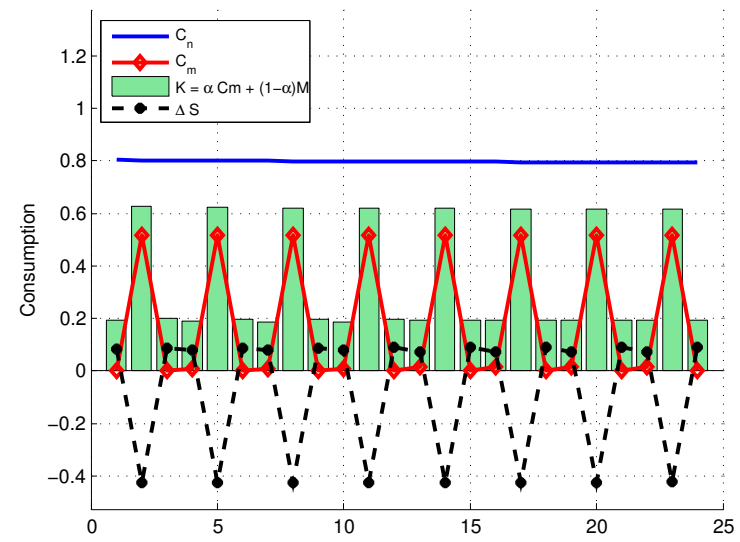

(a) $S_{1}=\bar{S}, M_{1}=\bar{M}, N_{1}=\bar{N}$

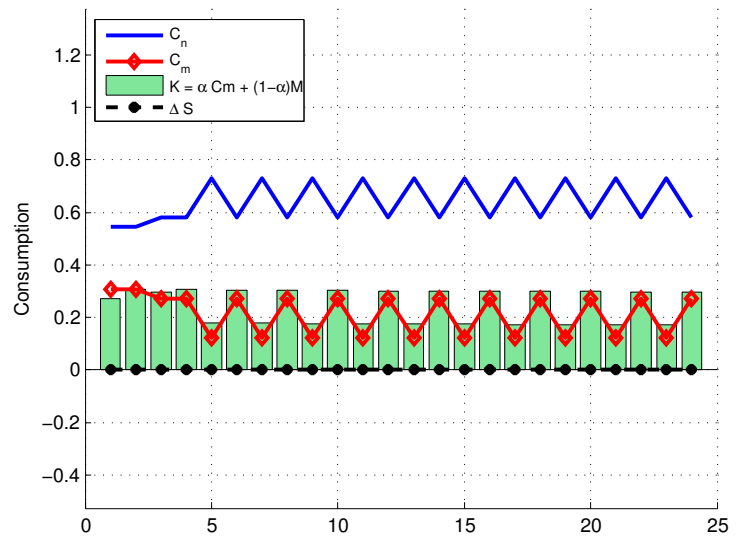

(b) $S_{1}=0, M_{1}=0, N_{1}=0$

Figure 2: Changes in Consumption and Savings (Benchmark Scenario)

Moreover, although the dynamics of nondurable consumption is largely unaffected by the presence of memorable goods for asset-rich households, ${ }^{14}$ the same is not true for liquidity constrained households, as Figure 2(b) demonstrates. For a household without financial wealth, it is still optimal to consume memorable goods in spikes; however, they become smaller and more frequent. For an asset-rich household, the positive spikes are two times as large as the household's 24-month average memorable goods expenditure, whereas for a household which is at or near borrowing constraint, the relative size of a positive memorable goods expenditure is significantly smaller. Interestingly, if the borrowing constraint is binding a positive spike in memorable consumption must be met by a fall in nondurable consumption (given that income is constant). Consequently nondurable consumption fluctuates as well, even in the absence of any realized income shocks, and even with utility from nondurable and memorable consumption being additively separable. ${ }^{15}$

Next we turn to household behavior in response to negative and positive income shocks (scenar-

\footnotetext{
${ }^{14}$ If the utility function was not separable between nondurable consumption and memorable goods this statement would not apply, since then spikes in memorable consumption would affect the marginal utility from nondurable consumption.

${ }^{15}$ Figures 6 and 7 in the appendix plot the time paths of the state variables in the benchmark scenario for asset-rich households and liquidity-constrained households respectively.
} 
ios II and III, respectively). Table 2 Panel A summarizes the simulated consumption and savings response to negative and positive income shocks, and Figures 3 and 4 display the simulated time paths for consumption and savings. For comparison, Table 2 Panel B reports the simulated consumption and savings response in the special case when memorable goods are standard nondurable goods $(\alpha=1)$.

There is a significant difference in the nondurable consumption response to income shocks between households at or near the borrowing constraints and those with significant positive wealth. Furthermore, this difference is asymmetric with respect to positive and negative income shocks. Households far removed from the borrowing constraint behave in a way that is typical in standard consumption-savings models without memorable goods (as shown in Figures 3(a) and 4(a)). They reduce nondurable consumption in response to a (persistent, but not permanent) negative income shock and increase it (somewhat less) when facing a positive income shock of the same magnitude. ${ }^{16}$

The presence of memorable goods has a much more significant impact on the dynamics of consumption in response to income shocks for asset-poor households. As discussed above, nondurable consumption fluctuates for these households even in the absence of shocks (see Figure 2(b)), and the occurrence of income movements modifies this behavior. To interpret the figures and the table, note that the period of the shock $(t=13)$ was planned to be a period of memorable goods abstention for asset-constrained households, and the subsequent period $(t=14)$ would display a memorable goods spike in the absence of a shock.

¿From Figure 3(b), we observe that a negative income shock leads to a delay in a memorable consumption spike by one month (to $t=15$ ) and a decline in the spike (compare Figure 3(b) with Figure 2(b)). A positive income shock induces an anticipation of the memorable goods spending spike by one month (to $t=13$, compare Figure 4(b) with Figure 2(b)). The budget constraint for borrowing-constrained households, in conjunction with the abstention of memorable goods consumption in period $t=13$ then implies an increase in nondurable consumption in the period of the negative income shock ${ }^{17}$, although this increase is smaller than what was planned prior to the shock (see again Figure 3). In the period following the shock the fall in nondurable consumption is again smaller than "planned" as the abstention in memorable purchases is extended by one period,

\footnotetext{
${ }^{16}$ The magnitude of these changes is smaller in the model with memorable goods than in the model without them (compare panel A and panel B) since future consumption of memorable goods responds to the income shocks as well in the former model.

${ }^{17}$ This explains the perhaps surprising sign on the nondurable consumption response to an income decline documented for the liquidity-constrained households in Table 2 (Panel (a), second column).
} 
Table 2: Consumption Response to Unanticipated Income Shocks

\begin{tabular}{|c|c|c|c|c|}
\hline \multicolumn{5}{|l|}{ Panel A: Benchmark Model } \\
\hline & \multicolumn{2}{|c|}{ Scenario II $(\Delta Y<0)$} & \multicolumn{2}{|c|}{ Scenario III $(\Delta Y>0)$} \\
\hline Variable & not constraine & constrained & not constrainec & constrained \\
\hline percent change in income $\frac{\Delta Y}{Y}$ & -0.148 & -0.148 & 0.148 & 0.148 \\
\hline absolute change in income $|\Delta Y|$ & 0.126 & 0.126 & 0.126 & 0.126 \\
\hline$\frac{\Delta C_{n}}{|\Delta Y|}$ & -0.450 & 0.366 & 0.410 & 0.415 \\
\hline$\frac{\Delta C_{m}}{|\Delta Y|}$ & 0.000 & -1.366 & 4.465 & 0.585 \\
\hline$\frac{\Delta S^{\prime}}{|\Delta Y|}$ & 0.153 & 0.000 & -3.171 & 0.000 \\
\hline$\frac{\Delta C_{n}}{|\Delta Y|}+\frac{\Delta C_{m}}{|\Delta Y|}+\frac{\Delta S^{\prime}}{|\Delta Y|}$ & -0.297 & -1.000 & 1.703 & 1.000 \\
\hline$\frac{\Delta K}{|\Delta Y|}$ & -0.133 & -1.169 & 3.812 & 0.555 \\
\hline$\frac{\Delta M^{\prime}}{|\Delta Y|}$ & -1.045 & -0.388 & 2.086 & 0.688 \\
\hline changes in the timing of the spike & 0 & -1 & 1 & 1 \\
\hline
\end{tabular}

\begin{tabular}{|c|c|c|c|c|}
\hline \multirow[b]{2}{*}{ Variable } & \multicolumn{2}{|c|}{ Scenario II $(\Delta Y<0)$} & \multicolumn{2}{|c|}{ Scenario III $(\Delta Y>0)$} \\
\hline & not constrained & constrained & not constrained & constrained \\
\hline percent change in income $\frac{\Delta Y}{Y}$ & -0.148 & -0.148 & 0.148 & 0.148 \\
\hline absolute change in income $|\Delta Y|$ & 0.126 & 0.126 & 0.126 & 0.126 \\
\hline$\frac{\Delta C_{n}}{|\Delta Y|}$ & -0.504 & -0.764 & 0.458 & 0.747 \\
\hline$\frac{\Delta C_{m}}{|\Delta Y|}$ & 0.000 & -0.236 & 0.269 & 0.253 \\
\hline$\frac{\Delta S^{\prime}}{|\Delta Y|}$ & -1.578 & 0.000 & -0.809 & 0.000 \\
\hline$\frac{\Delta C_{n}}{|\Delta Y|}+\frac{\Delta C_{m}}{|\Delta Y|}+\frac{\Delta S^{\prime}}{|\Delta Y|}$ & -2.083 & -1.000 & -0.083 & 1.000 \\
\hline$\frac{\Delta K}{|\Delta Y|}$ & 0.000 & -0.236 & 0.269 & 0.253 \\
\hline$\frac{\Delta M^{\prime}}{|\Delta Y|}$ & -0.393 & -0.224 & -0.125 & 0.056 \\
\hline changes in the timing of the spike & $\mathrm{N} / \mathrm{A}$ & $\mathrm{N} / \mathrm{A}$ & $\mathrm{N} / \mathrm{A}$ & $\mathrm{N} / \mathrm{A}$ \\
\hline
\end{tabular}

Note: Households who are not constrained start from the long run average of the state variable level $(\bar{S}, \bar{M}, \bar{N})$, the constrained households refer to households that start from $\left(S_{1}=0, M_{1}=0, N_{1}=0\right)$; and $K=\alpha C_{m}+(1-\alpha) M$. The first 8 rows compare the changes in consumption and savings immediately before and after the income shock. The last row compares the timing of the spike immediately after the income shock to the timing in the case with zero income shocks: -1 for a one period delay, 0 for no change, 1 for one period forward. 
relative to the no-shock benchmark.

Thus negative income shock reduces the planned increase in nondurable consumption since the current month features abstention in memorable consumption purposes (compare again Figures 3(b) to Figure 2(b) respectively). This result bears resemblance to Browning and Crossley (1999)'s analysis of the role of semi-durable goods in coping with income losses. Here households let their stock of memories depreciate longer in response to a negative income shock. In this sense they access their internal "memory capital market" to smooth out the negative income shock (see Figure 8 in the appendix for the time paths of state variables in the case of a negative income shock).

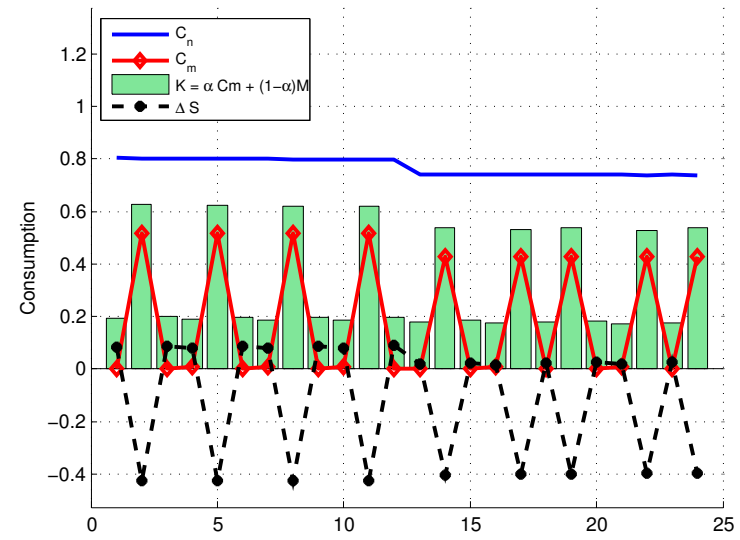

(a) $S_{1}=\bar{S}, M_{1}=\bar{M}, N_{1}=\bar{N}$

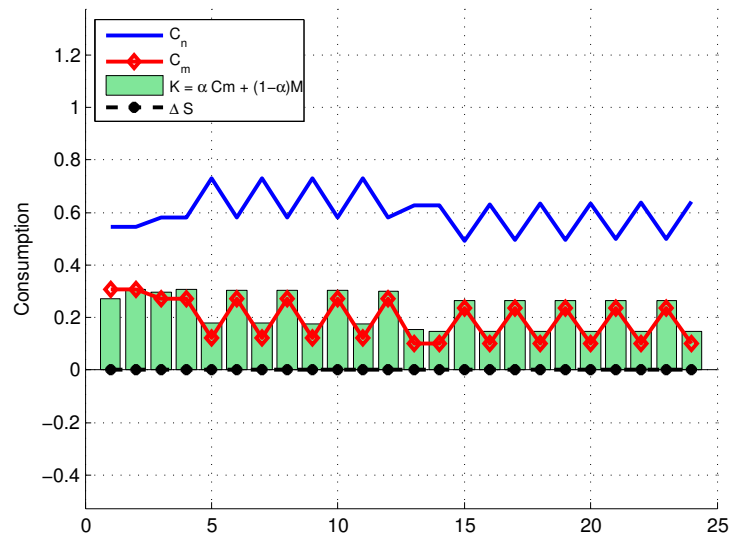

(b) $S_{1}=0, M_{1}=0, N_{1}=0$

Figure 3: Changes in Consumption and Savings (Scenario II: Negative Shock)

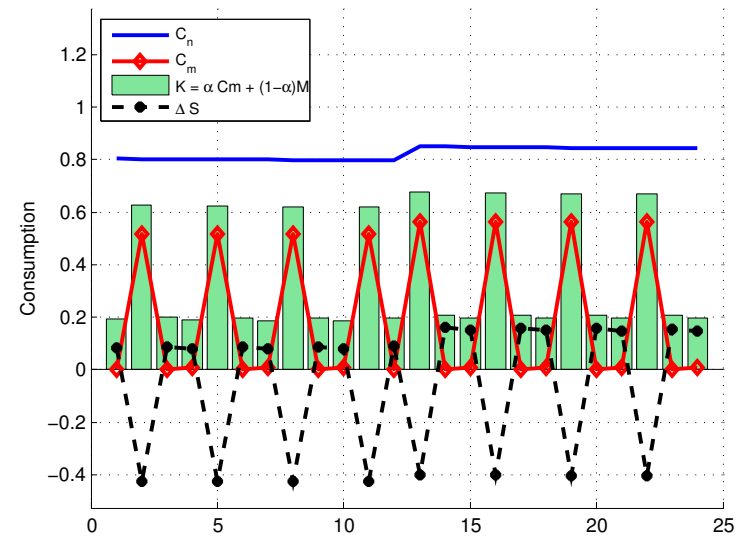

(a) $S_{1}=\bar{S}, M_{1}=\bar{M}, N_{1}=\bar{N}$

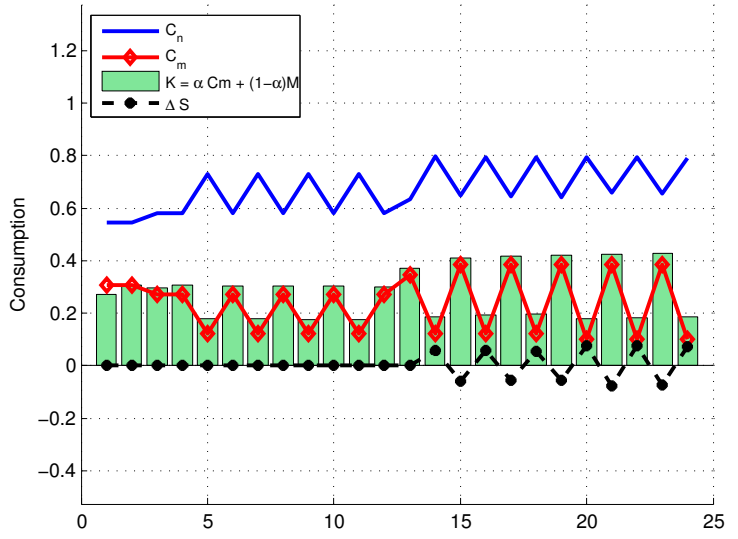

(b) $S_{1}=0, M_{1}=0, N_{1}=0$

Figure 4: Changes in Consumption and Savings (Scenario III: Positive Shock)

This mechanism also works in the upward direction. For a positive income shock households 
move the purchase of memorable goods forward. In the period of the positive shock they also respond by increasing nondurable consumption (with a spike that is smaller than in the absence of the positive income innovation). As standard permanent income logic dictates nondurable consumption is persistently higher from that point on, but continues to fluctuate to permit memorable consumption spikes for households near the borrowing constraint.

The previous discussion suggests that the introduction of the memory stock into the utility function plays a key role in determining households' consumption and savings behavior. In the special case with $\alpha=1$, the stock of memories does not enter households' utility functions, and memorable goods become standard nondurable goods. As seen in Figures 12 to 18 in the appendix, not surprisingly households then optimally choose a smooth consumption plan both for $C_{n}$ and $C_{m}$ in the absence of income shocks. Both memorable consumption and nondurable goods consumption fall in response to a negative income shock and increase in response to a positive income shock.

Before using this model for an evaluation of the welfare cost of consumption fluctuations we first briefly employ household consumption data from the CEX to document that expenditure patterns indeed differ significantly between nondurable and memorable (as well as durable) consumption goods in the way predicted by the theory. It is these data that will also be used to structurally estimate the model in Section 4 as well as to conduct the empirical analysis of the consumption response to anticipated tax rebates in Section 5 of the paper.

\section{Data}

In this section we describe the US Consumer Expenditure data (CEX) that we use for our empirical analysis.

\subsection{Sample and Consumption Categories}

\subsubsection{Consumer Expenditure Survey (CEX)}

The data is obtained from the Consumer Expenditure Survey (CEX) for the period 1980-2003. ${ }^{18}$ The CEX, constructed by the Bureau of Labor Statistics (BLS) contains comprehensive measures of consumption expenditures and earnings for a large cross section of households. In addition,

\footnotetext{
${ }^{18}$ Starting in 2004 the CEX introduced many changes in both income and consumption expenditure variables that reduce the comparability with the data from the earlier period.
} 
and crucially for our purposes, it has a limited panel dimension. ${ }^{19}$ The CEX is a rotating panel of households that are selected to be representative of the U.S. population. Each household is interviewed every three months over five calendar quarters, and in every quarter 20 percent of the sample is replaced by new households. In the first preliminary interview the CEX procedures are explained to the members of the household, and they are asked to keep track of their expenditures for future interviews. After this first interview, each household is subsequently interviewed for a maximum of four more times, once every three months. In each of these interviews, detailed information is collected on household consumption expenditures for the last three months. In the second and fifth interviews, demographic and income data are collected for each household, including earnings and income information for the previous 12 months.

We include in our sample only households that are classified as complete income reporters in the CEX. We also drop observations that report zero food expenditures, and those who report only food expenditures. In addition, we exclude all observations of households for which the household reference person is below 21 or above 64, and those households with negative or zero disposable income (as defined later in this section). Finally, we exclude households classified as rural, and those households who do not have consecutive 12 months of consumption expenditure reports. Our final sample consists of 28,969 households with the full 12 months of consecutive consumption expenditure observations. Table 13 and Table 14 report selected summary statistics of our sample.

\subsubsection{Consumption Categories}

In this section we provide an empirical classification of the set of memorable goods (MG), nondurable goods (ND) and durable goods. The set of memorable goods (MG) is meant to comprise goods for which the timing of the physical act of consumption and the utility this act generates are typically de-coupled, and for which both expenditures as well as physical consumption occur infrequently. It should be noted that our choice of which goods to include in the set of memorable goods is subjective.

We define memorable goods (MG) as food away from home, food for catered affairs, alcohol out, nondurable expenditure on trips and vacations, clothing and shoes, jewelry and watches, photographic rental and services, and religious and welfare activities. ${ }^{20}$ Nondurable expenditure on trips

\footnotetext{
${ }^{19}$ The Panel Study of Income Dynamics (PSID) has extended its coverage of consumption in recent years, but the higher frequency of observations in the CEX (as well as the longer overall sample with comprehensive consumption data) make us prefer the CEX over the PSID consumption data for this study.

${ }^{20}$ Prior to 2001Q2, expenditures on religious and welfare activities were asked only in the 5th interview, and the
} 
and vacations includes nondurable expenditure of food, alcohol, entertainment, and transportation on trips and vacations. For a complete and detailed list of memorable goods, see Table 11.

Our definition of nondurable goods (ND) encompasses most, but not all, of the goods traditionally classified as nondurable goods (Lusardi (1996), Parker (1999), Krueger and Perri (2006), Aguiar and Hurst (2008)). We include in ND food at home, food at school, meals received as pay, tobacco, alcohol at home, utility, household operation, rents for the primary residence (including rental equivalent), local transportation, business services, education, and health care. For more detailed information on nondurable consumption goods, refer to Table 10.

Finally we include in the set of durable goods furniture, motor vehicles (net outlays and car loans), and recreation equipment. The durable goods expenditure does not include expenditures on housing assets, since we have already included a measure of the service flow from housing assets (the rental equivalent) in our nondurable goods expenditure variable. More detailed information is contained in Table 12. Total household consumption expenditures is the sum of memorable goods, nondurable goods and durable goods.

\subsubsection{CEX Data Frequencies}

Because we are interested in how households change expenditures in different consumption categories over time, a panel dimension with a reasonably high frequency of observations is desirable. Although the CEX interview is conducted at quarterly frequency, the highest frequency for consumption data is monthly. Specifically, each expenditure reported by a household is identified by Universal Classification Code (UCC) and the month in which the expenditure occurred in CEX Monthly Expenditure (MTAB) file.

The algorithm that BLS used to construct MTAB files after each interview quarter is called the Time Adjustment (TA henceforth) process. It maps each UCC into a monthly time frame. In general, whenever the reference month information is available, the TA algorithm maps the UCC to the exact month in which the expenditure occurs (for example, all trip related expenditures, expenditures on jewelry, food for catered affairs and cars). There are also many UCCs (mostly representing nondurable goods) where only quarterly information is available, the TA algorithm

amounts have been divided by 12 to transform the data into a monthly expenditure in the ITAB files. Starting from 2001Q2, households are asked to report their religious and welfare activities expenditures made for the previous three month period prior to the month of the interview in MTAB file. Thus by construction, the expenditure of religious and welfare activities are very "smooth" across the year for each individual before 2001Q2, and there is an upward "jump" before and after interview quarter 2001Q2 due to measurement issues. 
converts monthly expenditure by dividing quarterly expenditure by 3 (e.g. food at home).

The TA algorithm is complex. Moreover, because the TA algorithm is based on the very detailed UCCs, when we aggregate more than 600 UCCs into 57 consumption categories, many of these consumption categories contain "mixed" frequency information. ${ }^{21}$ Based on the 2006 TA mapping algorithm, ${ }^{22}$ we report the underlying frequencies of our consumption expenditure categories as an illustration (Table 15). We say a consumption category contains monthly information, if any of the UCCs contained in this category has information on specific expenditure month in CEX data. As we can see from Table 15, most of the consumption categories contains monthly information, and this is especially true for memorable goods and durable goods expenditures.

In addition, as a robustness check, in Section 3.2 we conduct our empirical analysis both for data at monthly frequency (our preferred data) and for data at quarterly frequency.

\subsection{Descriptive Analysis}

Before turning to the two applications of our theory we briefly document the salient descriptive facts for expenditures on memorable goods from the data. Specifically we provide measures of volatility and the frequency and size of spikes in consumption expenditures for different consumption categories. We will demonstrate that expenditures on memorable goods are more volatile, more infrequent and lumpy, relative to expenditures on nondurable goods. Section 3.2.1 documents the expenditure shares, volatility measures and inactivity of different consumption categories, and Section 3.2.2 displays summary measures of lumpiness of expenditures on different consumption goods.

\subsubsection{Consumption Expenditure Volatility}

In this section, we document the extent of household-level consumption expenditure volatility associated with each of the three consumption goods categories. Specifically, monthly consumption expenditure volatility of good $i$ for household $h$ is measured as the standard deviation of household consumption expenditures over 12 months, divided by the household-specific 12 month average

\footnotetext{
${ }^{21}$ The mapping between CEX UCCs and detailed consumption and income categories is available upon request.

${ }^{22}$ We thank Jeffrey Crilley from BLS for providing us with the file.
} 
consumption expenditure, ${ }^{23}$

$$
\operatorname{vol}_{i}^{h}=\frac{\sqrt{\sum_{l}\left(E_{i, l}^{h}-\bar{E}_{i}^{h}\right)^{2}}}{\bar{E}_{i}^{h}}=\frac{\text { standard deviation }_{i}^{h}}{\operatorname{mean}_{i}^{h}}
$$

where $E_{i, l}^{h}$ denotes household $h$ 's expenditure on good $i$ in month $l$, and $\bar{E}_{i}^{h}$ is the average consumption expenditure for household $h$ over the 12 months for that good $i$. If $\bar{E}_{i}^{h}=0$, then household $h$ has zero expenditure over 12 months in category $i$, and we assign $\operatorname{vol}_{i}^{h}=0 .{ }^{24}$ We call a household who did not incur any expenditure on consumption good $i$ over the 12-month observation period an "inactive household" for consumption good $i$. The inactive ratio is the number of inactive households divided by the number of all households. It is a descriptive measure of the purchasing frequency associated with a particular consumption category $i$.

The first three columns of Table 16 report the average consumption share, volatility measures and the inactive ratio, for the entire sample and also for selected subsamples of households with low and with high cash at hand. Specifically, we measure cash at hand as the sum of the amount in checking and savings and disposable income. We then sort households by cash at hand and report results for those households in the bottom and the top quintiles of the cash at hand distribution. We think of the first group of households as likely to be liquidity-constrained and the latter group as very unlikely to be liquidity-constrained.

Nondurable goods constitute $77.94 \%$ of the total outlays and have the lowest average volatility. Memorable goods constitute $14.19 \%$ of the total outlays and are 3 times as volatile as nondurable goods. Durable goods expenditures account for $7.9 \%$ of total outlays, and are 7 times as volatile as those on nondurable goods. We also report the measured expenditure volatilities based on data at quarterly frequency (Table 17). As one can see from tables 16 and 17, the relative magnitudes of the volatility measures of these consumption goods groups do not change as we move from monthly to quarterly frequency. Quarterly memorable goods expenditures are 3 times as volatile

\footnotetext{
${ }^{23}$ This measure is analogous to that of Davis and Kahn (2008). Davis and Kahn (2008) measure volatility of consumption as the absolute value of the log change in 6 month consumption expenditures for each household, and then average over households. However, because we need to allow for zero expenditures in some consumption categories for our analysis, instead of taking log changes for each household we calculate the coefficient of variation.

${ }^{24}$ Note that our volatility measure is a conservative measure of consumption volatility for memorable and durable goods with infrequent expenditures because we assign a zero volatility to households for which we do not observe any positive expenditure during the 12 month observation period (inactive households). If we drop the households who have zero expenditure throughout the 12 month periods, the measured volatility of memorable goods and durable goods expenditures would be significantly higher.
} 
as nondurable goods, and durable goods expenditures are 6 times as volatile as expenditures on nondurable goods. 0.48 percent of households do not have any memorable goods purchase over the 12 month periods, 3.89 percent of households do not have any durable goods purchase in the sample period. For completeness, Table 18 and Table 19 in the appendix report the measured volatility of 57 detailed consumption goods categories based on monthly expenditures and quarterly expenditures respectively.

Comparing the expenditure patterns between liquidity-constrained households and asset-rich households, memorable goods constitute a much larger share of total outlays for asset-rich households $(18.8 \%)$ than for liquidity-constrained households $(9.2 \%)$. The measured volatility of both memorable goods and durable goods is smaller for asset-rich households than for liquidity-constrained households. $1.7 \%$ of liquidity-constrained households did not have any memorable goods expenditure during the 12 month reference periods and $0.1 \%$ of asset-rich households did not have any memorable goods consumption in the reference periods.

Our theoretical model also predicts that households optimally choose to have zero expenditure in memorable goods in certain periods (which we refer as inactive periods). To further investigate whether such expenditure patterns exist in our defined memorable goods categories, we document the frequency of expenditure inactivity for the following six detailed memorable goods categories: food for catered affairs, food on trips and vacations, entertainment on trips and vacations, total expenditure on trips and vacations, clothes and shoes, jewelry and watches. We also report the inactivity patterns for two durable goods categories, new and used vehicles (net outlay), and tires, tubes, accessories and other parts, as a comparison with memorable goods. From Figure 19 we observe that indeed, memorable goods, as well as durable goods, display infrequent monthly expenditures. In fact, with the exception of the clothes and shoes categories the mode of the distribution of months of inactivity is 12 , that is, most households are expenditure-inactive for a given consumption category for each of the twelve months the household spends in the sample.

\subsubsection{Consumption Expenditure Spikes}

Another salient expenditure pattern for memorable goods, as shown in our model simulation, is that when expenditures on memorable goods occur, they occur in lumps. To investigate the lumpy expenditure patterns in memorable goods expenditure, we denote by $n_{i}^{h} \in\{0,1, \ldots, 11\}$ the number

of expenditure spikes of size $\kappa>1$ relative to household $i$ 's mean expenditure on good $i$. Thus $n_{i}^{h}$ 
is defined as:

$$
n_{i}^{h}=\sum_{l=1}^{12} \mathbf{1}\left\{l: E_{i, l}^{h}>\kappa \cdot \bar{E}_{i}^{h}\right\}, \quad \kappa>1 .
$$

For each consumption category $i$ we now plot the frequency distribution of the number of expenditure spikes $n_{i}^{h}$ of size at least size $\kappa=1.5$ among households who report at least one positive expenditure on goods $i$ within the 12-month periods. This statistic gives us a measure of expenditure lumpiness for different consumption categories. Figure 20 shows that most households have at least one consumption expenditure spike within a 12 month period for these selected memorable and durable goods, and the expenditure on these goods tends to be quite lumpy.

We also summarize frequencies of spikes and relative size of spikes for total consumption outlays, as well as separately for nondurables, memorable goods and durables In the last two columns of Tables 18 and 19, for the entire sample but also for selected subsamples of households with low and with high cash at hand. We measure the average frequency of consumption spikes as the average number of consumption spikes divided by the total number of reference periods. To measure the relative size of consumption spikes, we normalize households' expenditure spikes by household-level 12-month average total consumption outlays. One prediction from our model (derived through simulations) is that liquidity constrained households choose more frequent spikes of memorable goods expenditures. This is indeed the case as the fourth column of tables 16 and 17 show. A related prediction holds that asset rich individuals experience larger consumption spikes when they occur, indeed something present in the data (see the last column of tables 16 and 17).

To summarize our descriptive empirical findings, expenditures on memorable consumption goods are a significant share of a typical household's budget, and they display substantially larger fluctuations at a monthly (and quarterly) frequency than nondurable consumption goods. Furthermore, memorable goods expenditures in each category spike once or twice during the year, and are otherwise characterized by a higher inactive ratio.

However, as argued in Section 2 these spikes and spells of inactivity might well be optimal even in the absence of idiosyncratic income shocks or/and incomplete financial markets, and thus might not contribute to welfare losses from inefficient consumption fluctuations. We will now turn to a formal quantitative investigation of this point, using the CEX data described above. 


\section{Welfare Cost Analysis}

One immediate implication of our model of memorable goods is that the observed large consumption expenditure fluctuations of memorable goods does not necessarily lead to welfare losses from volatile consumption. A household's underlying utility flow from memorable goods can be much smoother than the per-period memorable goods consumption expenditure because of the substitutability between contemporaneous memorable goods consumption and the stock of memory accumulated in the past. The optimal consumption of memorable goods for households depends on both the stock of memory and the average level of recent past memorable goods consumption. Hence, households adjust their memorable goods consumption over time based on their memory stock and the average level of past memorable goods consumption. This is the case even in the absence of income risk and incomplete financial markets.

To demonstrate the potential biases of measured welfare cost associated with consumption fluctuations when the presence of memorable goods is not account for, we proceed in two steps. First we conduct a reduced-form analysis of the welfare cost of consumption fluctuations whose aim is to show that the bias due to incorrectly ascribing welfare losses to expenditure fluctuations of memorable consumption can be substantial. Second, we use a structurally estimated version of our consumption model developed in Section 2 to give a more precise answer, grounded in economic theory, to the question of how much the welfare losses of consumption fluctuations might be overstated by not accounting for the fact that memorable goods expenditure fluctuations are part of optimal household consumption choices, even in the absence of uninsurable shocks (to income, say) that may make consumption volatile otherwise.

\subsection{Welfare Cost of Consumption Fluctuations: A Reduced Form Comparison}

In this section, to carry out welfare analysis, we continue to assume that a typical household's flow utility function is given by equation (1) from Section 2. However, in this subsection we do not specify the underlying source of the consumption fluctuations that lead to welfare losses, relative to a smooth consumption profile. Instead, we directly take advantage of the empirically observed consumption expenditure data to estimate statistical consumption processes, which we then evaluate in terms of their welfare properties (relative to perfectly smooth profiles) using the utility function in (1).

To do this, we need to assume a specific stochastic process for the observed consumption ex- 
penditures. The advantage of this approach is that it does not rely on specific model frictions; however, the disadvantage of this approach is that without observing the stock of memory and the parameters that govern the evolution of the memory stock, we cannot calculate the welfare losses associated with memorable goods expenditure fluctuations (if there are any). Nevertheless, this approach can give us an upper bound on the possible bias in calculating welfare cost of consumption fluctuations that one gets when failing to distinguish memorable goods from nondurable goods, of course under the maintained assumption that the empirically estimated consumption expenditure process is specified correctly.

In particular, suppose the empirical process for household $h$ 's nondurable goods consumption expenditures $C_{n, t}^{h}$ at period (month) $t$ is described as

$$
\begin{aligned}
\ln \left(C_{n, t}^{h}\right) & =\sum_{l=2}^{12} \alpha_{l} d_{l}+\alpha_{13} \cdot \text { year }+X_{h, t} \boldsymbol{\beta}+\sigma_{c} z_{t}^{h}, \quad z_{t}^{h} \sim N(0,1) \\
& =P_{t}^{h}+\sigma_{c} z_{t}^{h}
\end{aligned}
$$

where $d_{l}$ is a dummy variable for month $l$, the term $\alpha_{13} \cdot$ year allows long-run yearly consumption growth, and $X_{h, t}$ is a vector of known individual characteristics of household $h$, including education, marital status, race and sex of the reference person, family size, and regional dummies. The term $\sigma_{c}$ measures the size of shocks to household consumption. Thus the process in (12) decomposes monthly consumption expenditures into a predictable component $P_{t}^{h}$ and a consumption shock $\sigma_{c} z_{t}^{h}$

To obtain an upper bound for the bias that is generated by ignoring the potential optimality of memorable consumption fluctuations, we now assume that there are no welfare losses from fluctuations in memorable consumption expenditures. As demonstrated in Section 2, such fluctuations are part of an optimal consumption plan, and we therefore implicitly assume that the empirically observed fluctuations of expenditures on memorable goods are optimal.

Following Lucas (1987), we define the welfare cost of nondurable goods consumption fluctuations as the percentage increase in consumption, uniform across all dates and states, required to leave the consumer indifferent between the stochastic consumption process $\left\{\left(1+g\left(\sigma_{c}\right)\right) C_{t}^{h}\right\}$ and the deterministic process $\left\{\mathbb{E}\left\{C_{t}^{h}\right\}\right\}=\exp \left(P_{t}^{h}+\frac{1}{2} \sigma_{c}^{2}\right)$. It can be shown that $g\left(\sigma_{c}\right)$ is given by ${ }^{25}$

$$
g\left(\sigma_{c}\right) \approx \frac{1}{2} \gamma \sigma_{c}^{2}
$$

where we recall that $\gamma$ is the coefficient of relative risk aversion for nondurable consumption.

\footnotetext{
${ }^{25}$ The proof of this is in appendix A.
} 
Let $\sigma_{N D}^{2}$ be the variance of nondurable consumption obtained when estimating (12) with data for nondurable consumption expenditures alone. Denote by $\sigma_{N D M G}$ as the estimated value from equation (12), with $C_{n, t}^{h}$ constituting the sum of expenditures on both nondurables and memorable goods. Therefore, with $\sigma_{N D M G}$ corresponding to the measured volatility of nondurable goods without distinction between nondurable and memorable consumption, this is just a special case of our utility function (1) with $\xi=1$.

The bias from misclassifying memorable goods predicted by this reduced-form welfare cost calculation thus depends on the relative magnitude of household-level residual consumption volatility of nondurable and memorable goods $\left(\sigma_{N D M G}^{2}\right.$ and $\left.\sigma_{N D}^{2}\right)$, and is directly proportional to the coefficient of relative risk aversion $\gamma$. The estimated average consumption volatility for the combined (nondurable and memorable) consumption expenditures is $\bar{\sigma}_{N D M G}=0.28$, and is $\bar{\sigma}_{N D}=0.25$ for nondurable consumption alone. The fact that $\bar{\sigma}_{N D M G}$ is three percentage points larger than $\bar{\sigma}_{N D}$ comes from the fact that the average volatility of memorable goods expenditure is $\bar{\sigma}_{M G}=1.01$, significantly larger than $\bar{\sigma}_{N D}=0.28$, but that, on the other hand, the expenditure share of memorable goods is only $16 \%$ of the combined expenditure, on average across households. ${ }^{26}$

The welfare cost of fluctuations in total consumption of memorable goods and nondurable goods can be calculated using equation 14. Using the estimated average household consumption volatility (0.28), the associated welfare cost of household-level consumption fluctuations is reported in Table 20. With logarithmic preferences the estimated welfare cost of consumption fluctuations is $3.95 \%$ of total consumption of memorable and nondurable goods, and is $3.64 \%$ of total outlays. Evidently this loss increases linearly with risk aversion $\gamma$ as equation 14 implies.

In order to assess the extent to which the potential misclassification of memorable goods might bias the calculations above, Table 21 reports the estimated welfare cost of household nondurable consumption alone. Not surprisingly, given the reported volatile expenditure patterns of memorable goods in Section 3.2, the estimate of $\bar{\sigma}_{N D}$ is lower than that of $\bar{\sigma}_{N D M G}$. This difference has significant consequences for the welfare cost of consumption fluctuations calculations. As shown in Table 21 the welfare cost falls considerably. Again with logarithmic preferences they now amount to $3.19 \%$ of nondurable goods consumption and only $2.49 \%$ of total outlays. Compared to the case where the distinction between memorable goods and nondurable goods is ignored, the estimated

\footnotetext{
${ }^{26}$ Note that the same argument we make here for memorable goods also applies to durable goods (although we are obviously not the first ones to point it out for durable goods). Thus our quantitative conclusions are not necessarily invalidated even if we mis-classify some durable goods as memorable goods in our analysis.
} 
welfare cost is reduced by about $32 \%$ in terms of total outlays on account of the presence of memorable goods. We stress again that we interpret this number as an upper bound on the bias in the welfare cost calculations. ${ }^{27}$

\subsection{Welfare Cost of Consumption Fluctuations: A Structural Approach}

The previous section simply stipulated an empirical consumption process and used an empirical estimate of consumption volatility, together with a utility function, to determine the welfare cost of these consumption fluctuations. We did not take a stance on what underlying shocks might induce these fluctuations and made rather stark assumptions about the degree to which they might be optimal (not at all for nondurable consumption, perfectly optimal for memorable consumption).

In our structural model the only source of suboptimal consumption fluctuations stems from uninsurable idiosyncratic labor income risk; recall that households could only self-insure through building up and drawing down their balance of risk free assets. ${ }^{28}$ We now ask, in the context of our structural model, how large are the welfare losses from consumption fluctuations induced by idiosyncratic income shocks, and how these losses are affected by explicitly modeling memorable goods. To do this, we compare (both in the model with, and in the model without memorable goods) household welfare in two scenarios: one in which households in the model face a stochastic income process and one in which households receive deterministic incomes with the same mean as in the stochastic world. In order to implement these calculations we first have to parameterize our structural model, which we do through a combination of calibration and structural estimation. We describe this procedure next. We need a fully parameterized version of our model to carry out the welfare cost of income shock-induced consumption fluctuations calculations, but we also view it as informative to provide structural estimates especially of those preference parameters associated with memorable goods consumption for which there is little evidence in the existing literature.

\footnotetext{
${ }^{27}$ We also calculate the estimated volatility and welfare cost under a different categorization of consumption goods, adopting a more conservative approach of what constitutes memorable goods. More concretely, we now group clothes \& shoes, and jewelry \& watches into nondurable goods (as opposed to memorable goods) and call the resulting aggregate "ND Plus". The estimated consumption volatility is 0.27 and the associated welfare cost is displayed in Table 22. With this classification the (upper bound for the) bias for the welfare cost of consumption fluctuations amounts about $17 \%$ (the welfare cost falls from from 3.64 to 3.02 as a percent of total outlays).

${ }^{28}$ In Lucas' (1982) representative agent endowment economy household income and consumption fluctuations are indistinguishable.
} 
Table 3: Externally Calibrated Parameters

\begin{tabular}{llll}
\hline \hline Parameters & Interpretation & Value & Target \\
\hline$\rho_{z}$ & Persistence of log income process & 0.9900 & \\
$\sigma_{\epsilon}$ & Volatility of $\log$ income process & 0.0797 & Covariance of $\ln Y_{t}$ and $\ln Y_{t-12}=0.28(\mathrm{CEX})$ \\
$\bar{y}$ & Average log income & -0.1598 & $\mathbb{E}(Y)=1$ (Normalization) \\
$r$ & Monthly real interest rate & $0.33 \%$ & Annual real interest rate $4 \%$ \\
$\gamma$ & Relative risk aversion coefficient & 1.0 & Log Utility as Benchmark \\
\hline \hline
\end{tabular}

\subsubsection{Calibrated Parameters}

We first calibrate a subset of the parameters as follows. In line with the frequency of our CEX data a model period is one month. We specify the monthly income process to be highly persistent ${ }^{29}$ and set $\rho_{z}=0.9900$. We set the standard deviation of the log income process to be $\sigma_{\epsilon}=0.0797$ so that the covariance of current income and last year's income matches CEX data. ${ }^{30}$ We normalize the deterministic component of log income to $\bar{y}=-0.1598$ so that the unconditional expectation of an individual's monthly income is normalized to 1 . We use an annual real interest rate of $4 \%$, and thus the monthly real interest rate in our model is set to be $0.33 \%$. In our benchmark parameterization we assume a log utility function, $\gamma=1$. The parameter values from the outside sources are reported in Table 3.

\subsubsection{Estimation Results}

The solution of the model serves as input to the estimation procedure. Estimation is by simulated method of moments (SMM). Specifically, the average distance between five CEX data sample moments and simulated model moments is minimized with respect to the five model parameters $\left(\beta, \xi, \alpha, \delta_{m}, \rho_{n}\right)$. Notice that the five parameters specify the preferences for and the law of motion associated with memorable goods. The five moments we use consist of the (liquid) asset to income ratio, the average expenditure share of ND out of total consumption expenditures $(N D+M G)$, and the average volatilities of ND, of memorable, and of total expenditures.

\footnotetext{
${ }^{29}$ Our value implies an annual persistence of labor income of 0.89 which is at the lower end of the spectrum of the empirical estimates. See e.g. Guvenen (2009). Note that, ceteris paribus, less persistent labor income shocks are easier to insure through precautionary saving, and thus the welfare costs from these shocks are bound to be lower that fluctuations with even higher persistence.

${ }^{30}$ Under the assumption of our income process, $\operatorname{cov}\left(\ln Y_{t-12}, \ln Y_{t}\right)=\rho_{z}^{12} \operatorname{var}\left(\ln Y_{t}\right)=\frac{\rho_{z}^{12}}{1-\rho_{z}} \sigma_{\epsilon}$.
} 
Table 4: Estimated Parameters

\begin{tabular}{clc}
\hline \hline & Interpretation & Value \\
\hline$\beta$ & Subjective discount factor & 0.9944 \\
$\xi$ & Weight on $C_{n}$ in $U$ & 0.7598 \\
$\alpha$ & Weight on $C_{m}$ in $U$ & 0.8836 \\
$\rho$ & Weight on $C_{m}$ in $N$ & 0.2881 \\
$\delta_{m}$ & Deprec. of Memory & 0.0861 \\
\hline \hline
\end{tabular}

Table 5: Model Fit

\begin{tabular}{lcc}
\hline \hline Targeted Moments & Data & Model \\
\hline Median Liquid Assets/Annual Income & 0.25 & 0.26 \\
Average Share of ND/(ND+Memorable) & 0.84 & 0.83 \\
Average Freq of Memorable Goods Spikes & 0.19 & 0.27 \\
Average Volatility of (ND+Memorable) & 0.31 & 0.25 \\
Average Volatility of Memorable & 1.01 & 1.16 \\
\hline \hline
\end{tabular}

The estimated values of model parameters $\left(\beta, \xi, \alpha, \delta_{m}, \rho\right)$ are reported in Table 4 . The estimated relative importance of nondurable goods is fairly large, $\xi=0.7598$, relative to the weight $1-\xi=$ 0.2402 on memorable goods. Although immediate memorable consumption $C_{m}$ constitutes the most important component of the utility flow from memorable goods consumption $(\alpha=0.8836)$, the memory stock $M_{t}$ is also significant. The weight of current memorable goods consumption on future memory threshold $N$ is moderate $(\rho=0.2881)$. Last, after one year $2 / 3$ of the memorable shock is depreciated, absent spending, and thus only $1 / 3=(1-.0861)^{12}$ remains. We also report the values of targeted moments and the simulated moments under the parameter estimates ${ }^{31}$ in Table 5.

\footnotetext{
${ }^{31}$ Although the fit of the moments is satisfactory, it is not perfect, due to the inability of the model to generate, jointly, sufficiently volatile nondurable consumption and sufficiently smooth memorable consumption expenditures in the model, relative to the data. Note, however, that household consumption in the CEX is likely measured with substantial error which might overstate the empirical expenditure volatility for a given household over a twelve month interval.
} 


\subsubsection{Welfare Cost Calculation}

Equipped with the structurally estimated model we now can calculate the welfare losses from uninsurable income shocks, both in the presence and absence of memorable goods. Denoting by $\Phi$ the normal cdf with zero mean and variance $\sigma_{\epsilon}^{2}$, we can rewrite the household's value function, equation 10) as:

$V(M, N, S, z)=\max _{C_{n}, C_{m}, S^{\prime}}\left\{\xi \frac{C_{n}^{1-\gamma}}{1-\gamma}+(1-\xi) \frac{\left(\alpha C_{m}+(1-\alpha) M\right)^{1-\gamma}}{1-\gamma}+\beta \int V\left(M^{\prime}, N^{\prime}, S^{\prime}, \rho_{z} z+\epsilon^{\prime}\right) d \Phi\left(\epsilon^{\prime}\right)\right\}$

s.t.

$C_{n}=Y+(1+r) S-C_{m}-S^{\prime}$

$M^{\prime}=\left(1-\delta_{m}\right) M+\max \left\{C_{m}-N, 0\right\}$

$N^{\prime}=(1-\rho) N+\rho C_{m}$

$S^{\prime} \geq 0$

$\ln Y=\bar{y}+z$.

The outcome of this dynamic programming problem are value and policy functions $V(M, N, S, z)$, $C_{n}(M, N, S, z), C_{m}(M, N, S, z), S^{\prime}(M, N, S, z)$. Similarly, define the dynamic programming problem for a household facing no income risk as

$$
\bar{V}(M, N, S)=\max _{C_{n}, C_{m}, S^{\prime}}\left\{\xi \frac{C_{n}^{1-\gamma}}{1-\gamma}+(1-\xi) \frac{\left(\alpha C_{m}+(1-\alpha) M\right)^{1-\gamma}}{1-\gamma}+\beta \bar{V}\left(M^{\prime}, N^{\prime}, S^{\prime}\right)\right\}
$$

subject to equations (15) to (18), and with income

$$
\ln Y=\bar{y}+\frac{\sigma_{\epsilon}^{2}}{2\left(1-\rho_{z}^{2}\right)} .
$$

Note that the last equation ensures that the household faces the same expected income as in the case with income risk. Again denote value and policy functions from this dynamic program as $\bar{V}(M, N, S), \bar{C}_{n}(M, N, S), \bar{C}_{m}(M, N, S), \bar{S}^{\prime}(M, N, S)$.

In the same vein, we can define

$$
W(S, z)=\max _{C_{n}, S^{\prime}}\left\{\frac{C_{n}^{1-\gamma}}{1-\gamma}+\beta \int W\left(S^{\prime}, \rho_{z} z+\epsilon^{\prime}\right) d \Phi\left(\epsilon^{\prime}\right)\right\}
$$

subject to equation (15), (18) and (19) as the dynamic programming problem in the presence of income risk, but absent memorable goods, with value and policy functions $W(S, z), C_{n}^{W}(S, z), S^{W \prime}(S, z)$. Finally, in the absence of both income risk and memorable goods the dynamic program reads as

$$
\bar{W}(S)=\max _{C_{n}, S^{\prime}}\left\{\frac{C_{n}^{1-\gamma}}{1-\gamma}+\beta \bar{W}\left(S^{\prime}\right)\right\}
$$


subject to equation (15), (18) and (20), with associated value and policy functions $\bar{W}(S), \bar{C}_{n}^{W}(S), \bar{S}^{W^{\prime}}(S)$.

For each state $(M, N, S)$, we define the welfare cost of consumption fluctuations induced by uninsurable income shock as the permanent percent reduction in consumption that would make a household living in a world without income risk indifferent to living in a world with income risk. As Appendix A shows, that these numbers can be calculated from the value functions alone:

$$
\begin{aligned}
g(M, N, S) & =\left[\frac{V(M, N, S, z=0)}{\bar{V}(M, N, S ; g=0)}\right]^{\frac{1}{1-\gamma}}-1 \\
g^{W}(S) & =\left(\frac{W(S, z=0)}{\bar{W}(S ; g=0)}\right)^{\frac{1}{1-\gamma}}-1
\end{aligned}
$$

where $\bar{V}(M, N, S ; g)$ is lifetime utility in the no-risk economy with memorable goods, but with nondurable and memorable consumption scaled up by a factor $g$ at all future dates. The function $\bar{W}(S ; g)$ has a similar interpretation. ${ }^{32}$

By construction, the welfare cost function $g(M, N, S)$ in the model with memorable goods depends on the state variables $M, N$ and $S$. Let $F(M, N, S)$ denote the invariant marginal distribution over state variables $(M, N, S)$ in the model with memorable goods and income risk. Similarly, let $F^{W}(S)$ denote the invariant marginal distribution over wealth in the model with income risk but without memorable goods. Therefore,

$$
\begin{aligned}
F(M, N, S) & =\int_{z} H(M, N, S, z) d \Phi^{z}(z) \\
F^{W}(S) & =\int_{z} H^{W}(S, z) d \Phi^{z}(z)
\end{aligned}
$$

where $H(M, N, S, z)$ and $H^{W}(S, z)$ are the invariant distributions over the states in models with memorable goods and without memorable goods respectively, $\Phi^{z}$ is the normal cdf with zero mean and variance $\sigma_{\epsilon}^{2} /\left(1-\rho^{2}\right)$. We can then calculate two aggregate welfare cost measures as follows:

$$
\begin{aligned}
\bar{g} & =\int_{M, N, S} g(M, N, S) d F(M, N, S) \\
\bar{g}^{W} & =\int_{S} g^{W}(S) d F^{W}(S) .
\end{aligned}
$$

The difference between the welfare costs calculated in the two cases, $\bar{g}^{W}-\bar{g}$, is then our measure of the overstatement of the welfare cost of consumption fluctuations that stem from ignoring

\footnotetext{
${ }^{32}$ For $\gamma=1$, a similar derivation yields$$
g(M, N, S)=\exp [(1-\beta)(V(M, N, S, z=0)-\bar{V}(M, N, S ; g=0))]-1
$$$$
g^{W}(S)=\exp [(1-\beta)(W(S, z=0)-\bar{W}(S ; g=0))]-1 .
$$ 
Table 6: Aggregate Welfare Cost

\begin{tabular}{clc}
\hline \hline & Interpretation & Estimated Value \\
\hline $\bar{g}$ & Welfare cost with memorable goods & $11.9 \%$ \\
$\bar{g}^{W}$ & Welfare cost without memorable goods & $13.6 \%$ \\
\hline \hline
\end{tabular}

Figure 5: Welfare Cost Comparison

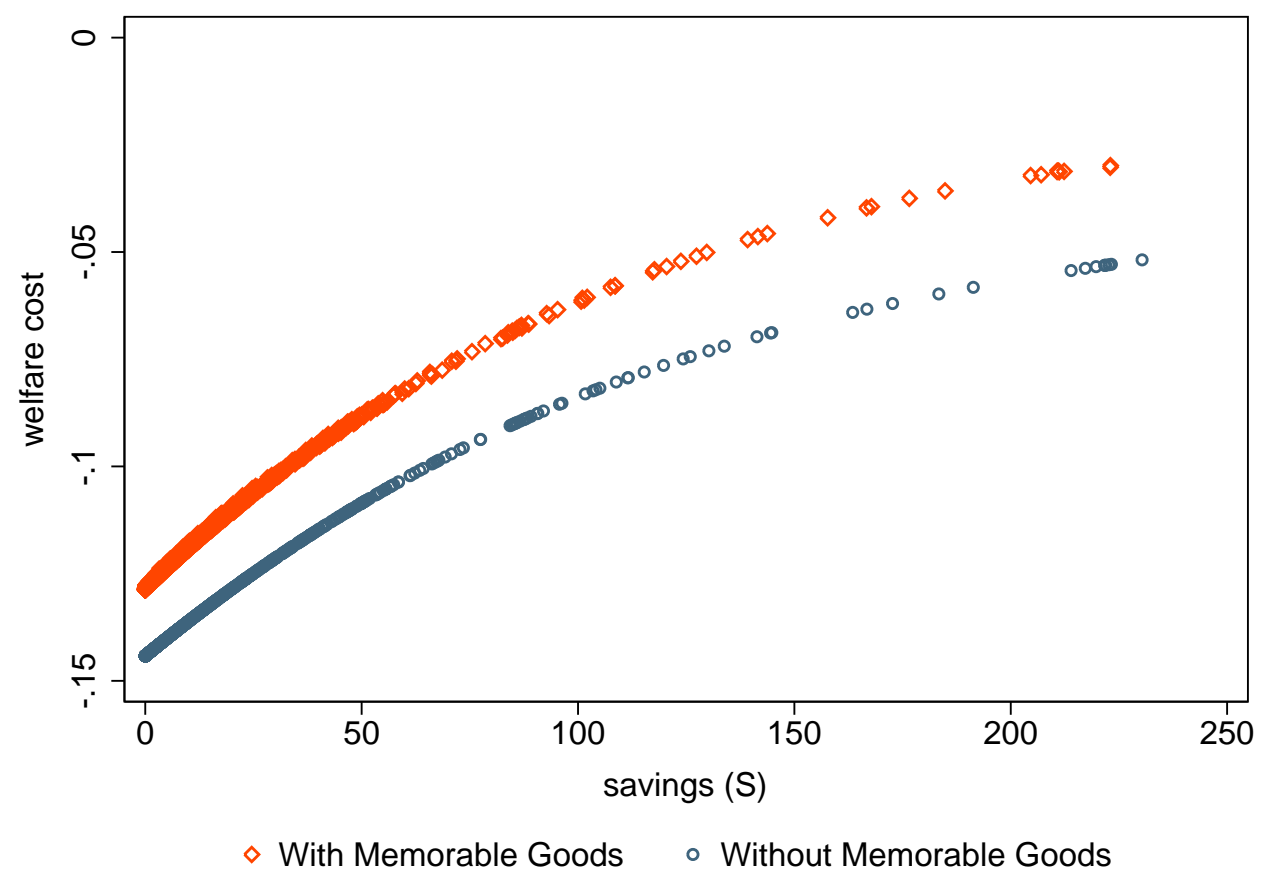

memorable goods.

Table 6 reports the estimated aggregate welfare cost measures $\bar{g}$ and $\bar{g}^{W}$ from the structurally estimated model. The reduction in the welfare cost of consumption fluctuations amounts to a significant 1.7 percentage points, or to approximately $13 \%$ of the overall welfare cost in the absence of memorable goods.

To further interpret this result, Figure 5 compares the welfare cost in the model with memorable goods with the welfare cost in the model without memorable goods at each asset level $(S)$ averaged across states $M$ and $N$. We observe that the magnitude of the welfare costs of consumption fluctuations, is significantly smaller in the model with memorable goods than in the model without memorable goods, at each asset level. Also note that the average asset level is lower in the model 
with memorable goods, because the memorable goods stock is used as an alternative asset to smooth adverse income shocks. ${ }^{33}$

\section{Revisiting an Excess Sensitivity Test of Consumption}

In the previous section we demonstrated that accounting for and explicitly modeling memorable consumption goods may significantly change our quantitative assessment of the welfare cost of consumption fluctuations induced by uninsurable income shocks. Next we provide a second application from the empirical consumption literature that is sensitive to the exclusion of memorable consumption. The standard consumption-savings model predicts that, absent borrowing constraints, consumption should not respond to predictable changes in income. If it does, then consumption is said to exhibit excess sensitivity (to predictable income changes).

Our goal here is not to rewrite the huge empirical literature on excess sensitivity of consumption. We simply want to demonstrate that one important piece of evidence for excess sensitivity stemming from the consumption response to predictable federal income tax refunds, as documented in the important paper by Souleles (1999), could be entirely due to the response of memorable consumption expenditures to these tax refunds. In our empirical analysis we indeed find that nondurable consumption, not including memorable consumption expenditures, does not exhibit any excess sensitivity with respect to predictable income tax refunds.

\subsection{Implications of Model for Consumption Responses to Expected Income Changes}

The basic idea of consumption excess sensitivity tests is to investigate whether consumption expenditures respond to predictable changes in disposable income. According to the standard intertemporal consumption-savings model with rational expectation it should not, absent binding borrowing

\footnotetext{
${ }^{33}$ In the presence of income risk and borrowing constraints, both the models with memorable goods and without memorable goods have a non-degenerate invariant distribution over their respective state variables. In the model with uninsurable income risk but without memorable goods, asset accumulation is the only option available for households to smooth consumption and insure against income risk. However, in the model with memorable goods, under a moderate depreciation rate $\left(\delta_{m}=0.0861\right)$, memorable goods serve as an alternative buffer to insure against income shocks. When faced with negative income shocks households can access their internal capital market by delaying expenditure spikes of memorable goods and letting the stock of memories depreciate. In the model with income shocks but no memorable goods, the average savings rate is 11.88; in the model with income shocks and memorable goods, the average savings rate is 11.13 .
} 
constraints.

The basic test for excess sensitivity of nondurable consumption to predictable income changes can then be conducted by estimating the following specification:

$$
C_{n, t+1}-C_{n, t}=\beta_{0}+\sum_{i} \beta_{1, i} X_{i, t+1}+\beta_{2} \Delta Y_{t}
$$

where $X_{i, t+1}$ controls the change in household preferences and $\Delta Y_{t}$ is a change of income between period $t$ and $t+1$ that is predictable at time $t$. In Appendix $\mathrm{A}$ we show how this equation can be derived from a linearization of the Euler equation for nondurable consumption expenditures. ${ }^{34}$ Thus, absent binding borrowing constraints, the standard consumption-savings model based on the permanent income hypothesis implies that nondurable consumption changes should not be sensitive to predictable income changes, or $\beta_{2}=0$.

However, for memorable goods consumption $C_{m, t}$, even in the absence of borrowing constraint, expenditures on memorable goods $C_{m, t+1}$ may still respond to predictable income changes. To see this, notice that since typically $\Delta Y_{t}$ is correlated with $C_{m, t}$ in our model ${ }^{35}$, it does not predict that $\tilde{\beta}_{2}=0$ in the regression ${ }^{36}$ :

$$
C_{m, t+1}-C_{m, t}=\tilde{\beta}_{0}+\sum_{i} \tilde{\beta}_{1, i} X_{i, t+1}+\tilde{\beta}_{2} \Delta Y_{t}
$$

We now briefly discuss the data used to implement these two basic regressions before turning to the results.

\subsection{Empirical Test Using CEX Tax-Refund Data}

\subsubsection{Data and Sample Selection}

To insure comparability with Souleles (1999) our empirical strategy, as well as crucial sample selection choices and variable definitions, follows his as much as possible. The data used in this section are drawn from the CEX surveys from 1980 to 1991, which covers exactly the same time period as in Souleles (1999). Our definition of nondurable and memorable goods is the same as in previous sections. Furthermore we define strictly nondurable goods (Strictly ND) as all nondurable goods, but excluding health, education and reading. Finally we define strictly memorable goods as

\footnotetext{
${ }^{34}$ See Parker and Preston (2005) and Parker (1999) for similar analyses.

${ }^{35}$ The same is true if $\Delta Y_{t}$ is correlated with $\lambda_{m, t}$, the (transformed) Lagrange multiplier associated with law of motion for memorable goods; see equation (35) in the appendix.

${ }^{36} \mathrm{~A}$ linear approximation of the Euler equation for memorable consumption goods expenditure is derived in appendix A that displays the explicit form on which this regession equation is based.
} 
memorable goods excluding clothes and jewelry. Thus our definition of nondurable and memorable goods combined is equivalent to Souleles (1999)'s nondurable goods (ND+MG), and our definition of strictly nondurable and strictly memorable goods combined equals to Souleles (1999)'s definition of strictly nondurable goods (Strictly $(\mathrm{ND}+\mathrm{MG})) .{ }^{37}$

The sample was selected in a way that closely follows the selection criteria provided in Souleles (1999). ${ }^{38}$ The CEX asks about tax refunds twice, in a household's first and final interview. Each time what is recorded is the value of federal tax refunds received by the households in the 12 months before the interview month. Thus the refund variable in the CEX has a reference period of 12 months. About 80 percent of the refunds were mailed out in March, April and May during the years 1980-1991, ${ }^{39}$ and thus following Souleles (1999), we deflate refunds by the average of the monthly CPI for all items averaged over March, April, and May. All nominal variables were deflated to 1982-1984 dollars.

\subsubsection{Empirical Specification and Estimation}

Souleles (1999) provides evidence for excess sensitivity in consumption by estimating two regressions, both of which we will revisit here. The first specification to be estimated is

$$
C_{t, I I}^{h}-C_{t, I}^{h}=\sum_{t} \beta_{0 t} * \operatorname{year}_{t}^{h}+\beta_{1}^{\prime} X_{t}^{h}+\beta_{2} * \operatorname{refund}_{t}^{h}+u_{t}^{h}
$$

The dependent variable $C_{t, I I}^{h}-C_{t, I}^{h}$ is the change in a given household $h$ 's real consumption expenditures (in levels) between quarter I (January through March) and quarter II (April through June) of a given year $t$. The variable year $t_{t}^{h}$ is the year dummy that is included to control for aggregate shocks and interest rates across time. The variable refund $t_{t}^{h}$ measures the tax refund received by

\footnotetext{
${ }^{37}$ The major components of strictly nondurables, defined in Souleles (1999), are food; household operations, including monthly utilities and small-scale rentals; apparel services and rentals; transportation fuel and services; personal services; and entertainment services and high-frequency fees. We further break down the above consumption groups into two consumption categories: strictly nondurable and strictly memorable goods by introducing memorable goods.

${ }^{38} \mathrm{~A}$ household was dropped from the sample if there were multiple 'consumer units' in the household, or if the household lived in student housing or the head of household was a farmer; a household quarter was dropped if the household lacked basic food expenditure for any month of the quarter, or if any food was received as pay in the quarter. A household quarter is dropped if the age of household head increased by more than one or decreased, on moving into next quarter. The sample was further restricted to households with heads aged 24-64. Finally, a household is dropped if the income report is incomplete or any of the income or financial records is invalid. We thank Nicholas Souleles for sharing the data appendix of Souleles (1999).

${ }^{39}$ Refer to Table 2 in Souleles (1999).
} 
household $h$ in year $t$. As discussed in Appendix A, with $\beta_{2}=0$ equation (24) can be derived as a linearized version of the standard household consumption Euler equation; no linearization is necessary if the period utility function is quadratic. The vector $X_{t}^{h}$ contains demographic variables (the age of the household head and changes in the number of adults and in the number of children) and is included in the regression to control for basic changes in household preferences.

The refund variable in the CEX, refund $t_{t}^{h}$, has a reference period of 12 months. To make sure that the refund reference period covers the consumption change period, that is, quarter I and quarter II of year $t$, we further restrict the sample to households whose refund reference periods covers January to June. ${ }^{40}$ Specifically, the interview month of the final interview is restricted to be either January or July-December, so that the the key regressor refund $t_{t}^{h}$, which records the real value of refunds (in levels) that household $h$ received in the past 12 months before the final interview, covers the first two quarters of year $t$ (when about 90 percent of the refunds are received). This sample restriction ensures that the regressor refund ${ }_{t}^{h}$ is predetermined, and so under the basic consumption-savings model based on the permanent income hypothesis $\beta_{2}$ should be zero.

An alternative to the standard frictionless intertemporal consumption model in which households might not display excess smoothness is a model proposed by Campbell and Mankiw (1990) and adopted by Souleles (1999) in which households simply consume a fraction $\mu$ of their tax refunds, upon the receipt of the refund check. The number $\mu$ can then be interpreted as the marginal propensity to consume (MPC) out of tax refunds. One could estimate $\mu$ by replacing $\beta_{2} * \operatorname{refund}_{t}^{h}$ in equation (24) with $\mu * \Delta \operatorname{refund}_{t}^{h}$, where $\Delta \operatorname{refund}_{t}^{h}=\operatorname{refund}_{t, I I}^{h}-\operatorname{refund}_{t, I}^{h}$, the value of refunds received in quarter II of year $t$ minus the value of refunds received in quarter I of year $t$. The CEX however, does not record refunds at quarterly frequency. Therefore following Souleles (1999), we use the information on the distribution of aggregate refund disbursement to account for the difference between refund $t_{t}^{h}$ and $\Delta$ refund $_{t}^{h}$.

Specifically, we calculate an 'attenuation factor' $\pi$ from the distribution of aggregate refund disbursements: $\pi_{t}^{h}=p_{h}^{t, I I}-p_{h}^{t, I}$, where $p_{h}^{t, I I}\left(p_{h}^{t, I}\right)$ is the proportion of the refunds disbursed during $h$ 's refund reference period that was disbursed in particular in quarter $I$ (quarter II) of year $t$. Multiplying the regressor refund $t_{t}^{h}$ by these factors to correct for the probability that some of refunds

\footnotetext{
${ }^{40}$ Under this sample restriction, our final sample size is larger than that of Souleles (1999). This is because we use monthly reference periods, whereas Souleles (1999) uses quarterly reference periods. For example, a consumption record that covers from Dec. 1996 to Feb. 1997, is dropped from Souleles (1999) because it does not exactly cover the calendar quarter I, whereas in our sample, we use 12 months consumption data to construct the consumption record in quarter I and quarter II.
} 
have been received in the second quarter of the reference year instead of first quarter; essentially, we use approximation $\Delta\left(\operatorname{refund}_{t}^{h}\right) \approx \operatorname{refund}_{t}^{h} * \pi_{t}^{h}$. The attenuation factors used in this paper are taken directly from Souleles (1999) and are reported in Table 8. The equation for estimating the $\mathrm{MPC} \mu$ is then given by,

$$
C_{t, I I}^{h}-C_{t, I}^{h}=\sum_{t} \beta_{0 t} * \operatorname{year}_{t}^{h}+\beta_{1}^{\prime} X_{t}^{h}+\beta_{2} * \operatorname{refund}_{t}^{h} * \pi_{t}^{h}+u_{t}^{h}
$$

\subsubsection{Results}

Equation (24) is estimated by ordinary least squares (OLS), with the standard errors corrected for heteroskedasticity. The estimation is undertaken including households that report no refund. A statistically significant and positive coefficient $\beta_{2}$ then indicates, using the terminology of the literature, that consumption is excessively sensitive to changes in after-tax incomes (due to the tax rebates) that could have been anticipated by households. The results are reported in Table 7. As a comparison, we also report the estimation results from Souleles (1999) for the same consumption categories in Table 7 .

Table 7 first displays the impact of federal income tax refunds on consumption categories for which memorable goods and nondurable goods are not differentiated from each other. For consumption defined as the sum of strictly nondurable and memorable goods (corresponding to the definition of strictly nondurable consumption used in Souleles (1999)), the coefficient of the refund variable refund $t_{t}^{h}$ is 0.023 and is statistically significant. However, once we exclude memorable goods from this consumption measure, the excess sensitivity of nondurable consumption to tax refunds becomes economically small and statistically insignificant: $\beta_{2}$ equals 0.007 and 0.001 for strictly nondurable and nondurable consumption goods (but now excluding memorable goods), respectively. Furthermore, we find that the coefficient on the refund variable for memorable goods and durable goods is both economically and statistically significant, 0.023 and 0.134 respectively. Thus the excess sensitivity of strictly nondurable consumption expenditure found in Souleles (1999) can entirely be attributed to the response of memorable consumption expenditure.

The OLS estimation results of equations (25) are reported in Table 8, with the standard errors corrected for heteroskedasticity. We first report the estimated MPC for consumption categories that do not differentiate between nondurable and memorable goods, but rather lump them together. We then display results if memorable goods are treated as a separate consumption category. The MPC of strictly nondurable consumption, including memorable goods, is positive and significant, as Soule- 


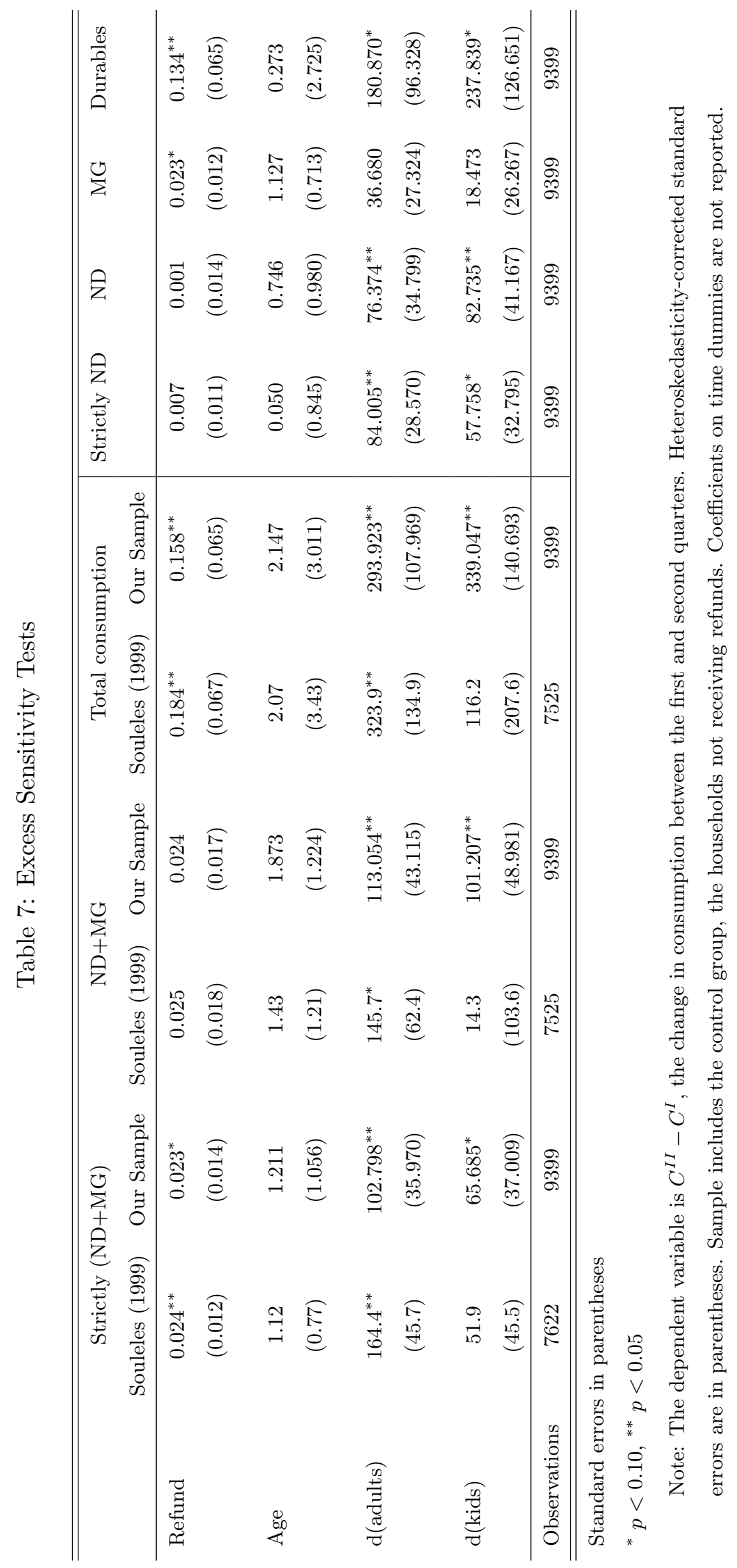




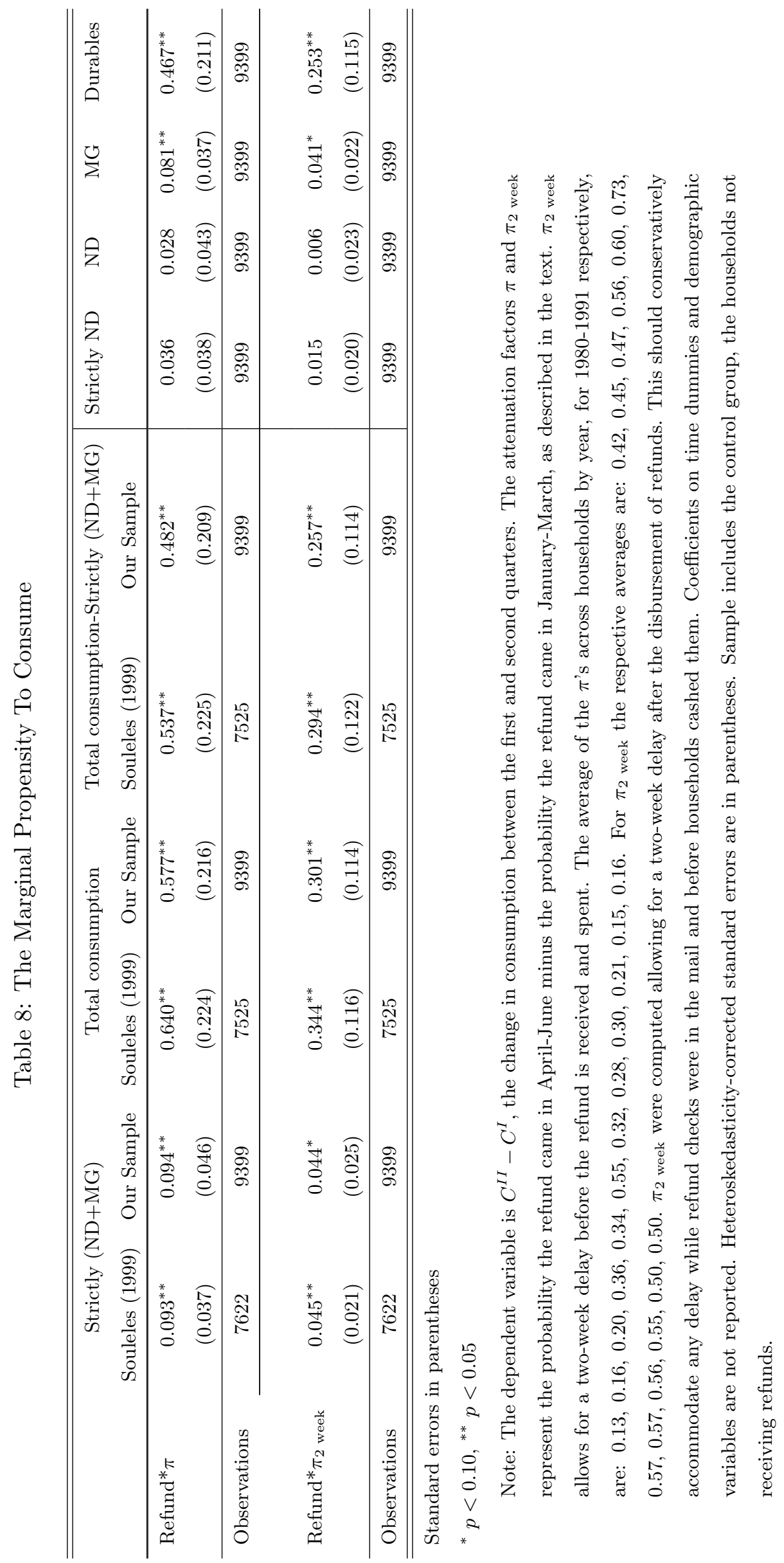


les (1999) finds. However, once memorable goods are excluded from the definition of nondurable goods, the MPC of both strictly nondurable and nondurable goods again becomes economically modest and statistically insignificant ( $\beta_{2}$ is estimated to equal 0.036 and 0.028 respectively). Moreover, as before memorable goods and durable goods display a large and significantly positive MPC (0.081 and 0.467 respectively) out of the tax refunds.

To summarize, our results show that nondurable goods, memorable goods, and durable goods may have very distinct responses to income tax refunds. After excluding memorable goods from the traditionally defined nondurable goods category, nondurable goods consumption does not respond to income tax refunds in an economically and statistically significantly way, whereas memorable goods consumption responds to these refunds in a fairly sizeable way. Last, durable goods consumption display the most pronounced response.

\section{Conclusion}

In this paper we propose a novel consumption model that augments the canonical categorization of consumption goods into nondurable and durable goods by a third category which we call memorable goods. Memorable goods consumption impacts future utility through the accumulation process of memory stock. We show that households optimally choose a non-smooth consumption profile of memorable goods. We then estimate the welfare costs associated with consumption fluctuations, and find that relative to the benchmark model, in which all nondurable consumption is lumped together (and which is nested in our framework), an explicit distinction and modeling of memorable goods reduces the estimated welfare costs by at least $10 \%$, and possibly as much as $32 \%$. We furthermore argue that the rejection of the permanent income hypothesis (PIH) based on the excess sensitivity of consumption to predictable income changes documented in important papers of the literature might be entirely due to the presence of memorable goods. In addition to allocations, the presence of memorable goods may have additional implications for asset prices, which we plan to explore in future work.

Our consumer is an infinitely lived agent in a stationary world, modeled in this way to easily compare her consumption behavior to that in the classical model. We believe the usefulness of the memorable goods concept goes beyond the particular application in this paper, however. One could use the memorable goods concept we introduce here to address other important applied questions. For example, it is sometimes suggested that people undersave, as evidenced by a decline 
in consumption when they are old. To the extent that early-life consumption includes memorable goods, an approach that ignores memorable goods will overstate the drop in utility accompanying decreased consumption later.

Finally, an important simplification in this paper is that all consumers are homogeneous; in particular, the classification of goods as memorable goods is the same for all households and independent of income or wealth. It would be interesting to relax this homogeneity assumption and investigate whether there are secular trends in the importance and categorization of memorable goods and differences in the depreciation of memorable goods across households with different socioeconomic characteristics. Additionally, how the set of goods that are memorable changes across an agent's life cycle and how this set depends on her income, location, family composition and other socioeconomic characteristics is an interesting question that future research could pursue. 


\section{References}

Andrew B. Abel. Asset prices under habit formation and catching up with the joneses. The American Economic Review, 80(2):38-42, 1990.

Mark Aguiar and Erik Hurst. Deconstructing lifecycle expenditure. March 2008.

Volker Barthelmann, Erich Novak, and Klaus Ritter. High dimensional polynomial interpolation on sparse grids. Advances in Computational Mathematics, 12:273-288, 2000.

Martin Browning and Thomas F. Crossley. Shocks, stocks and socks: Consumption smoothing and the replacement of durables during an unemployment spell. 1999.

Martin Browning and Thomas F. Crossley. Luxuries are easier to postpone: A proof. Journal of Political Economy, 108(5):1022-1026, October 2000.

John Y. Campbell and John Cochrane. Force of habit: A consumption-based explanation of aggregate stock market behavior. Journal of Political Economy, 107(2):205-251, April 1999.

John Y. Campbell and N. Gregory Mankiw. Consumption, income, and interest rates: Reinterpreting the time series evidence. May 1990.

Kerwin Kofi Charles and Melvin Stephens. The level and composition of consumption over the business cycle: The role of "quasi-fixed" expenditures. July 2006.

Steven J. Davis and James A. Kahn. Interpreting the great moderation: Changes in the volatility of economic activity at the macro and micro levels. Journal of Economic Perspectives, 22(4): 155-80, Fall 2008.

Larry G. Epstein and Stanley E. Zin. Substitution, risk aversion, and the temporal behavior of consumption and asset returns: A theoretical framework. Econometrica, 57(4):pp. 937-969, 1989.

Milton Friedman. A Theory of the Consumption Function. Princeton University Press, 1957.

Olga Gorbachev. Did household consumption become more volatile? American Economic Review, 101(5):2248-70, September 2011.

Fatih Guvenen. An empirical investigation of labor income processes. Review of Economic Dynamics, 12(1):58-79, January 2009. 
Robert E. Hall. Stochastic implications of the life cycle-permanent income hypothesis: Theory and evidence. Journal of Political Economy, 86(6):pp. 971-987, 1978.

Robert E Hall and Frederic S Mishkin. The sensitivity of consumption to transitory income: Estimates from panel data on households. Econometrica, 50(2):461-81, March 1982.

Daniel S. Hamermesh. Social insurance and consumption: An empirical inquiry. The American Economic Review, 72(1):101-113, 1982.

Tullio Jappelli and Luigi Pistaferri. The consumption response to income changes. Annual Review of Economics, 2(1):479-506, 092010.

Dirk Krueger and Felix Kubler. Computing equilibrium in olg models with stochastic production. Journal of Economic Dynamics and Control, 28(7):1411-1436, April 2004.

Dirk Krueger and Fabrizio Perri. Does income inequality lead to consumption inequality? evidence and theory. Review of Economic Studies, 73(1):163-193, 012006.

George Loewenstein and Jon Elster, editors. Choice Over Time. Sage Publications, New York, NY, 1992.

Robert E. Lucas. Models of business cycles. Blackwell Publishers, 1987.

Annamaria Lusardi. Permanent income, current income, and consumption: Evidence from two panel data sets. Journal of Business E Economic Statistics, 14(1):81-90, 1996.

Benjamin Malin, Dirk Krueger, and Felix Kubler. Computing stochastic dynamic economic models with a large number of state variables: A description and application of a smolyak-collocation method. (13517), October 2007.

N.Gregory Mankiw. Hall's consumption hypothesis and durable goods. Journal of Monetary Economics, 10(3):417 - 425, 1982.

Franco Modigliani and Richard Brumberg. Utility Analysis and the Consumption Function: An Interpretation of Cross-Section Data. 1954.

Julie A. Nelson. On testing for full insurance using consumer expenditure survey data. The Journal of Political Economy, 102(2):384-394, 1994. 
Jonathan A. Parker. The reaction of household consumption to predictable changes in social security taxes. The American Economic Review, 89(4):959-973, 1999.

Jonathan A. Parker and Bruce Preston. Precautionary saving and consumption fluctuations. American Economic Review, 95(4):1119-1143, 2005.

Adam Smith. The Theory of Moral Sentiments. Printed for A. Millar, in the Strand; and A. Kincaid and J. Bell, in Edinburgh, 1759.

S. Smolyak. Quadrature and interpolation formulas for tensor products of certain classes of functions. Soviet Mathematics, Doklady, (4, 240-243), 1963.

Nicholas S. Souleles. The response of household consumption to income tax refunds. The American Economic Review, 89(4):947-958, 1999.

Robert. H. Strotz. Myopia and inconsistency in dynamic utility maximization. The Review of Economic Studies, 23(3):pp. 165-180, 1955.

Stephen P Zeldes. Consumption and liquidity constraints: An empirical investigation. Journal of Political Economy, 97(2):305-46, April 1989. 


\section{A Derivations}

Derivation of Euler Equations. The household's maximization problem is given by

$$
\begin{aligned}
V(M, N, S, z)= & \max _{C_{m}, S^{\prime}}\left\{U\left(C_{n}, C_{m}, M\right)+\beta \mathbb{E} V\left(M^{\prime}, N^{\prime}, S^{\prime}, z^{\prime}\right) \mid z\right\} \\
& \text { s.t. } \\
C_{n}= & Y+(1+r) S-C_{m}-S^{\prime} \\
M^{\prime}= & \left(1-\delta_{m}\right) M+\max \left\{C_{m}-N, 0\right\} \\
N^{\prime}= & (1-\rho) N+\rho C_{m} \\
S^{\prime} \geq & 0 \\
\ln Y= & \bar{y}+z \\
z^{\prime}= & \rho_{z} z+\epsilon .
\end{aligned}
$$

We could rewrite the household's maximization problem as

$$
\begin{aligned}
V(M, N, S, z)= & \max _{N^{\prime}, S^{\prime}}\left\{U\left(C_{n},\left(N^{\prime}-(1-\rho) N\right) / \rho, M\right)+\beta \mathbb{E} V\left(M^{\prime}, N^{\prime}, S^{\prime}, z^{\prime}\right) \mid z\right\} \\
& \text { s.t. } \\
C_{n}= & Y+(1+r) S-S^{\prime}-\frac{1}{\rho}\left(N^{\prime}-(1-\rho) N\right) \\
M^{\prime}= & \left(1-\delta_{m}\right) M+\frac{1}{\rho} \max \left\{N^{\prime}-N, 0\right\} \\
S^{\prime} \geq & 0 \\
\ln Y= & \bar{y}+z \\
z^{\prime}= & \rho_{z} z+\epsilon .
\end{aligned}
$$

The first order conditions imply that the following two equations must hold at optimum,

$$
\begin{aligned}
\frac{\partial U}{\partial C_{n}}\left(C_{n}, C_{m}, M\right) & =\beta \mathbb{E} \frac{\partial V}{\partial S}\left(M^{\prime}, N^{\prime}, S^{\prime}, z^{\prime}\right)+\lambda_{S^{\prime}} \\
\frac{\partial U}{\partial C_{n}}\left(C_{n}, C_{m}, M\right)-\frac{\partial U}{\partial C_{m}}\left(C_{n}, C_{m}, M\right) & =\mathbf{1}_{C_{m}>N} \cdot \beta \mathbb{E} \frac{\partial V}{\partial M}\left(M^{\prime}, N^{\prime}, S^{\prime}, z^{\prime}\right)+\rho \beta \mathbb{E} \frac{\partial V}{\partial N}\left(M^{\prime}, N^{\prime}, S^{\prime}, z^{\prime}\right)
\end{aligned}
$$

where $C_{n}=Y+(1+r) S-C_{m}-S^{\prime}, \lambda_{S^{\prime}}$ is the Lagrange multiplier associated with the borrowing constraint $S^{\prime} \geq 0$, and $\mathbf{1}_{C_{m}>N}$ is an indicator function that equals to 1 if and only if $C_{m}>N$. 
The envelope theorem implies that the following conditions hold at the optimum,

$$
\begin{aligned}
\frac{\partial V}{\partial M}(M, N, S, z) & =\frac{\partial U}{\partial M}\left(C_{n}, C_{m}, M\right)+\left(1-\delta_{m}\right) \beta \mathbb{E} \frac{\partial V}{\partial M}\left(M^{\prime}, N^{\prime}, S^{\prime}, z^{\prime}\right) \\
\frac{\partial V}{\partial N}(M, N, S, z) & =\frac{1-\rho}{\rho} \frac{\partial U}{\partial C_{n}}\left(C_{n}, C_{m}, M\right)-\frac{1-\rho}{\rho} \frac{\partial U}{\partial C_{m}}\left(C_{n}, C_{m}, M\right)-\mathbf{1}_{C_{m}>N} \cdot \beta \mathbb{E} \frac{\partial V}{\partial M}\left(M^{\prime}, N^{\prime}, S^{\prime}, z^{\prime}\right) \\
\frac{\partial V}{\partial S}(M, N, S, z) & =(1+r) \frac{\partial U}{\partial C_{n}}\left(C_{n}, C_{m}, M\right) .
\end{aligned}
$$

The Euler equation for the optimal consumption path of nondurable goods $C_{n}$ is standard,

$$
\frac{\partial U}{\partial C_{n}}\left(C_{n}, C_{m}, M\right)-(1+r) \beta \mathbb{E} \frac{\partial U}{\partial C_{n}}\left(C_{n}^{\prime}, C_{m}^{\prime}, M^{\prime}\right)=\lambda_{S^{\prime}}
$$

where $\lambda_{S^{\prime}}$ is the Lagrange multiplier associated with the borrowing constraint $S^{\prime} \geq 0$.

Under our utility specification, the Euler equation of $C_{n, t}$ is given by the following equation

$$
C_{n, t}^{-\gamma}-(1+r) \beta \mathbb{E}_{t} C_{n, t+1}^{-\gamma}=\frac{\lambda_{S_{t+1}}}{\xi}
$$

The optimal consumption path of memorable goods $C_{m}$ rely on not only the borrowing constraint and the interest rate but also the memory stock $M$ and the past experience level of memorable goods consumption $N$,

$$
\begin{aligned}
& \frac{\partial U}{\partial C_{n}}\left(C_{n}, C_{m}, M\right)-\frac{\partial U}{\partial C_{m}}\left(C_{n}, C_{m}, M\right) \\
= & (1-\rho) \beta \mathbb{E}\left(\frac{\partial U}{\partial C_{n}}\left(C_{n}^{\prime}, C_{m}^{\prime}, M^{\prime}\right)-\frac{\partial U}{\partial C_{m}}\left(C_{n}^{\prime}, C_{m}^{\prime}, M^{\prime}\right)\right) \\
& +\mathbf{1}_{C_{m}>N} \cdot \beta \mathbb{E} \frac{\partial V}{\partial M}\left(M^{\prime}, N^{\prime}, S^{\prime}, z^{\prime}\right)-\rho \beta^{2} \mathbb{E}\left(\mathbf{1}_{C_{m}^{\prime}>N^{\prime}} \cdot \mathbb{E} \frac{\partial V}{\partial M}\left(M^{\prime \prime}, N^{\prime \prime}, S^{\prime \prime}, z^{\prime \prime}\right)\right) .
\end{aligned}
$$

Under our current utility specification, the above equation can be rewritten as

$$
\begin{aligned}
& \alpha(1-\xi)(1-\rho) \beta \mathbb{E}_{t}\left(\left(\alpha C_{m, t+1}+(1-\alpha) M_{t+1}\right)^{-\gamma}\right)-\alpha(1-\xi)\left(\alpha C_{m, t}+(1-\alpha) M_{t}\right)^{-\gamma} \\
= & \xi(1-\rho) \beta \mathbb{E}_{t} C_{n, t+1}^{-\gamma}-\xi C_{n, t}^{-\gamma} \\
& +\mathbf{1}_{C_{m, t}>N_{t}} \cdot \beta \mathbb{E}_{t} \frac{\partial V}{\partial M}\left(M_{t+1}, N_{t+1}, S_{t+1}, z_{t+1}\right)-\rho \beta^{2} \mathbb{E}_{t}\left(\mathbf{1}_{C_{m, t+1}>N_{t+1}} \cdot \mathbb{E} \frac{\partial V}{\partial M}\left(M_{t+2}, N_{t+2}, S_{t+2}, z_{t+2}\right)\right) .
\end{aligned}
$$

Proof of proposition 1 . The Euler equation for the optimal consumption path of nondurable goods $C_{n}$ is standard, and is given by the following equation

$$
C_{n, t}^{-\gamma}-(1+r) \beta \mathbb{E}_{t} C_{n, t+1}^{-\gamma}=\frac{\lambda_{S_{t+1}}}{\xi}
$$

where $\lambda_{S_{t+1}}$ is the Lagrange multiplier associated with the borrowing constraint $S_{t+1} \geq 0$. Thus the dynamics of nondurable consumption is affected by the presence of memorable goods only 
through the impact of the latter on the binding patterns of the borrowing constraint. We will show below that for households far away from the constraints, the nondurable consumption dynamics and response to income shock are substantially identical to that of the standard consumption-savings model $^{41}$, the same is not true for households with little or no financial wealth.

The optimal consumption choice for memorable goods consumption $C_{m}$ depends strongly on the current period stock of memories $M$ and the average level of past memorable goods consumption $N$. The first order condition for $C_{m, t}$ is

$$
\begin{aligned}
& \alpha(1-\xi)(1-\rho) \beta \mathbb{E}_{t}\left(\left(\alpha C_{m, t+1}+(1-\alpha) M_{t+1}\right)^{-\gamma}\right)-\alpha(1-\xi)\left(\alpha C_{m, t}+(1-\alpha) M_{t}\right)^{-\gamma} \\
= & \xi(1-\rho) \beta \mathbb{E}_{t} C_{n, t+1}^{-\gamma}-\xi C_{n, t}^{-\gamma} \\
& +\mathbf{1}_{C_{m, t}>N_{t}} \cdot \beta \mathbb{E}_{t} \frac{\partial V}{\partial M}\left(M_{t+1}, N_{t+1}, S_{t+1}, z_{t+1}\right)-\rho \beta^{2} \mathbb{E}_{t}\left(\mathbf{1}_{C_{m, t+1}>N_{t+1}} \cdot \mathbb{E} \frac{\partial V}{\partial M}\left(M_{t+2}, N_{t+2}, S_{t+2}, z_{t+2}\right)\right)
\end{aligned}
$$

where the dynamics of marginal value of $M_{t}$ and $N_{t}$ along the optimal consumption path are given by the following two equations

$$
\begin{aligned}
& \frac{\partial V}{\partial M}(M, N, S, z)=\frac{\partial U}{\partial M}\left(C_{n}, C_{m}, M\right)+\left(1-\delta_{m}\right) \beta \mathbb{E} \frac{\partial V}{\partial M}\left(M^{\prime}, N^{\prime}, S^{\prime}, z^{\prime}\right) \\
& \frac{\partial V}{\partial N}(M, N, S, z)=\frac{1-\rho}{\rho} \frac{\partial U}{\partial C_{n}}\left(C_{n}, C_{m}, M\right)-\frac{1-\rho}{\rho} \frac{\partial U}{\partial C_{m}}\left(C_{n}, C_{m}, M\right)-\mathbf{1}_{C_{m}>N} \cdot \beta \mathbb{E} \frac{\partial V}{\partial M}\left(M^{\prime}, N^{\prime}, S^{\prime}, z^{\prime}\right)
\end{aligned}
$$

To show that $\forall \bar{C}_{m} \geq 0$, a consumption plan $C_{m, t}=\bar{C}_{m}$ for all $t$ is never optimal, it is sufficient to prove that $C_{m, t}=\bar{C}_{m}$ does not satisfy the optimality condition derived from the dynamic programming problem.

First, notice that when $\rho=1$,

$$
\frac{\partial V}{\partial N}\left(M_{t}, N_{t}, S_{t}, z_{t}\right)=-\mathbf{1}_{C_{m, t}>N_{t}} \cdot \beta \mathbb{E} \frac{\partial V}{\partial M}\left(M_{t+1}, N_{t+1}, S_{t+1}, z_{t+1}\right) .
$$

When there is no income uncertainty and no borrowing constraint, and $(1+r) \beta=1$, the optimal consumption profile must satisfies the following equation,

$$
\begin{aligned}
& \xi C_{n, t}^{-\gamma}-\alpha(1-\xi)\left(\alpha C_{m, t}+(1-\alpha) M_{t}\right)^{-\gamma} \\
= & \mathbf{1}_{C_{m, t}>N_{t}} \cdot \beta \mathbb{E}_{t} \frac{\partial V}{\partial M}\left(M_{t+1}, N_{t+1}, S_{t+1}, z_{t+1}\right)-\beta^{2} \mathbb{E}_{t}\left(\mathbf{1}_{C_{m, t+1}>N_{t+1}} \cdot \mathbb{E} \frac{\partial V}{\partial M}\left(M_{t+2}, N_{t+2}, S_{t+2}, z_{t+2}\right)\right) .
\end{aligned}
$$

Because $\rho=1$, under the smooth consumption plan $C_{m, t}=\bar{C}_{m}$ for all $t, N_{t}=\bar{C}_{m}$ for $t \geq 1$. Thus the optimality principle implies the following condition must be true for all $t$

$$
\xi C_{n, t}^{-\gamma}-\alpha(1-\xi)\left(\alpha C_{m, t}+(1-\alpha) M_{t}\right)^{-\gamma}=0 .
$$

\footnotetext{
${ }^{41}$ And of course in the frictionless case when there is no income uncertainty and no borrowing constraint, and if $(1+r) \beta=1$, the household's optimal consumption profile satisfies $C_{n, t}^{*}=\bar{C}_{n}$ for some $\bar{C}_{n}>0$.
} 
The Euler equation of $C_{n, t}$ implies that $C_{n, t}^{-\gamma}=C_{n, t+1}^{-\gamma}$, therefore the above condition implies that at optimum $\left(\alpha C_{m, t}+(1-\alpha) M_{t}\right)^{-\gamma}$ must be constant. However, under the smooth consumption plan $C_{m, t}=\bar{C}_{m}, M_{t+1}=\left(1-\delta_{m}\right) M_{t}<M_{t}$. Thus a consumption plan $C_{m, t}=\bar{C}_{m}, \forall \bar{C}_{m} \geq 0$, for all $t$ is never optimal.

\section{Proof of Equation 14.}

The welfare cost of consumption fluctuations, $g\left(\sigma_{c}\right)$, is implicitly defined by the following equation,

$$
\mathbb{E} \frac{\left(\left(1+g\left(\sigma_{c}\right)\right) C_{n, t}^{h}\right)^{1-\gamma}}{1-\gamma}=\frac{\left(\mathbb{E}\left(C_{n, t}^{h}\right)\right)^{1-\gamma}}{1-\gamma}
$$

Because

$$
\begin{aligned}
\mathbb{E}\left\{U\left(\left(1+g\left(\sigma_{c}\right)\right) C_{t, l}^{h}\right)\right\} & =\frac{\left(1+g\left(\sigma_{c}\right)\right)^{1-\gamma}}{1-\gamma} \mathbb{E}\left\{\exp \left((1-\gamma) P_{t, l}^{h}+(1-\gamma) \sigma_{c} z_{t, l}^{h}\right)\right\} \\
& =\frac{\exp \left((1-\gamma) P_{t, l}^{h}\right)}{1-\gamma}\left(1+g\left(\sigma_{c}\right)\right)^{1-\gamma} \exp \left(\frac{1}{2}(1-\gamma)^{2} \sigma_{c}^{2}\right)
\end{aligned}
$$

and $U\left(\mathbb{E}\left\{C_{t, l}^{h}\right\}\right)=\frac{1}{1-\gamma} \exp \left((1-\gamma) P_{t, l}^{h}+\frac{1}{2}(1-\gamma) \sigma_{c}^{2}\right), g\left(\sigma_{c}\right)$ satisfies

$$
\left(1+g\left(\sigma_{c}\right)\right)^{1-\gamma} \exp \left(\frac{1}{2}(1-\gamma)^{2} \sigma_{c}^{2}\right)=\exp \left(\frac{1}{2}(1-\gamma) \sigma_{c}^{2}\right)
$$

Thus

$$
\ln \left(1+g\left(\sigma_{c}\right)\right)=\frac{1}{2} \gamma \sigma_{c}^{2}
$$

but since $\ln \left(1+g\left(\sigma_{c}\right)\right) \approx g\left(\sigma_{c}\right)$ when $g_{i}$ is small, then the welfare cost function associated with $\sigma_{i c}$ is given by,

$$
g\left(\sigma_{c}\right) \approx \frac{1}{2} \gamma \sigma_{c}^{2}
$$

Proof of Equation 21. Define as

$$
\begin{aligned}
\bar{V}(M, N, S ; g)= & \xi \frac{\left[(1+g) \bar{C}_{n}(M, N, S)\right]^{1-\gamma}}{1-\gamma}+(1-\xi) \frac{\left(\alpha(1+g) \bar{C}_{m}(M, N, S)+(1-\alpha)(1+g) M\right)^{1-\gamma}}{1-\gamma} \\
& +\beta \bar{V}\left(\bar{M}^{\prime}, \bar{N}^{\prime}(M, N, S), \bar{S}^{\prime}(M, N, S) ; g\right) .
\end{aligned}
$$

Note that

$$
\bar{V}(M, N, S ; g)=(1+g)^{1-\gamma} \bar{V}(M, N, S ; g=0) .
$$

As for $\bar{V}$, we can define $\bar{W}(S ; g)$ by

$$
\bar{W}(S ; g)=\frac{\left((1+g) \bar{C}_{n}^{W}(S)\right)^{1-\gamma}}{1-\gamma}+\beta \bar{W}\left(\bar{S}^{W \prime}(S) ; g\right) .
$$


Note that

$$
\bar{W}(S ; g)=(1+g)^{1-\gamma} \bar{W}(S ; g=0)
$$

For $\gamma=1$, a similar calculation yields

$$
\begin{aligned}
\bar{V}(M, N, S ; g) & =\frac{\log (1+g)}{1-\beta}+\bar{V}(M, N, S ; g=0) \\
\bar{W}(S ; g) & =\frac{\log (1+g)}{1-\beta}+\bar{W}(S ; g=0) .
\end{aligned}
$$

The welfare cost of consumption fluctuations for a household in state $(M, N, S)$ is then defined (in the model with and without memorable goods, respectively) as the solution to

$$
\begin{aligned}
\bar{V}(M, N, S ; g(M, N, S)) & =V(M, N, S, z=0) \\
\bar{W}\left(S ; g^{W}(S)\right) & =W(S, z=0)
\end{aligned}
$$

where setting $z=0$ in the model with risk again assures that households have the same income today and same expected income from tomorrow on in both worlds. Solving for $g(M, N, S)$ and $g^{W}(S)$ gives, exploiting equations (28) and (29),

$$
\begin{aligned}
g(M, N, S) & =\left[\frac{V(M, N, S, z=0)}{\bar{V}(M, N, S ; g=0)}\right]^{\frac{1}{1-\gamma}}-1 \\
g^{W}(S) & =\left(\frac{W(S, z=0)}{\bar{W}(S ; g=0)}\right)^{\frac{1}{1-\gamma}}-1 .
\end{aligned}
$$

Derivation of Euler Equations. Define

$$
\begin{aligned}
\lambda_{n, t}= & \frac{\lambda_{S_{t+1}}}{\xi(1+r) \beta \mathbb{E}_{t} C_{n, t+1}^{-\gamma}} \\
\lambda_{m, t}= & \frac{\left(\begin{array}{l}
\left(1-\frac{(1-\rho)}{1+r}\right) \xi C_{n, t}^{-\gamma}-\xi \frac{(1-\rho)}{1+r} \lambda_{S_{t+1}}-\mathbf{1}_{C_{m, t}>N_{t}} \cdot \beta \mathbb{E}_{t} \frac{\partial V}{\partial M}\left(M_{t+1}, N_{t+1}, S_{t+1}, z_{t+1}\right) \\
+\rho \beta^{2} \mathbb{E}_{t}\left(\mathbf{1}_{C_{m, t+1}>N_{t+1}} \cdot \mathbb{E} \frac{\partial V}{\partial M}\left(M_{t+2}, N_{t+2}, S_{t+2}, z_{t+2}\right)\right)
\end{array}\right)}{\alpha(1-\xi)(1-\rho) \beta \mathbb{E}_{t}\left(\left(\alpha C_{m, t+1}+(1-\alpha) M_{t+1}\right)^{-\gamma}\right)}
\end{aligned}
$$

Then the Euler equations for optimal consumption choices can be rewritten as

$$
\begin{aligned}
\mathbb{E}_{t} \frac{(1+r) \beta C_{n, t+1}^{-\gamma}}{C_{n, t}^{-\gamma}}\left(1+\lambda_{n, t}\right) & =1 \\
\mathbb{E}_{t} \frac{(1-\rho) \beta \mathbb{E}_{t}\left(\left(\alpha C_{m, t+1}+(1-\alpha) M_{t+1}\right)^{-\gamma}\right)}{\left(\alpha C_{m, t}+(1-\alpha) M_{t}\right)^{-\gamma}}\left(1+\lambda_{m, t}\right) & =1 .
\end{aligned}
$$


Rational expectations implies that at optimum the following equation must be true ${ }^{42}$ :

$$
\begin{aligned}
& \frac{(1+r) \beta C_{n, t+1}^{-\gamma}}{C_{n, t}^{-\gamma}}\left(1+\lambda_{n, t}\right)=1+e_{n, t+1} \\
& \frac{(1-\rho) \beta\left[\left(\alpha C_{m, t+1}+(1-\alpha) M_{t+1}\right)^{-\gamma}\right]}{\left(\alpha C_{m, t}+(1-\alpha) M_{t}\right)^{-\gamma}}\left(1+\lambda_{m, t}\right)=1+e_{m, t+1}
\end{aligned}
$$

where $e_{n, t+1}$ and $e_{m, t+1}$ can be interpreted as the expectation error, and by construction $e_{n, t+1}$ and $e_{m, t+1}$ are uncorrelated with information known at time $t$. Taking logs on both side and taking a linear approximation ${ }^{43}$ of equation 32 , we obtain the linearized Euler equation for nondurable consumption:

$$
\left.C_{n, t+1}-C_{n, t}=\frac{1}{\tilde{\gamma}}\left[\log ((1-\rho) \beta)+\log \left(1+\lambda_{n, t}\right)-\log \left(1+e_{n, t+1}\right)\right)\right]
$$

Note that when the borrowing constraint is not binding at period $t\left(\lambda_{S_{t+1}}=0\right) \lambda_{n, t}=0$.

Doing the same with equation 33 yields

$$
\left.C_{m, t+1}-C_{m, t}=\frac{1}{\alpha \gamma^{\prime}}\left[\log ((1-\rho) \beta)+\log \left(1+\lambda_{m, t}\right)-\log \left(1+e_{n, t+1}\right)\right)\right]-\frac{1-\alpha}{\alpha}\left(M_{t+1}-M_{t}\right)
$$

and plugging in the law of motion for $M_{t+1}$ delivers the linearized Euler equation for memorable consumption expenditures:

$\left.C_{m, t+1}-C_{m, t}=\frac{1}{\alpha \gamma^{\prime}}\left[\log ((1-\rho) \beta)+\log \left(1+\lambda_{m, t}\right)-\log \left(1+e_{n, t+1}\right)\right)\right]-\frac{1-\alpha}{\alpha}\left(-\delta_{m} M_{t}+\max \left\{C_{m, t}-N_{t}, 0\right\}\right)$

In these equations the constants $\tilde{\gamma}, \hat{\gamma}$ are products of the risk aversion coefficient $\gamma$ and approximation constants.

\section{B Model Solution Algorithm}

The model solution algorithm is as follows:

Step 1. Guess an initial value of value function $V^{(0)}$ at each grid point of the state space, use OLS regression to calculate the Smolyak coefficients associated with value function $V^{(0)}$.

Step 2. At each state space grid point, value function at the $i$-th iteration, $V^{(i)}$, is maximized by searching memorable goods consumption $C_{m}$ over a discrete grid

$$
V^{(i)}(M, N, S, z)=\max _{C_{m} \in \text { Grid of } C_{m}}\left\{W^{(i)}\left(M, N, S, z, C_{m}\right)\right\}
$$

\footnotetext{
${ }^{42}$ See Parker and Preston (2005) and Parker (1999) for similar analyses for nondurable goods expenditure.

${ }^{43}$ The linear approximation used here is $\log y_{t+1}-\log y_{t}=\left(y_{t+1}-y_{t}\right) / \bar{y}$ for some $\bar{y}$.
} 
where $W^{(i)}\left(M, N, S, z, C_{m}\right)$ is the value function associated with memorable goods consumption $C_{m}$ for given state space variables $(M, N, S, z)$, i.e.,

$$
W^{(i)}\left(M, N, S, z, C_{m}\right)=\max _{S^{\prime}}\left\{U\left(C_{n}, C_{m}, M\right)+\beta \mathbb{E}\left[V^{(i-1)}\left(M^{\prime}, N^{\prime}, S^{\prime}, z^{\prime}\right) \mid z\right]\right\} .
$$

The solution of optimal savings $S^{\prime *}$ associated with memorable goods consumption $C_{m}$ is characterized by the following equation

$$
-\frac{\partial U\left(Y+(1+r) S-C_{m}-S^{\prime *}, C_{m}, M\right)}{\partial C_{n}}+\beta \frac{\partial \mathbb{E}\left[V^{(i-1)}\left(M^{\prime}, N^{\prime}, S^{\prime *}, z^{\prime}\right) \mid z\right]}{\partial S^{\prime}}=0
$$

and $S^{*}=0$ if $-\frac{\partial U\left(Y+(1+r) S-C_{m}, C_{m}, M\right)}{\partial C_{n}}+\beta \frac{\partial \mathbb{E}\left[V^{(i-1)}\left(M^{\prime}, N^{\prime}, 0, z^{\prime}\right) \mid z\right]}{\partial S^{\prime}} \leq 0$.

For $\left(M^{\prime}, N^{\prime}, S^{\prime}, z^{\prime}\right)$ outside the state space grid, the value of value function $V^{(i-1)}\left(M^{\prime}, N^{\prime}, S^{\prime}, z^{\prime}\right)$ is calculated via interpolation using Smolyak coefficients. Furthermore, $\mathbb{E}\left[V^{(i-1)}\left(M^{\prime}, N^{\prime}, S^{\prime *}, z^{\prime}\right) \mid z\right]$ is calculated using quadratic rule numerical integration method.

Step 3. Update Smolyak coefficients associated with value function $V^{(i)}$.

Step 4. Repeat Step 2 to 3 until the value of value function at each state space grid point and associated Smolyak coefficients converge.

\section{Stationary Distribution}

Our model predicts that there is a cross-sectional stationary distribution of state variables. There is no analytical solution to the household's consumption-savings problem, so we characterize the cross-sectional distribution of $\left(M_{t}, N_{t}, S_{t}, z_{t}\right)$ numerically using Markov chain Monte Carlo (MCMC) simulation method. Specifically our procedure is as follows:

Step 1: At period $t=0$, we randomly simulate state variables $\left(M_{0}, N_{0}, S_{0}\right)$ for each household $h \in$ $\{1, \ldots, H\}$ from an arbitrary initial distribution $F^{(0)}(M, N, S)$, and draw $z_{0}$ from the distribution $N\left(0, \sigma^{2} /\left(1-\rho^{2}\right)\right)$ for each household.

Step 2: At period $t=0$, for given state variables $\left(M_{t}, N_{t}, S_{t}, z_{t}\right)$, households optimally make their current memorable goods consumption $C_{m, t}^{*}$ and period $t+1$ savings decisions $S_{t+1}^{*}$. Households' period $t+1$ state variables $M_{t+1}^{*}$ and $N_{t+1}^{*}$ are updated according to Equations 2 and 3 respectively. Households' period $t+1$ income shock $z_{t+1}$ is randomly drawn according to the conditional distribution $N\left(\rho_{z} z_{t}, \sigma^{2}\right)$. The updated state variables $\left(M_{t+1}^{*}, M_{t+1}^{*}, M_{t+1}^{*}\right)$ for $H$ households yield the numerical distribution $F^{(1)}(M, N, S)$. 
Step 3: Check if whether distribution $F^{(1)}(M, N, S)$ converges to $F^{(0)}(M, N, S)$ by checking whether the mean and variance of the state variable $M, N, S$ are the same under these two distributions. If the distribution is not converged, then repeat step 2 for $t=2, \ldots$.

\section{Data}

\section{D.1 Income Categories}

We define disposable income as income before tax minus reported federal, state and local income taxes payments, property tax not reported elsewhere and other tax (net of tax refunds), deductions for social security and pension plans. Household income before tax includes wages and salaries, net business income, net farm income, rents income, dividend income, interest income, pension income, social security and railroad retirement income, supplemental security income, unemployment compensation, workers' compensation and veterans benefits, welfare received, scholarship, food stamps, contributions received from others with alimony/child support, meals received as pay, rent received as pay, and lump sum receipts and lump sum child support payment. 


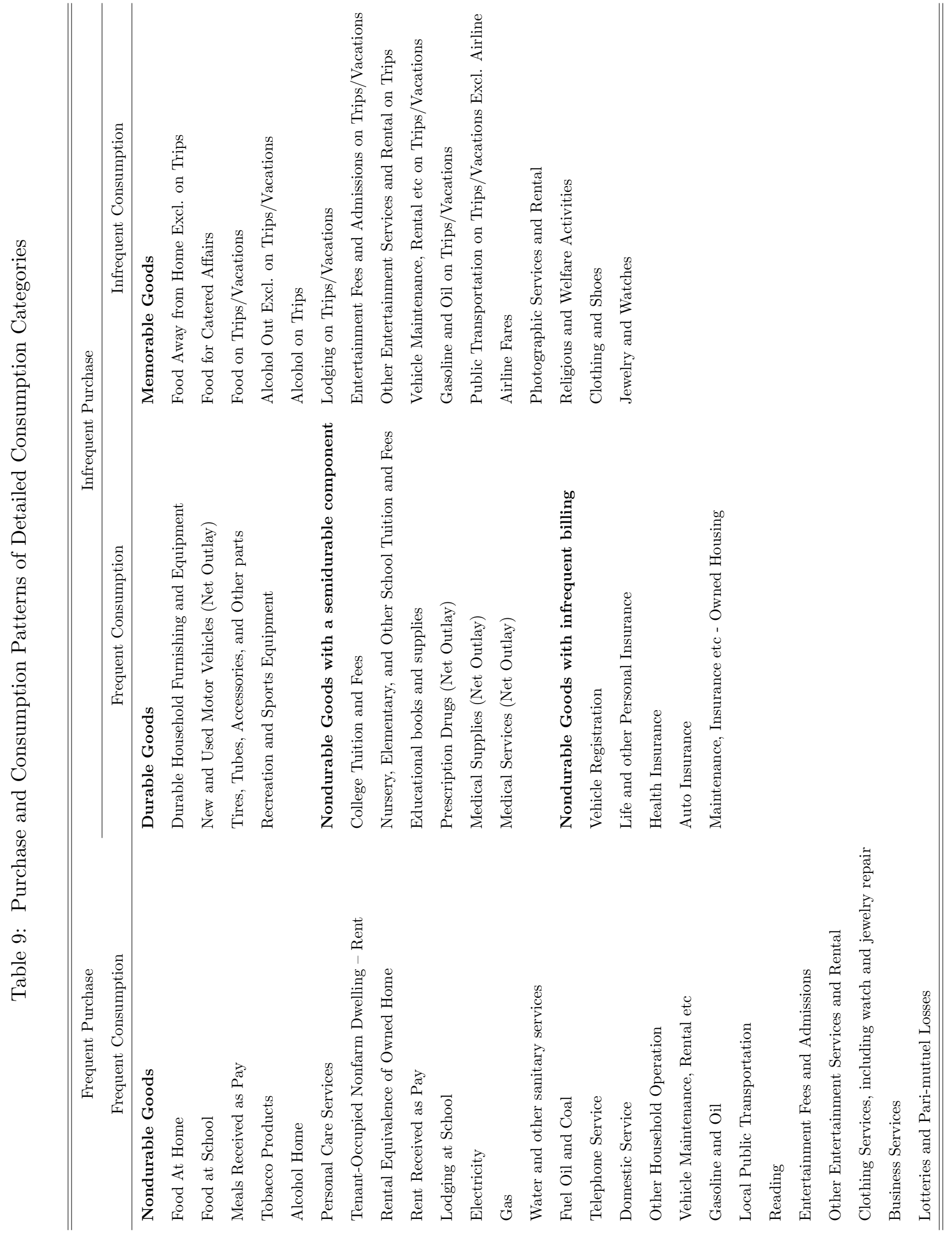




\section{Table 10: Nondurable Goods}

\begin{tabular}{|c|c|c|c|}
\hline Number & Categories & CPI used to deflate & CPI \\
\hline 1 & Food At Home & Food at home & SAF11 \\
\hline 2 & Food at School & Food away from home & SEFV \\
\hline 3 & Meals Received as Pay & Food away from home & SEFV \\
\hline 4 & Tobacco Products & Tobacco and smoking products & SEGA \\
\hline 5 & Alcohol Home & Alcoholic beverages at home & SEFW \\
\hline 6 & Personal Care Services & Personal care services & SEGC \\
\hline 7 & Maintenance, Insurance etc - Owned Housing & Shelter & SAH1 \\
\hline 8 & Tenant-Occupied Nonfarm Dwelling - Rent & Rent of primary residence & SEHA \\
\hline 9 & Rental Equivalence of Owned Home & Owners' equivalent rent of primary residence & SEHC \\
\hline 10 & Rent Received as Pay & Lodging away from home & SEHB \\
\hline 11 & Lodging at School & Lodging away from home & SEHB \\
\hline 12 & Electricity & Electricity & SEHF01 \\
\hline 13 & Gas & Utility (piped) gas service & SEHF02 \\
\hline 14 & Water and other sanitary services & Water, sewer and trash collection services & SEHG \\
\hline 15 & Fuel Oil and Coal & Fuel oil and other fuels & SEHE \\
\hline 16 & Telephone Service & Telephone services & SEED \\
\hline 17 & Domestic Service & Household operations & SEHP \\
\hline 18 & Other Household Operation & Household operations & SEHP \\
\hline 19 & Vehicle Registration & Motor vehicle fees & SETF \\
\hline 20 & Vehicle Maintenance, Rental etc & Transportation services & SAS4 \\
\hline 21 & Gasoline and Oil & Motor fuel & SETB \\
\hline 22 & Auto Insurance & Motor vehicle insurance & SETE \\
\hline 23 & Local Public Transportation & Intracity transportation & SETG03 \\
\hline 24 & Reading & Recreational reading materials & SERG \\
\hline 25 & Entertainment Fees and Admissions & Recreation services & SERF \\
\hline 26 & Other Entertainment Services and Rental & Recreation & SAR \\
\hline 27 & Clothing Services, including watch and jewlry repair & Miscellaneous personal services & SEGD \\
\hline 28 & Business Services & Miscellaneous personal services & SEGD \\
\hline 29 & Lotteries and Pari-mutuel Losses & Miscellaneous personal services & SEGD \\
\hline 30 & Life and other Personal Insurance & All items & SA0 \\
\hline 31 & Prescription Drugs (Net Outlay) & All items & SA0 \\
\hline 32 & Medical Supplies (Net Outlay) & Medical care commodities & SAM1 \\
\hline 33 & Medical Services (Net Outlay) & Medical care services & SAM2 \\
\hline 34 & Health Insurance & Medical care & SAM \\
\hline 35 & College Tuition and Fees & College tuition and fees & SEEB01 \\
\hline 36 & Nursery, Elementary, and Other School Tuition and Fees & Tuition, other school fees, and childcare & SEEB \\
\hline 37 & Educational books and supplies & Educational books and supplies & SEEA \\
\hline
\end{tabular}


Table 11: Memorable Goods

\begin{tabular}{|c|c|c|c|}
\hline Number & Categories & CPI used to deflate & $\mathrm{CPI}$ \\
\hline 1 & Food Away from Home Excl. on Trips & Food away from home & SEFV \\
\hline 2 & Food for Catered Affairs & Food away from home & SEFV \\
\hline 3 & Food on Trips/Vacations & Food away from home & SEFV \\
\hline 4 & Alcohol Out Excl. on Trips/Vacations & Alcoholic beverages away from home & SEFX \\
\hline 5 & Alcohol on Trips & Alcoholic beverages away from home & SEFX \\
\hline 6 & Lodging on Trips/Vacations & Lodging away from home & SEHB \\
\hline 7 & Entertainment Fees and Admissions on Trips/Vacations & Recreation services & SERF \\
\hline 8 & Other Entertainment Services and Rental on Trips & Recreation & SAR \\
\hline 9 & Vehicle Maintenance, Rental etc on Trips/Vacations & Transportation services & SAS4 \\
\hline 10 & Gasoline and Oil on Trips/Vacations & Motor fuel & SETB \\
\hline 11 & Public Transportation on Trips/Vacations Excl. Airline & Other intercity transportation & SETG02 \\
\hline 12 & Airline Fares & Airline fare & SETG01 \\
\hline 13 & Photographic Services and Rental & Photographers and film processing & SERD02 \\
\hline 14 & Religious and Welfare Activities & All items & SA0 \\
\hline 15 & Clothing and Shoes & Apparel & SAA \\
\hline 16 & Jewelry and Watches & Jewelry and watches & SEAG ${ }^{a}$ \\
\hline
\end{tabular}

${ }^{a}$ The BLS CPI for Jewelry and watches starts from December 1997. We extend it back to January 1986 using the CPI for Apparel (SAA).

Table 12: Durable Goods

\begin{tabular}{clll}
\hline \hline Number & Categories & CPI used to deflate & CPI \\
\hline 1 & Durable Household Furnishing and Equipment & Household furnishings and operations & SAH3 \\
2 & New and Used Motor Vehicles (Net Outlay $\left.{ }^{a}\right)$ & New and used motor vehicles & SETA $^{b}$ \\
3 & Tires, Tubes, Accessories, and Other parts & Motor vehicle parts and equipment & SETC \\
4 & Recreation and Sports Equipment & Recreation & SAR \\
\hline \hline
\end{tabular}

${ }^{a}$ This is based on the EXPN variable QTRADEX in the OVB file which is the "Amount paid for vehicle after trade-in allowance minus amount of cost paid by employer". It includes loans taken out. It represents the total final cost to the consumer of buying the car not just the down payment they make when purchasing the vehicle. In this case, it essentially means the total amount committed to new and used motor vehicles by the consumer not just the immediate out of pocket expenditure.

${ }^{b}$ The BLS CPI for New and used motor vehicles starts from January 1993. We extend it back to January 1986 using the CPI for New Vehicles (SETA01). 
Table 13: Average Monthly Income and Consumption Expenditures - Sample

\begin{tabular}{ccccccc}
\hline \hline & Disp Income & Total Outlays & ND+Memorables & ND & Memorables & Durables \\
\hline mean & 1972.32 & 1484.61 & 1193.87 & 965.68 & 228.19 & 290.74 \\
\hline \hline
\end{tabular}

Note: Averages are weighted using average CU replicate weights. Average CU weight is derived by summing the weight of each CU (FINLWT21) across four quarters and then dividing by 4 .

All consumption expenditures are deflated by their corresponding CPIs (please see table 10, table 11, and table 12). Income categories are deflated by monthly CPI for all urban consumers and all items. All the deflators are not seasonally adjusted and they are based on 1982-1984.

Disposable Income = Income before Tax - Income Taxes - Pension and Social Security Deductions.

Table 14: Average Demographic Characteristics - Sample

\begin{tabular}{ccccccc}
\hline \hline & Age of Head & Male Head & White Head & Married & High School Above & Family Size \\
\hline mean & 41.14 & 0.65 & 0.84 & 0.59 & 0.85 & 2.87 \\
\hline \hline
\end{tabular}

Note: Averages are weighted using average CU replicate weights. Average CU weight is derived by summing the weight of each CU (FINLWT21) across four quarters and then dividing by 4 . 
Table 15: Underlying Frequencies of CEX Expenditure Categories

\begin{tabular}{|c|c|c|c|c|c|}
\hline & Nondurable Goods & & & Memorable Goods & \\
\hline Number & Categories & Frequency & Number & Categories & Frequency \\
\hline 1 & Food At Home & Quarterly & 1 & Food Away from Home Excl. on Trips & Quarterly \\
\hline 2 & Food at School & Monthly & 2 & Food for Catered Affairs & Monthly \\
\hline 3 & Meals Received as Pay & Quarterly & 3 & Food on Trips/Vacations & Monthly \\
\hline 4 & Tobacco Products & Quarterly & 4 & Alcohol Out Excl. on Trips/Vacations & Quarterly \\
\hline 5 & Alcohol Home & Quarterly & 5 & Alcohol on Trips & Monthly \\
\hline 6 & Personal Care Services & Quarterly & 6 & Lodging on Trips/Vacations & Monthly \\
\hline 7 & Maintenance, Insurance etc - Owned Housing & Monthly & 7 & Entertainment Fees and Admissions on Trips/Vacations & Monthly \\
\hline 8 & Tenant-Occupied Nonfarm Dwelling - Rent & Monthly & 8 & Other Entertainment Services and Rental on Trips & Monthly \\
\hline 9 & Rental Equivalence of Owned Home & Annually & 9 & Vehicle Maintenance, Rental etc on Trips/Vacations & Monthly \\
\hline 10 & Rent Received as Pay & Quarterly & 10 & Gasoline and Oil on Trips/Vacations & Monthly \\
\hline 11 & Lodging at School & Monthly & 11 & Public Transportation on Trips/Vacations Excl. Airline & Monthly \\
\hline 12 & Electricity & Monthly & 12 & Airline Fares & Monthly \\
\hline 13 & Gas & Monthly & 13 & Photographic Services and Rental & Monthly \\
\hline 14 & Water and other sanitary services & Monthly & 14 & Religious and Welfare Activities & Monthly \\
\hline 15 & Fuel Oil and Coal & Monthly & 15 & Clothing and Shoes & Monthly \\
\hline 16 & Telephone Service & Monthly & 16 & Jewelry and Watches & Monthly \\
\hline 17 & Domestic Service & Monthly & & & \\
\hline 18 & Other Household Operation & Monthly & & & \\
\hline 19 & Vehicle Registration & Monthly & & Durable Goods & \\
\hline 20 & Vehicle Maintenance, Rental etc & Monthly & Number & Categories & Informative Frequency \\
\hline 21 & Gasoline and Oil & Monthly & 1 & Durable Household Furnishing and Equipment & Monthly \\
\hline 22 & Auto Insurance & Monthly & 2 & New and Used Motor Vehicles (Net Outlay) & Monthly \\
\hline 23 & Local Public Transportation & Monthly & 3 & Tires, Tubes, Accessories, and Other parts & Monthly \\
\hline 24 & Reading & Monthly & 4 & Recreation and Sports Equipment & Monthly \\
\hline 25 & Entertainment Fees and Admissions & Monthly & & & \\
\hline 26 & Other Entertainment Services and Rental & Monthly & & & \\
\hline 27 & Clothing Services, including watch and jewlry repair & Monthly & & & \\
\hline 28 & Business Services & Monthly & & & \\
\hline 29 & Lotteries and Pari-mutuel Losses & Monthly & & & \\
\hline 30 & Life and other Personal Insurance & Monthly & & & \\
\hline 31 & Prescription Drugs (Net Outlay) & Monthly & & & \\
\hline 32 & Medical Supplies (Net Outlay) & Monthly & & & \\
\hline 33 & Medical Services (Net Outlay) & Monthly & & & \\
\hline 34 & Health Insurance & Monthly & & & \\
\hline 35 & College Tuition and Fees & Monthly & & & \\
\hline 36 & Nursery, Elementary, and Other School Tuition and Fees & Monthly & & & \\
\hline 37 & Educational books and supplies & Monthly & & & \\
\hline
\end{tabular}


Table 16: Consumption Expenditure Statistics (Monthly Frequency)

\begin{tabular}{lccccc}
\hline \hline & Ave Share & Ave Vol & Inactive Ratio & Freq Spikes & Size Spikes \\
\hline Full Sample & & & & & \\
Outlays & 1.0000 & 0.5251 & 0.0000 & 0.0853 & 2.4704 \\
ND & 0.7794 & 0.2786 & 0.0000 & 0.0471 & 1.3350 \\
Memorables & 0.1419 & 1.0107 & 0.0048 & 0.1930 & 0.3660 \\
$\quad$ Durables & 0.0787 & 2.0475 & 0.0389 & 0.1687 & 0.7392 \\
Cash at Hand $\leq 20$ pct & & & & & \\
Outlays & 1.0000 & 0.4085 & 0.0000 & 0.0694 & 2.2619 \\
ND & 0.8617 & 0.2612 & 0.0000 & 0.0436 & 1.5073 \\
Memorables & 0.0923 & 1.2033 & 0.0170 & 0.1988 & 0.2625 \\
Durables & 0.0460 & 2.0534 & 0.1199 & 0.1474 & 0.5137 \\
Cash at Hand $\geq 80$ pct & & & & & \\
Outlays & 1.0000 & 0.6079 & 0.0000 & 0.1041 & 2.4976 \\
ND & 0.7083 & 0.3197 & 0.0000 & 0.0601 & 1.2411 \\
Memorables & 0.1882 & 0.9360 & 0.0012 & 0.1890 & 0.4814 \\
Durables & 0.1035 & 2.0025 & 0.0063 & 0.1766 & 0.8740 \\
\hline \hline
\end{tabular}

Note: Cash at hand is the sum of total amount in checking and savings and disposable income. The percentiles of cash at hand are calculated for each reference year. We say that an expenditure is a spike if the expenditure exceeds the household-level average. Average inactivity records the fraction of households who did not incur any expenditure during the 12-month reference period. The average frequency of consumption spikes is the average number of consumption expenditure spikes divided by 12 . The relative size of consumption spikes is the consumption expenditure spikes normalized by householdlevel 12-month average outlays. 
Table 17: Consumption Expenditure Statistics (Quarterly Frequency)

\begin{tabular}{lccccc}
\hline \hline & Ave Share & Ave Vol & Inactive Ratio & Freq Spikes & Size Spikes \\
\hline Full Sample & & & & & \\
$\quad$ Outlays & 1.0000 & 0.3211 & 0.0000 & 0.0688 & 1.9248 \\
ND & 0.7463 & 0.1946 & 0.0000 & 0.0188 & 1.2408 \\
Memorables & 0.1447 & 0.6202 & 0.0048 & 0.1735 & 0.2682 \\
$\quad$ Durables & 0.1090 & 1.1838 & 0.0389 & 0.2508 & 0.4482 \\
Cash at Hand $\leq 20$ pct & & & & & \\
Outlays & 1.0000 & 0.2788 & 0.0000 & 0.0503 & 1.8774 \\
ND & 0.8406 & 0.2072 & 0.0000 & 0.0229 & 1.3993 \\
Memorables & 0.0959 & 0.7723 & 0.0170 & 0.2010 & 0.1853 \\
Durables & 0.0634 & 1.2037 & 0.1199 & 0.2367 & 0.2891 \\
Cash at Hand $\geq 80$ pct & & & & & \\
Outlays & 1.0000 & 0.3566 & 0.0000 & 0.0866 & 1.8957 \\
ND & 0.6671 & 0.2062 & 0.0000 & 0.0227 & 1.1106 \\
Memorables & 0.1913 & 0.5523 & 0.0012 & 0.1567 & 0.3671 \\
Durables & 0.1415 & 1.1499 & 0.0063 & 0.2555 & 0.5433 \\
\hline \hline
\end{tabular}

Note: Cash at hand is the sum of total amount in checking and savings and disposable income. The percentiles of cash at hand are calculated for each reference year. We say that an expenditure is a spike if the expenditure exceeds the household-level average. Average inactivity records the fraction of households who did not incur any expenditure during the entire reference period. The average frequency of consumption spikes is the average number of consumption expenditure spikes divided by 4 quarters. The relative size of consumption spikes is the consumption expenditure spikes normalized by household-level average outlays during the reference period. 
Table 18: Consumption Volatility Measure: Detailed Consumption Categories (Monthly Frequency)

\begin{tabular}{|c|c|c|c|}
\hline Variable Names & Ave Share & Inactive Ratio & Ave Vol \\
\hline Rent Received as Pay & 0.0015 & 0.9791 & 0.0302 \\
\hline Lotteries and Pari-mutuel Losses & 0.0002 & 0.9595 & 0.0705 \\
\hline Lodging at School & 0.0008 & 0.9698 & 0.0774 \\
\hline Rental Equivalence of Owned Home & 0.0208 & 0.3850 & 0.0886 \\
\hline Meals Received as Pay & 0.0018 & 0.9263 & 0.1064 \\
\hline Tenant-Occupied Nonfarm Dwelling - Rent & 0.1033 & 0.5955 & 0.1267 \\
\hline Food for Catered Affairs & 0.0008 & 0.9381 & 0.2041 \\
\hline Nursery, Elementary, and Other School Tuition and Fees & 0.0023 & 0.9041 & 0.2370 \\
\hline Food At Home & 0.1801 & 0.0003 & 0.2674 \\
\hline Tobacco Products & 0.0126 & 0.5326 & 0.2787 \\
\hline Local Public Transportation & 0.0041 & 0.7480 & 0.2943 \\
\hline Health Insurance & 0.0198 & 0.3856 & 0.3376 \\
\hline Food at School & 0.0037 & 0.7139 & 0.3376 \\
\hline Gasoline and Oil & 0.0739 & 0.0625 & 0.3489 \\
\hline Electricity & 0.0505 & 0.0498 & 0.4207 \\
\hline College Tuition and Fees & 0.0040 & 0.8449 & 0.4261 \\
\hline Telephone Service & 0.0419 & 0.0134 & 0.4279 \\
\hline Other Entertainment Services and Rental on Trips & 0.0007 & 0.8587 & 0.4369 \\
\hline Fuel Oil and Coal & 0.0048 & 0.8020 & 0.4557 \\
\hline Gas & 0.0215 & 0.3810 & 0.4805 \\
\hline Alcohol Out Excl. on Trips/Vacations & 0.0052 & 0.4939 & 0.5248 \\
\hline Alcohol Home & 0.0092 & 0.3831 & 0.5344 \\
\hline Personal Care Services & 0.0123 & 0.0892 & 0.5515 \\
\hline Food Away from Home Excl. on Trips & 0.0421 & 0.0498 & 0.5835 \\
\hline Reading & 0.0075 & 0.1118 & 0.6633 \\
\hline Water and other sanitary services & 0.0162 & 0.3085 & 0.6887 \\
\hline Public Transportation on Trips/Vacations Excl. Airline & 0.0013 & 0.7592 & 0.7407 \\
\hline
\end{tabular}


... table 18 continued

\begin{tabular}{|c|c|c|c|}
\hline Variable Names & Ave Share & Inactive Ratio & Ave Vol \\
\hline Photographic Services and Rental & 0.0025 & 0.3292 & 0.7935 \\
\hline Domestic Service & 0.0176 & 0.4267 & 0.8625 \\
\hline Entertainment Fees and Admissions & 0.0114 & 0.2063 & 0.9013 \\
\hline Clothing Services, including watch and jewlry repair & 0.0057 & 0.2238 & 0.9476 \\
\hline Airline Fares & 0.0046 & 0.6869 & 0.9557 \\
\hline New and Used Motor Vehicles (Net Outlay) & 0.0193 & 0.7033 & 0.9888 \\
\hline Other Entertainment Services and Rental & 0.0268 & 0.0607 & 0.9989 \\
\hline Life and other Personal Insurance & 0.0156 & 0.4046 & 1.0173 \\
\hline Educational books and supplies & 0.0019 & 0.6342 & 1.0340 \\
\hline Religious and Welfare Activities & 0.0069 & 0.4147 & 1.0397 \\
\hline Medical Supplies (Net Outlay) & 0.0018 & 0.6613 & 1.1400 \\
\hline Vehicle Maintenance, Rental etc on Trips/Vacations & 0.0008 & 0.6122 & 1.1536 \\
\hline Alcohol on Trips & 0.0008 & 0.5858 & 1.1766 \\
\hline Maintenance, Insurance etc - Owned Housing & 0.0182 & 0.4059 & 1.2791 \\
\hline Business Services & 0.0132 & 0.1489 & 1.3998 \\
\hline Lodging on Trips/Vacations & 0.0050 & 0.4904 & 1.4687 \\
\hline Clothing and Shoes & 0.0510 & 0.0193 & 1.4897 \\
\hline Entertainment Fees and Admissions on Trips/Vacations & 0.0033 & 0.4742 & 1.5222 \\
\hline Other Household Operation & 0.0055 & 0.2997 & 1.5343 \\
\hline Jewelry and Watches & 0.0040 & 0.4563 & 1.5958 \\
\hline Gasoline and Oil on Trips/Vacations & 0.0052 & 0.3323 & 1.6267 \\
\hline Auto Insurance & 0.0210 & 0.2014 & 1.6668 \\
\hline Recreation and Sports Equipment & 0.0161 & 0.1743 & 1.7737 \\
\hline Vehicle Maintenance, Rental etc & 0.0226 & 0.1161 & 1.7936 \\
\hline Food on Trips/Vacations & 0.0077 & 0.2848 & 1.7999 \\
\hline Tires, Tubes, Accessories, and Other parts & 0.0083 & 0.3611 & 1.8129 \\
\hline Medical Services (Net Outlay) & 0.0146 & 0.1833 & 1.9942 \\
\hline Prescription Drugs (Net Outlay) & 0.0068 & 0.2869 & 2.0296 \\
\hline Durable Household Furnishing and Equipment & 0.0350 & 0.1006 & 2.0424 \\
\hline
\end{tabular}

Continued on next page... 
... table 18 continued

\begin{tabular}{lccc}
\hline \hline Variable Names & Ave Share & Inactive Ratio & Ave Vol \\
\hline Vehicle Registration & 0.0039 & 0.2343 & 2.2238 \\
\hline \hline
\end{tabular}


Table 19: Consumption Volatility Measure: Detailed Consumption Categories (Quarterly Frequency)

\begin{tabular}{|c|c|c|c|}
\hline Variable Names & Ave Share & Inactive Ratio & Ave Vol \\
\hline Rent Received as Pay & 0.0014 & 0.9791 & 0.0334 \\
\hline Lodging at School & 0.0009 & 0.9698 & 0.0474 \\
\hline Lotteries and Pari-mutuel Losses & 0.0002 & 0.9595 & 0.0554 \\
\hline Rental Equivalence of Owned Home & 0.0188 & 0.3850 & 0.0978 \\
\hline Meals Received as Pay & 0.0017 & 0.9263 & 0.1177 \\
\hline Food for Catered Affairs & 0.0011 & 0.9381 & 0.1193 \\
\hline Tenant-Occupied Nonfarm Dwelling - Rent & 0.0982 & 0.5955 & 0.1244 \\
\hline Nursery, Elementary, and Other School Tuition and Fees & 0.0024 & 0.9041 & 0.1444 \\
\hline College Tuition and Fees & 0.0049 & 0.8449 & 0.2410 \\
\hline Other Entertainment Services and Rental on Trips & 0.0008 & 0.8587 & 0.2539 \\
\hline Fuel Oil and Coal & 0.0048 & 0.8020 & 0.2764 \\
\hline Food At Home & 0.1673 & 0.0003 & 0.2956 \\
\hline Electricity & 0.0470 & 0.0498 & 0.3016 \\
\hline Tobacco Products & 0.0117 & 0.5326 & 0.3079 \\
\hline Telephone Service & 0.0390 & 0.0134 & 0.3175 \\
\hline Local Public Transportation & 0.0039 & 0.7480 & 0.3234 \\
\hline Water and other sanitary services & 0.0154 & 0.3085 & 0.3278 \\
\hline Food at School & 0.0037 & 0.7139 & 0.3407 \\
\hline Life and other Personal Insurance & 0.0157 & 0.4046 & 0.3708 \\
\hline Health Insurance & 0.0183 & 0.3856 & 0.3730 \\
\hline Gas & 0.0203 & 0.3810 & 0.3830 \\
\hline Gasoline and Oil & 0.0679 & 0.0625 & 0.3833 \\
\hline Medical Supplies (Net Outlay) & 0.0019 & 0.6613 & 0.4151 \\
\hline Public Transportation on Trips/Vacations Excl. Airline & 0.0017 & 0.7592 & 0.4438 \\
\hline Airline Fares & 0.0057 & 0.6869 & 0.5465 \\
\hline New and Used Motor Vehicles (Net Outlay) & 0.0402 & 0.7033 & 0.5686 \\
\hline Alcohol Out Excl. on Trips/Vacations & 0.0048 & 0.4939 & 0.5802 \\
\hline
\end{tabular}


... table 19 continued

\begin{tabular}{|c|c|c|c|}
\hline Variable Names & Ave Share & Inactive Ratio & Ave Vo \\
\hline Alcohol Home & 0.0084 & 0.3831 & 0.5908 \\
\hline Educational books and supplies & 0.0020 & 0.6342 & 0.5955 \\
\hline Personal Care Services & 0.0113 & 0.0892 & 0.6088 \\
\hline Food Away from Home Excl. on Trips & 0.0385 & 0.0498 & 0.6450 \\
\hline Vehicle Maintenance, Rental etc on Trips/Vacations & 0.0009 & 0.6122 & 0.6658 \\
\hline Domestic Service & 0.0168 & 0.4267 & 0.6769 \\
\hline Alcohol on Trips & 0.0009 & 0.5858 & 0.6776 \\
\hline Other Entertainment Services and Rental & 0.0257 & 0.0607 & 0.6797 \\
\hline Maintenance, Insurance etc - Owned Housing & 0.0198 & 0.4059 & 0.6829 \\
\hline Auto Insurance & 0.0213 & 0.2014 & 0.7205 \\
\hline Reading & 0.0069 & 0.1118 & 0.7325 \\
\hline Clothing and Shoes & 0.0532 & 0.0193 & 0.7977 \\
\hline Clothing Services, including watch and jewlry repair & 0.0053 & 0.2238 & 0.8139 \\
\hline Lodging on Trips/Vacations & 0.0059 & 0.4904 & 0.8413 \\
\hline Photographic Services and Rental & 0.0023 & 0.3292 & 0.8469 \\
\hline Entertainment Fees and Admissions & 0.0106 & 0.2063 & 0.8778 \\
\hline Entertainment Fees and Admissions on Trips/Vacations & 0.0039 & 0.4742 & 0.8905 \\
\hline Jewelry and Watches & 0.0045 & 0.4563 & 0.9139 \\
\hline Gasoline and Oil on Trips/Vacations & 0.0055 & 0.3323 & 0.9417 \\
\hline Other Household Operation & 0.0055 & 0.2997 & 0.9431 \\
\hline Medical Services (Net Outlay) & 0.0201 & 0.1833 & 1.0135 \\
\hline Prescription Drugs (Net Outlay) & 0.0065 & 0.2869 & 1.0211 \\
\hline Food on Trips/Vacations & 0.0086 & 0.2848 & 1.0329 \\
\hline Tires, Tubes, Accessories, and Other parts & 0.0090 & 0.3611 & 1.0350 \\
\hline Vehicle Maintenance, Rental etc & 0.0235 & 0.1161 & 1.0691 \\
\hline Religious and Welfare Activities & 0.0065 & 0.4147 & 1.1035 \\
\hline Recreation and Sports Equipment & 0.0184 & 0.1743 & 1.1305 \\
\hline Durable Household Furnishing and Equipment & 0.0413 & 0.1006 & 1.1723 \\
\hline Business Services & 0.0132 & 0.1489 & 1.1838 \\
\hline
\end{tabular}

Continued on next page... 
... table 19 continued

\begin{tabular}{|c|c|c|c|}
\hline Variable Names & Ave Share & Inactive Ratio & Ave Vol \\
\hline Vehicle Registration & 0.0039 & 0.2343 & 1.2653 \\
\hline
\end{tabular}

Table 20: Welfare Cost of Consumption Fluctuations without Distinguishing between Nondurables and Memorables

\begin{tabular}{|c|c|c|c|c|c|c|c|c|c|c|}
\hline & 1 & 2 & 3 & 4 & 5 & 6 & 7 & 8 & 9 & 10 \\
\hline in (ND+Memorables) $(\%)$ & 3.95 & 7.90 & 11.85 & 15.80 & 19.74 & 23.69 & 27.64 & 31.59 & 35.54 & 39.49 \\
\hline in Outlays (\%) & 3.64 & 7.28 & 10.91 & 14.55 & 18.19 & 21.83 & 25.47 & 29.11 & 32.74 & 36.38 \\
\hline
\end{tabular}

Table 21: Welfare Cost of Nondurables Consumption Fluctuations

\begin{tabular}{|c|c|c|c|c|c|c|c|c|c|c|}
\hline & 1 & 2 & 3 & 4 & 5 & 6 & 7 & 8 & 9 & 10 \\
\hline in ND (\%) & 3.19 & 6.38 & 9.57 & 12.76 & 15.95 & 19.14 & 22.33 & 25.52 & 28.71 & 31.90 \\
\hline in (ND+Memorables) $(\%)$ & 2.69 & 5.38 & 8.08 & 10.77 & 13.46 & 16.15 & 18.85 & 21.54 & 24.23 & 26.92 \\
\hline in Outlays (\%) & 2.49 & 4.97 & 7.46 & 9.94 & 12.43 & 14.92 & 17.40 & 19.89 & 22.37 & 24.86 \\
\hline
\end{tabular}

Table 22: Welfare Cost of Nondurables Plus Consumption Fluctuations

\begin{tabular}{|c|c|c|c|c|c|c|c|c|c|c|}
\hline & 1 & 2 & 3 & 4 & 5 & 6 & 7 & 8 & 9 & 10 \\
\hline in ND Plus (\%) & 3.62 & 7.24 & 10.86 & 14.49 & 18.11 & 21.73 & 25.35 & 28.97 & 32.59 & 36.21 \\
\hline in (ND Plus+MGminus) (\%) & 3.28 & 6.56 & 9.83 & 13.11 & 16.39 & 19.67 & 22.94 & 26.22 & 29.50 & 32.78 \\
\hline in Outlays (\%) & 3.02 & 6.04 & 9.07 & 12.09 & 15.11 & 18.13 & 21.15 & 24.17 & 27.20 & 30.22 \\
\hline
\end{tabular}


Figure 6: Changes in State Variables (Scenario I: Zero Shock)

$$
S_{1}=\bar{S}, M_{1}=\bar{M}, N_{1}=\bar{N}
$$
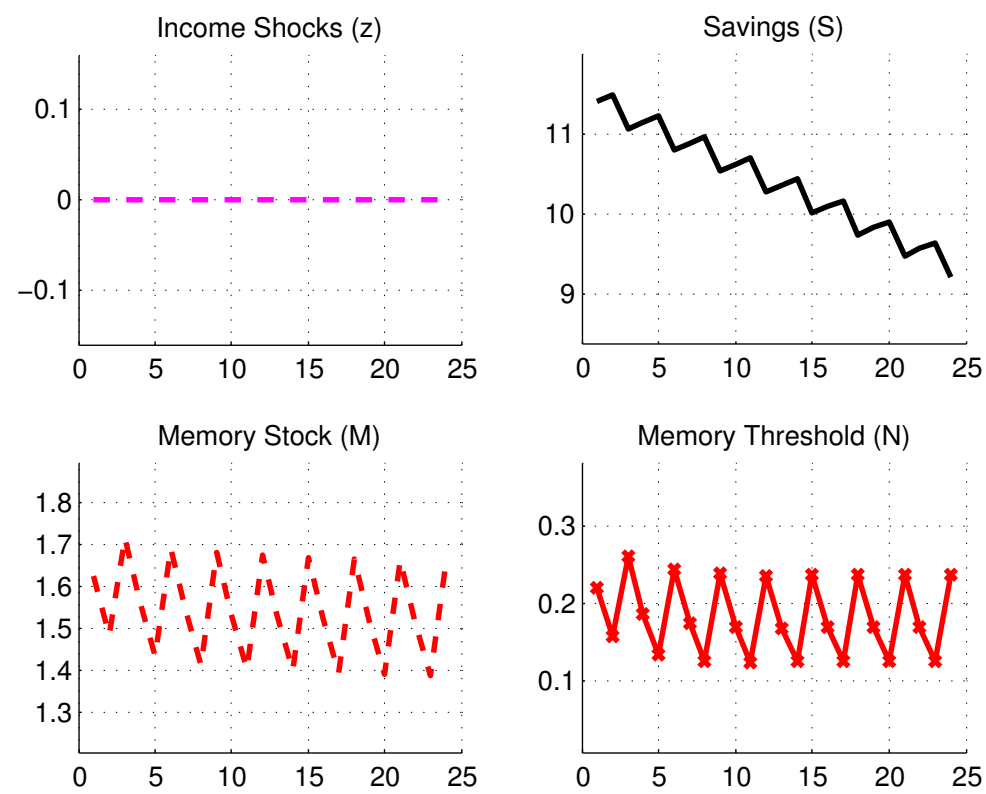

Figure 7: Changes in State Variables (Scenario I: Zero Shock)

$$
S_{1}=0, M_{1}=0, N_{1}=0
$$
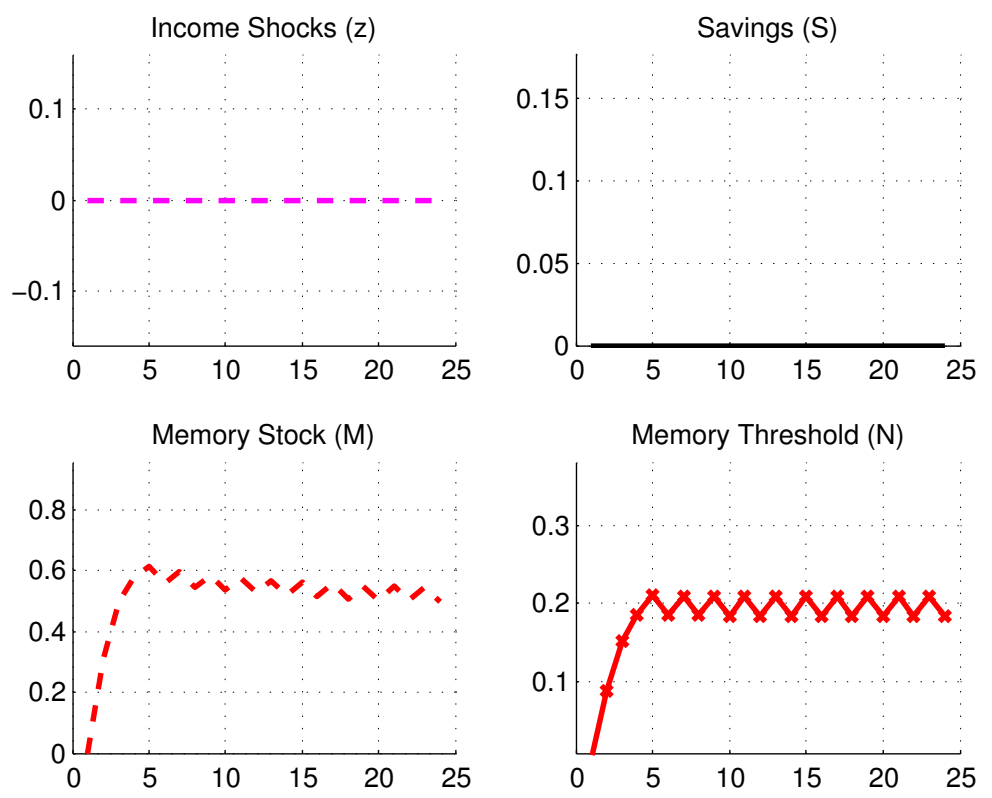
Figure 8: Changes in State Variables (Scenario II: Negative Shock)

$$
S_{1}=\bar{S}, M_{1}=\bar{M}, N_{1}=\bar{N}
$$
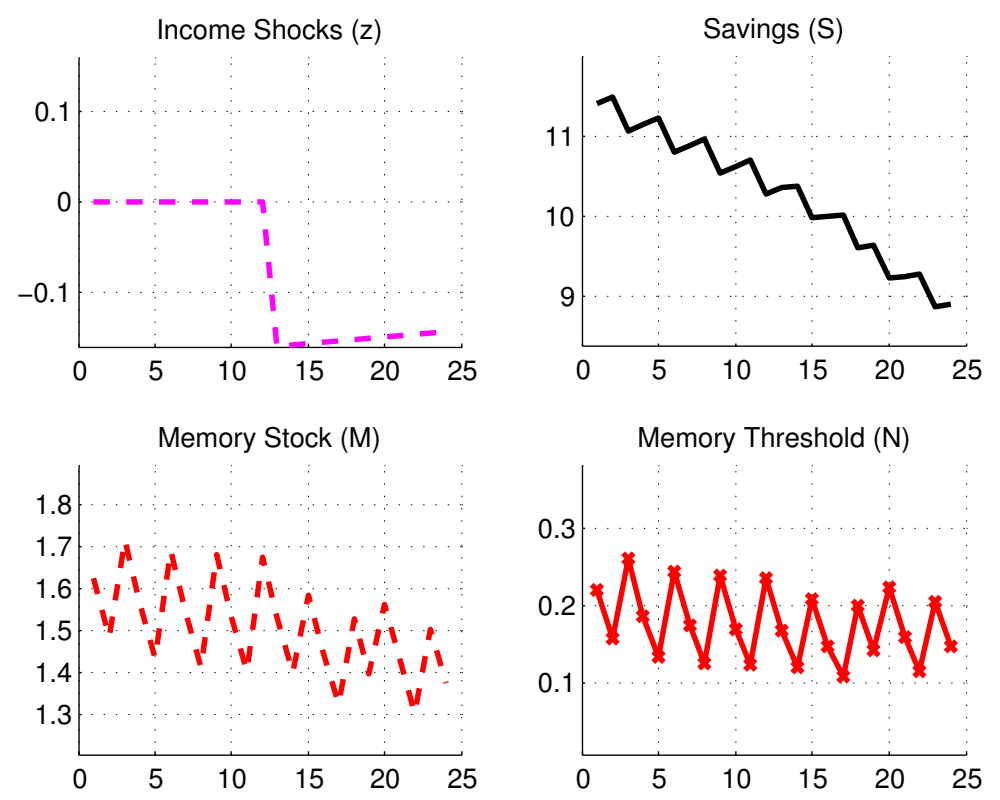

Figure 9: Changes in State Variables (Scenario II: Negative Shock)

$$
S_{1}=0, M_{1}=0, N_{1}=0
$$
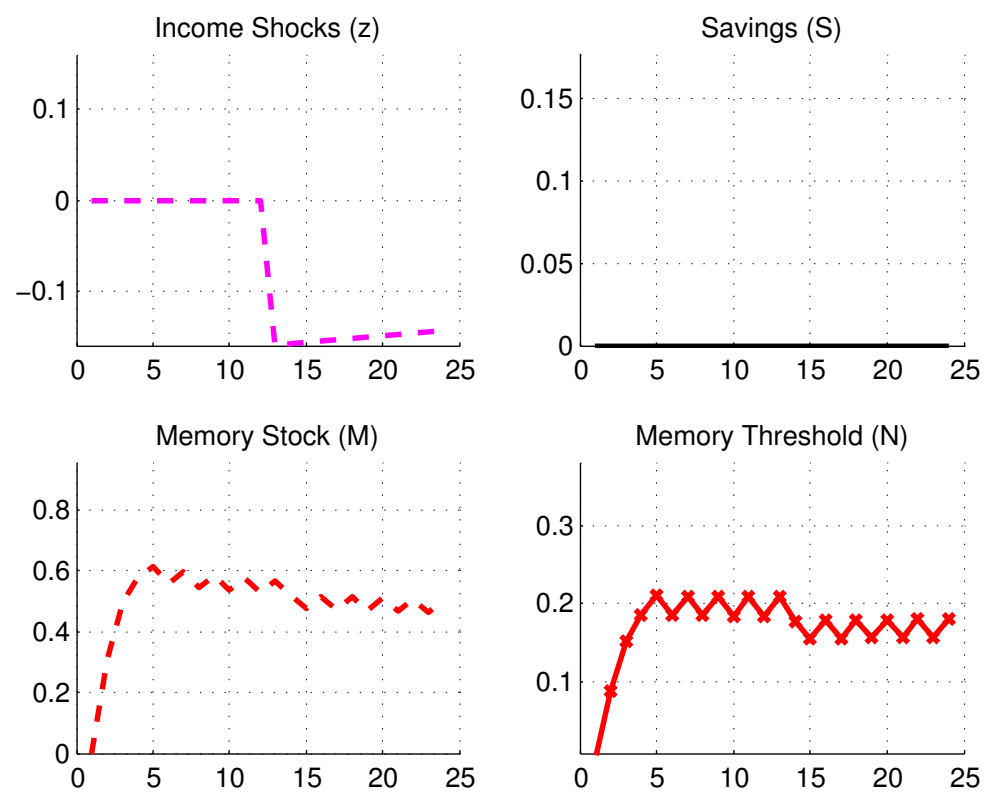
Figure 10: Changes in State Variables (Scenario III: Positive Shock)

$$
S_{1}=\bar{S}, M_{1}=\bar{M}, N_{1}=\bar{N}
$$
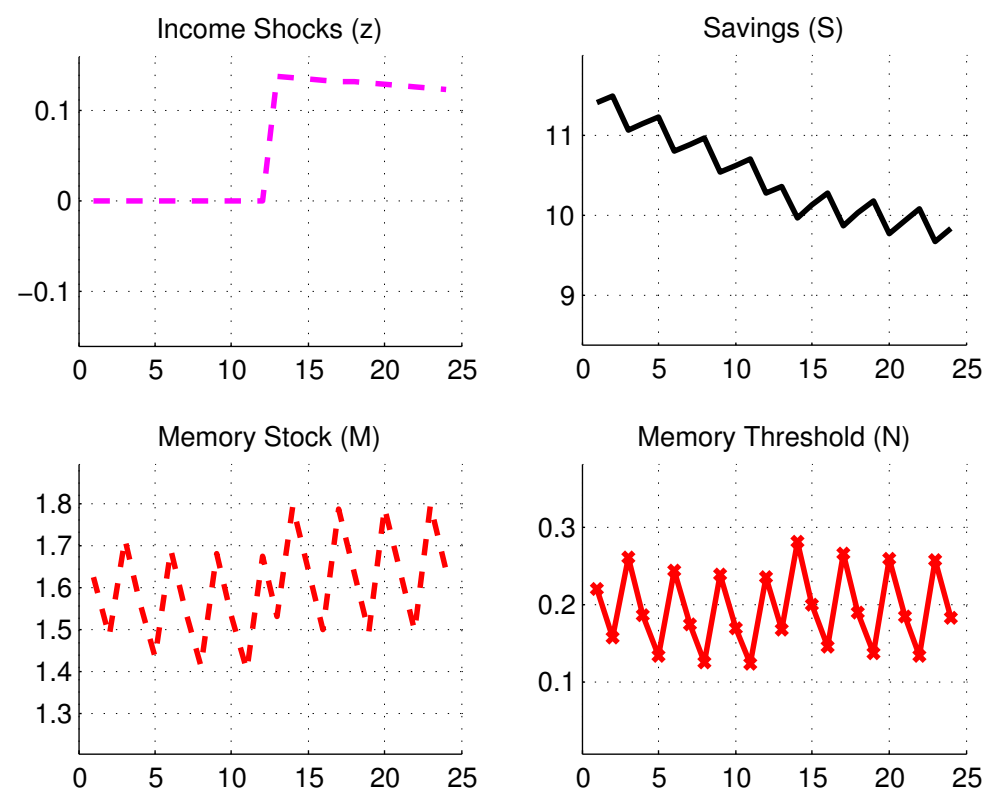

Figure 11: Changes in State Variables (Scenario III: Positive Shock)

$$
S_{1}=0, M_{1}=0, N_{1}=0
$$
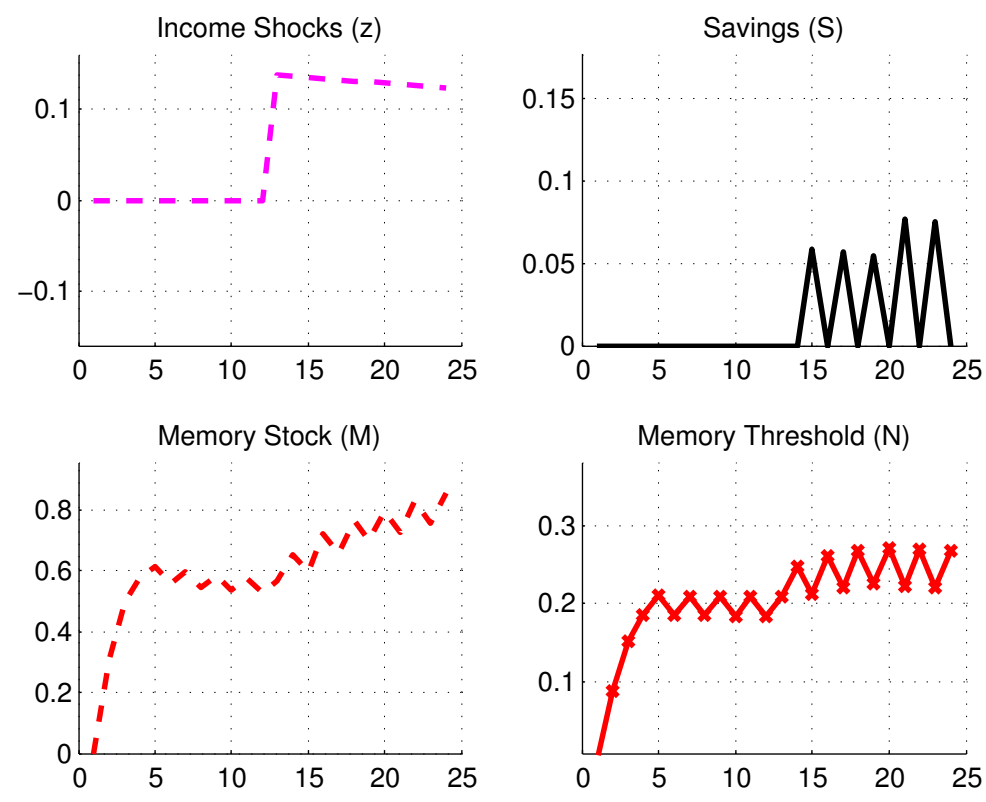
Figure 12: Changes in Consumption and Savings $(\alpha=1)$
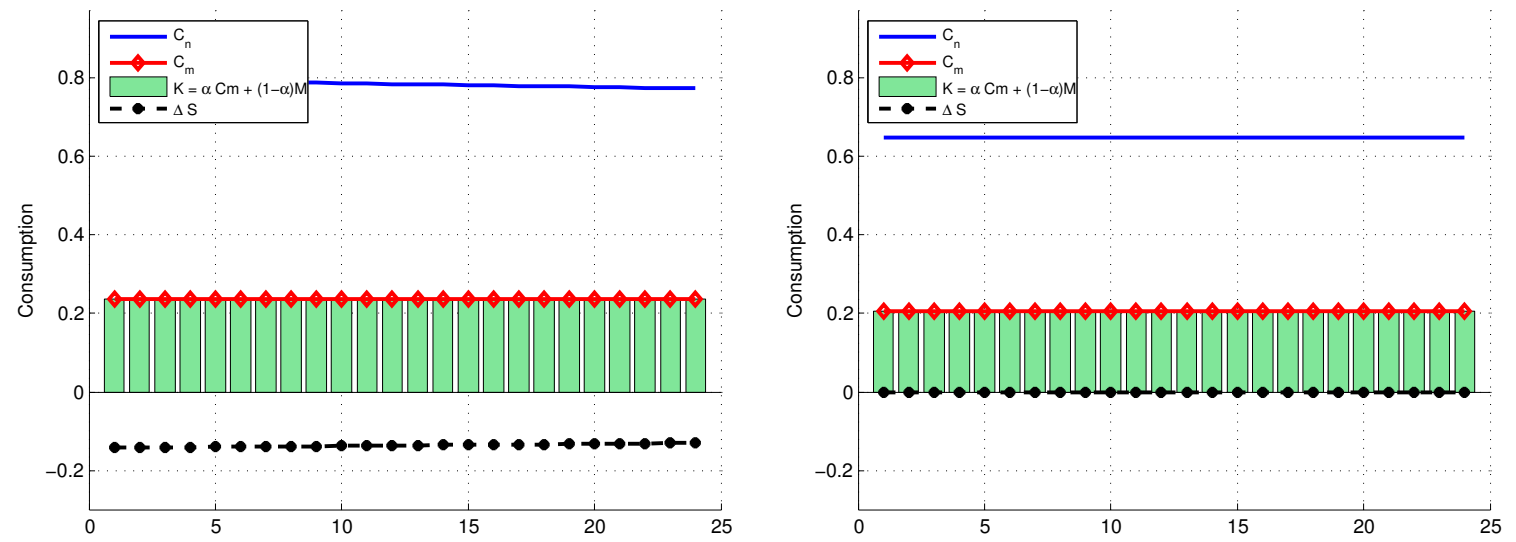

(a) Scenario I (Zero Shock): $S_{1}=\bar{S}, M_{1}=\bar{M}, N_{1}=\bar{N}$

(b) Scenario I (Zero Shock): $S_{1}=0, M_{1}=0, N_{1}=0$
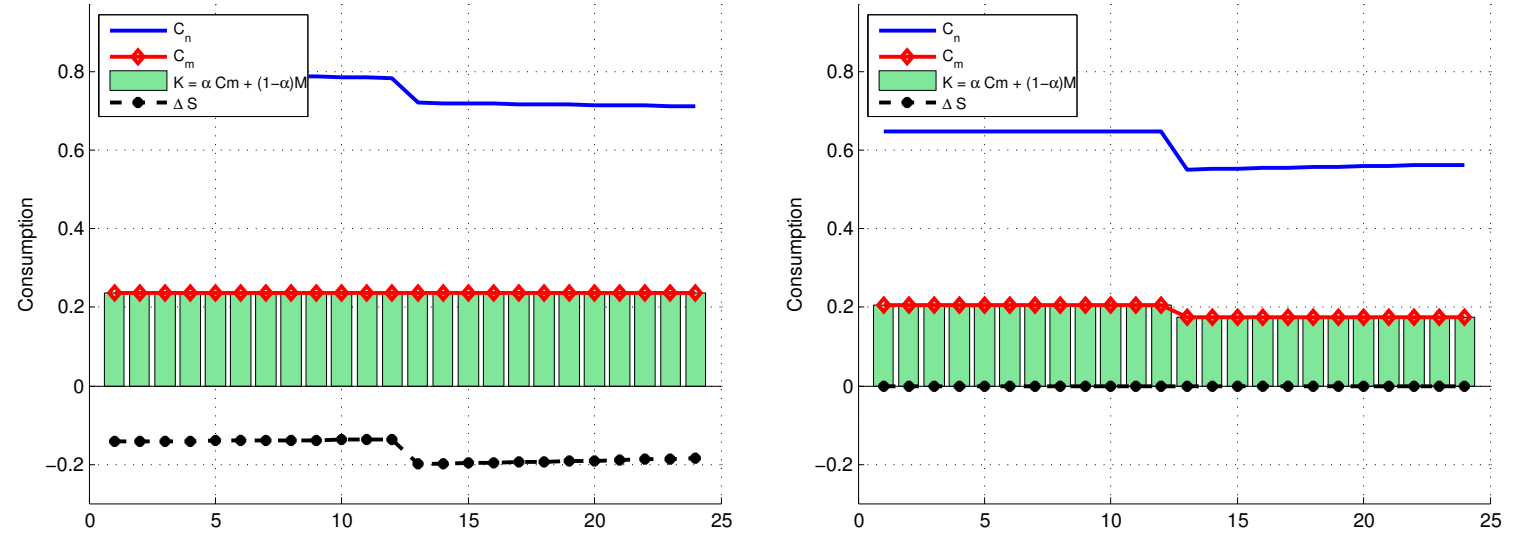

(c) Scenario II (Neg. Shock): $S_{1}=\bar{S}, M_{1}=\bar{M}, N_{1}=$ (d) Scenario II (Neg. Shock): $S_{1}=0, M_{1}=0, N_{1}=0$ $\bar{N}$
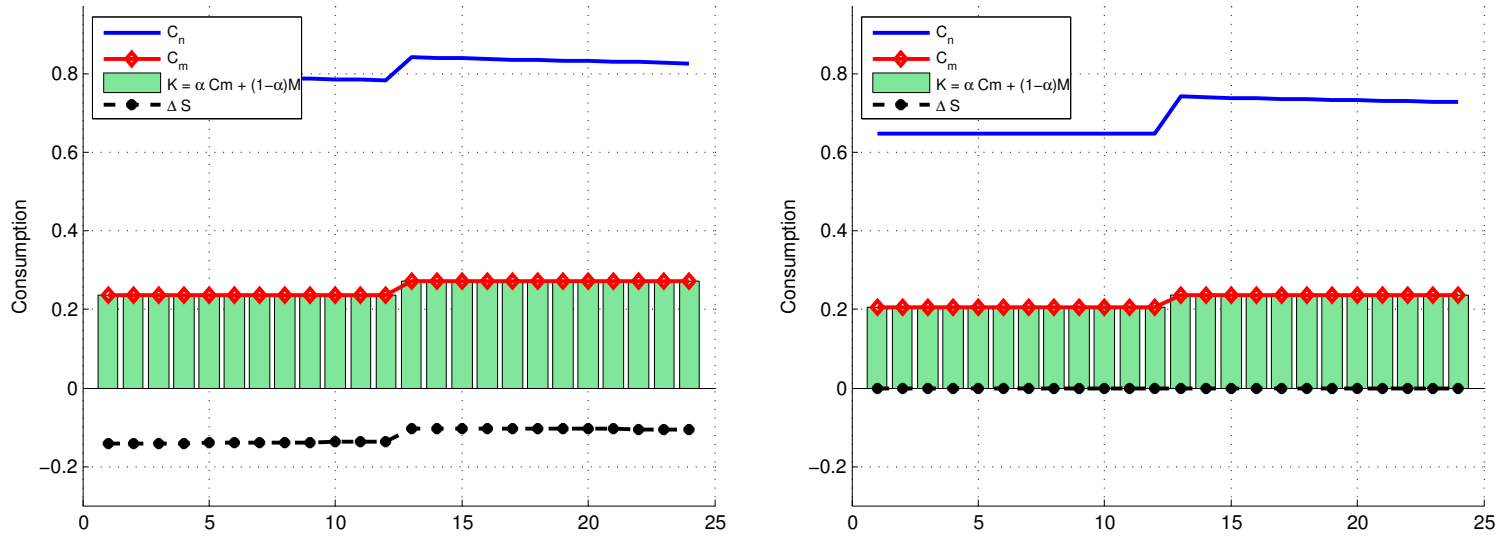

(e) Scenario III (Pos. Shock): $S_{1}=\bar{S}, M_{1}=\bar{M}, N_{1}=$ (f) Scenario III (Pos. Shock): $S_{1}=0, M_{1}=0, N_{1}=0$ $\bar{N}$ 
Figure 13: Changes in State Variables, $\alpha=1$ (Scenario I: Zero Shock)

$$
S_{1}=\bar{S}, M_{1}=\bar{M}, N_{1}=\bar{N}
$$
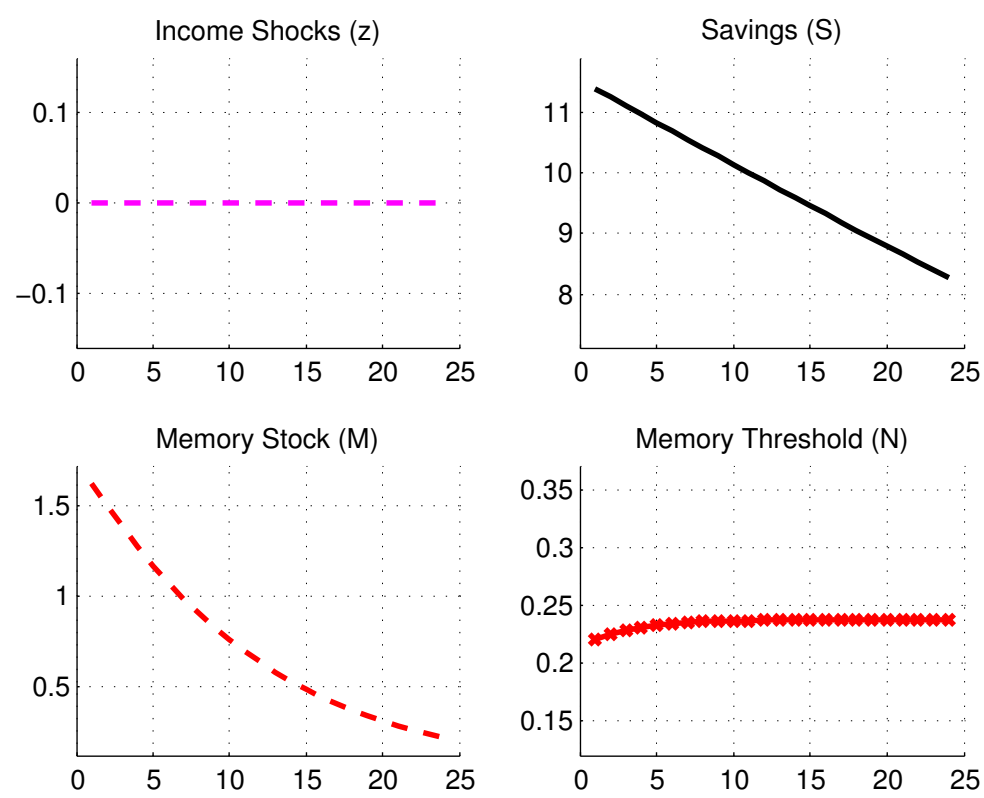

Figure 14: Changes in State Variables, $\alpha=1$ (Scenario I: Zero Shock)

$$
S_{1}=0, M_{1}=0, N_{1}=0
$$
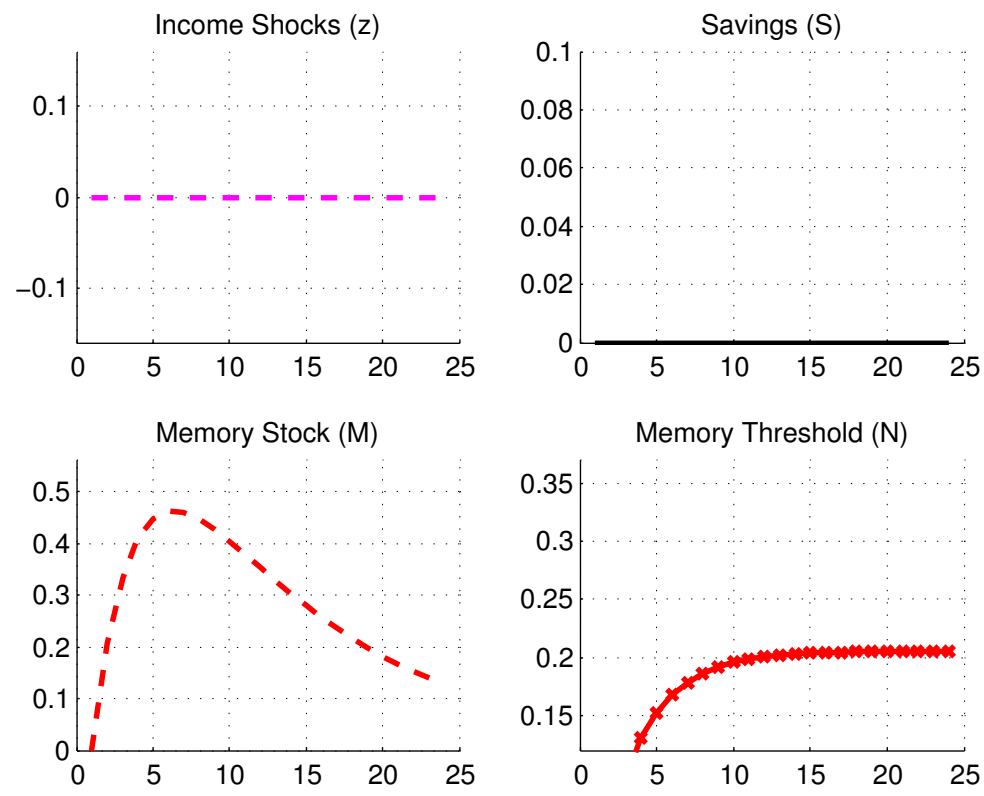
Figure 15: Changes in State Variables, $\alpha=1$ (Scenario II: Negative Shock) $S_{1}=\bar{S}, M_{1}=\bar{M}, N_{1}=\bar{N}$
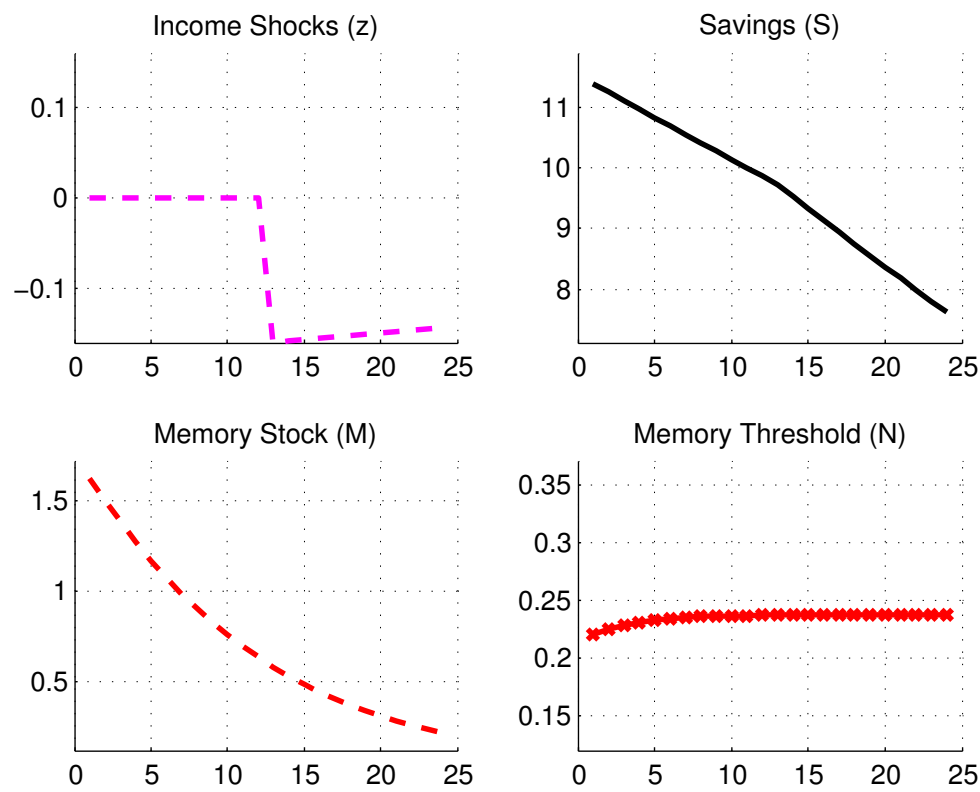

Figure 16: Changes in State Variables, $\alpha=1$ (Scenario II: Negative Shock) $S_{1}=0, M_{1}=0, N_{1}=0$
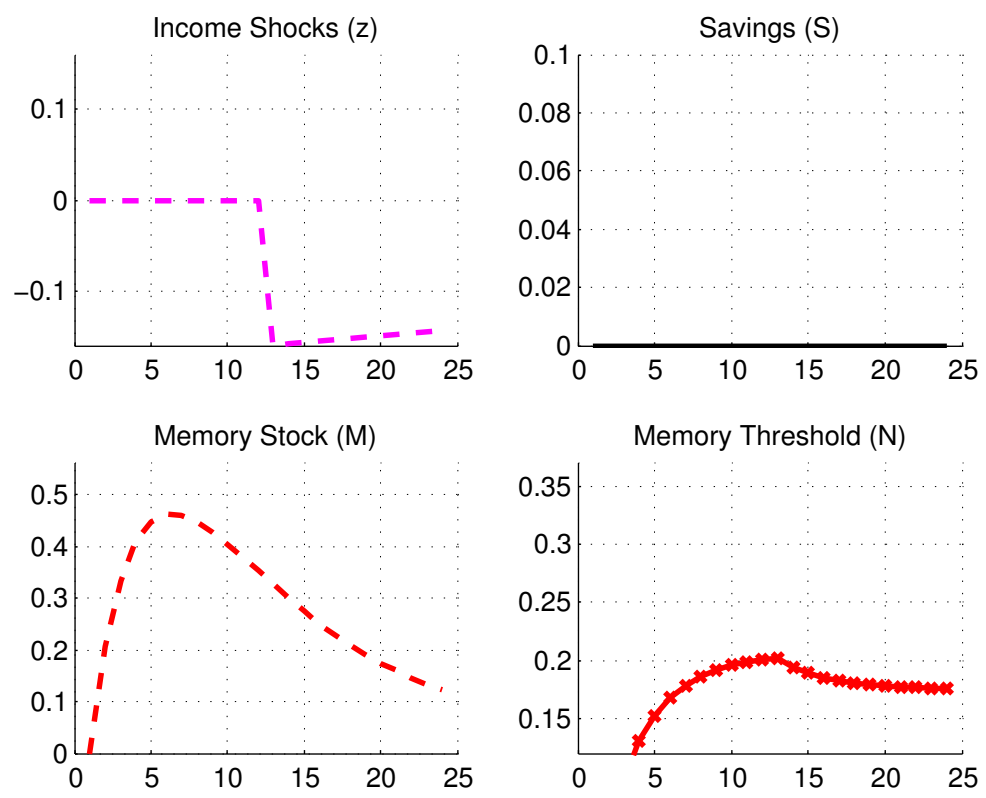
Figure 17: Changes in State Variables, $\alpha=1$ (Scenario III: Positive Shock) $S_{1}=\bar{S}, M_{1}=\bar{M}, N_{1}=\bar{N}$
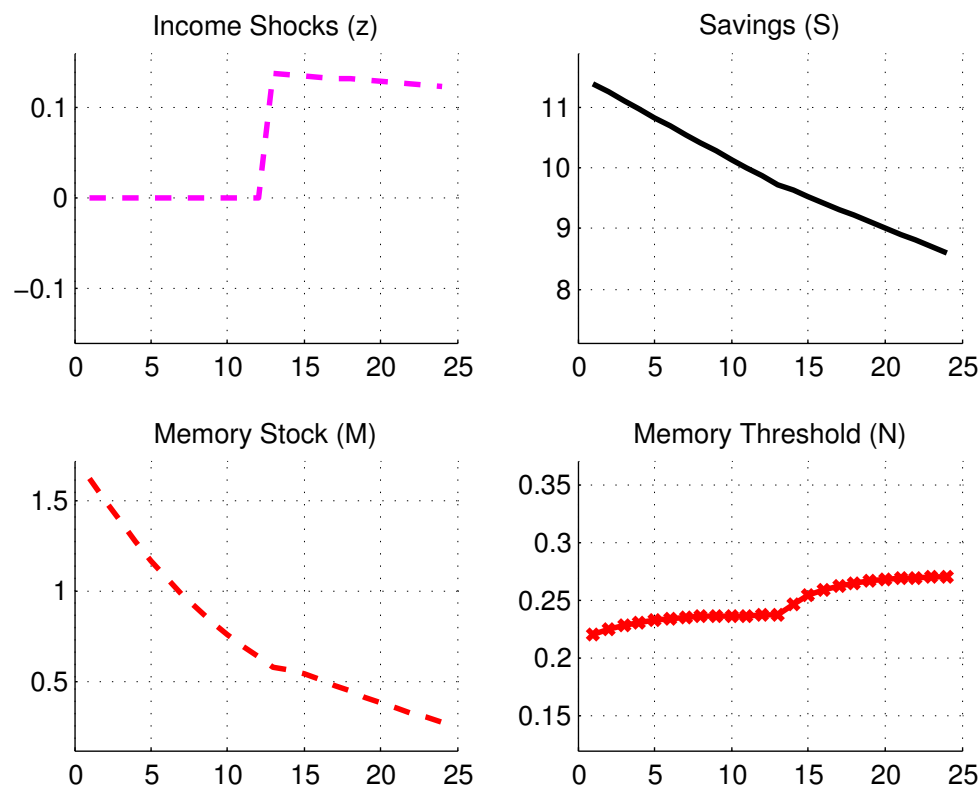

Figure 18: Changes in State Variables, $\alpha=1$ (Scenario III: Positive Shock) $S_{1}=0, M_{1}=0, N_{1}=0$
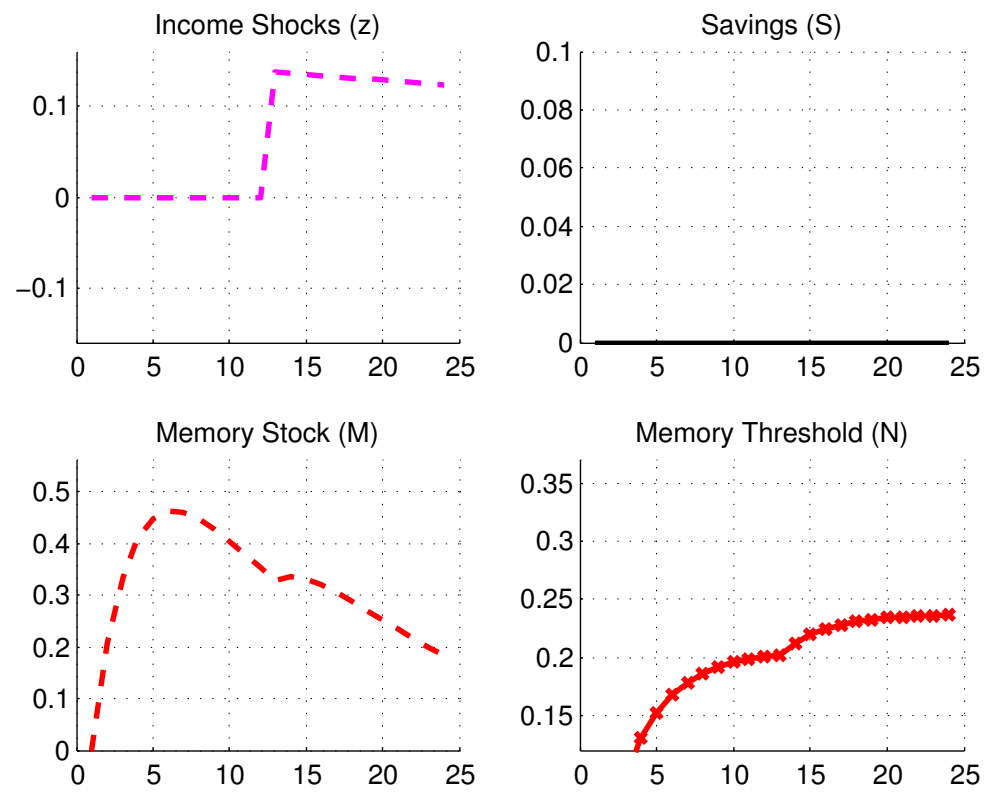
Figure 19: Number of Inactive Months
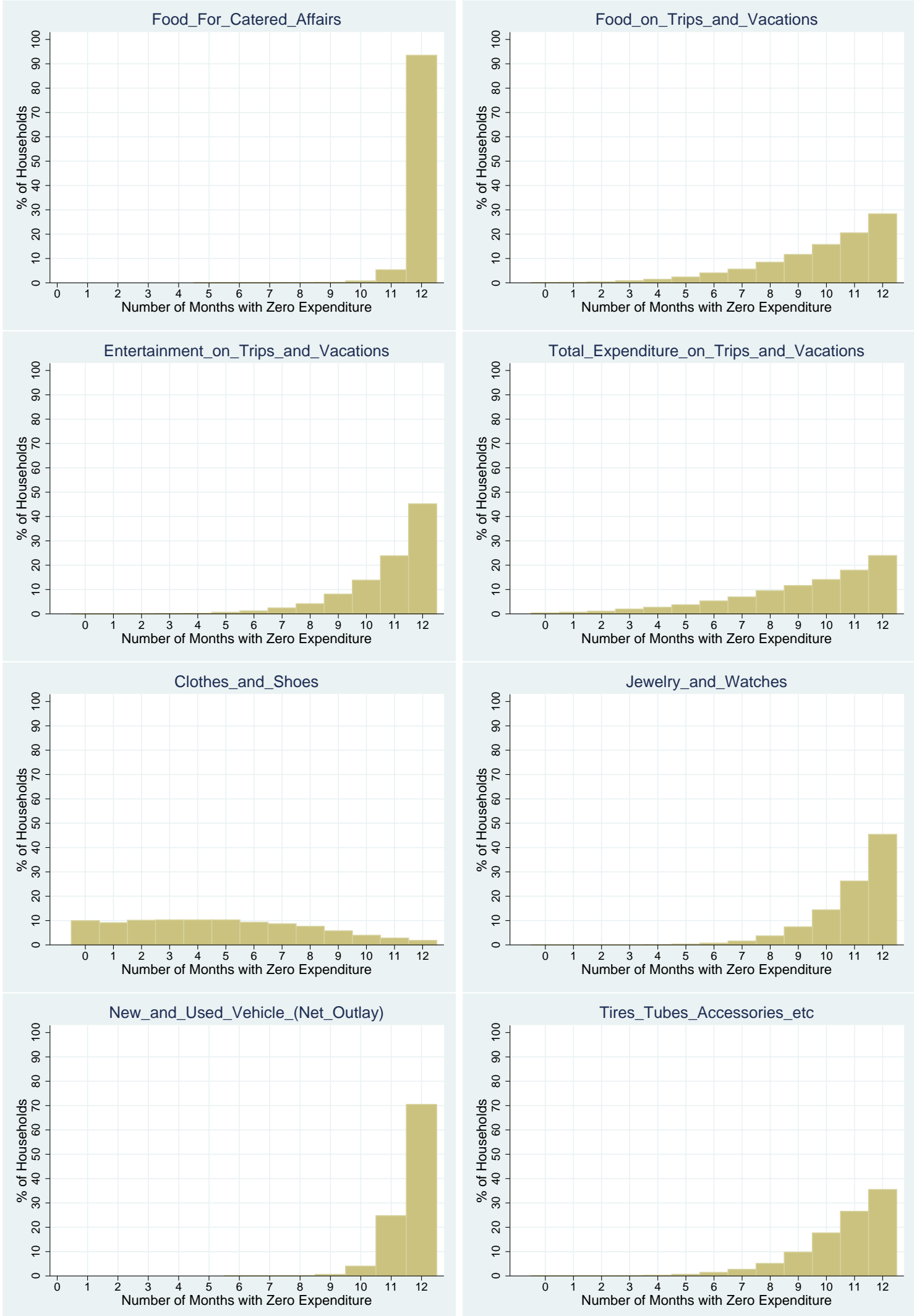
Figure 20: Number of Expenditure Spikes
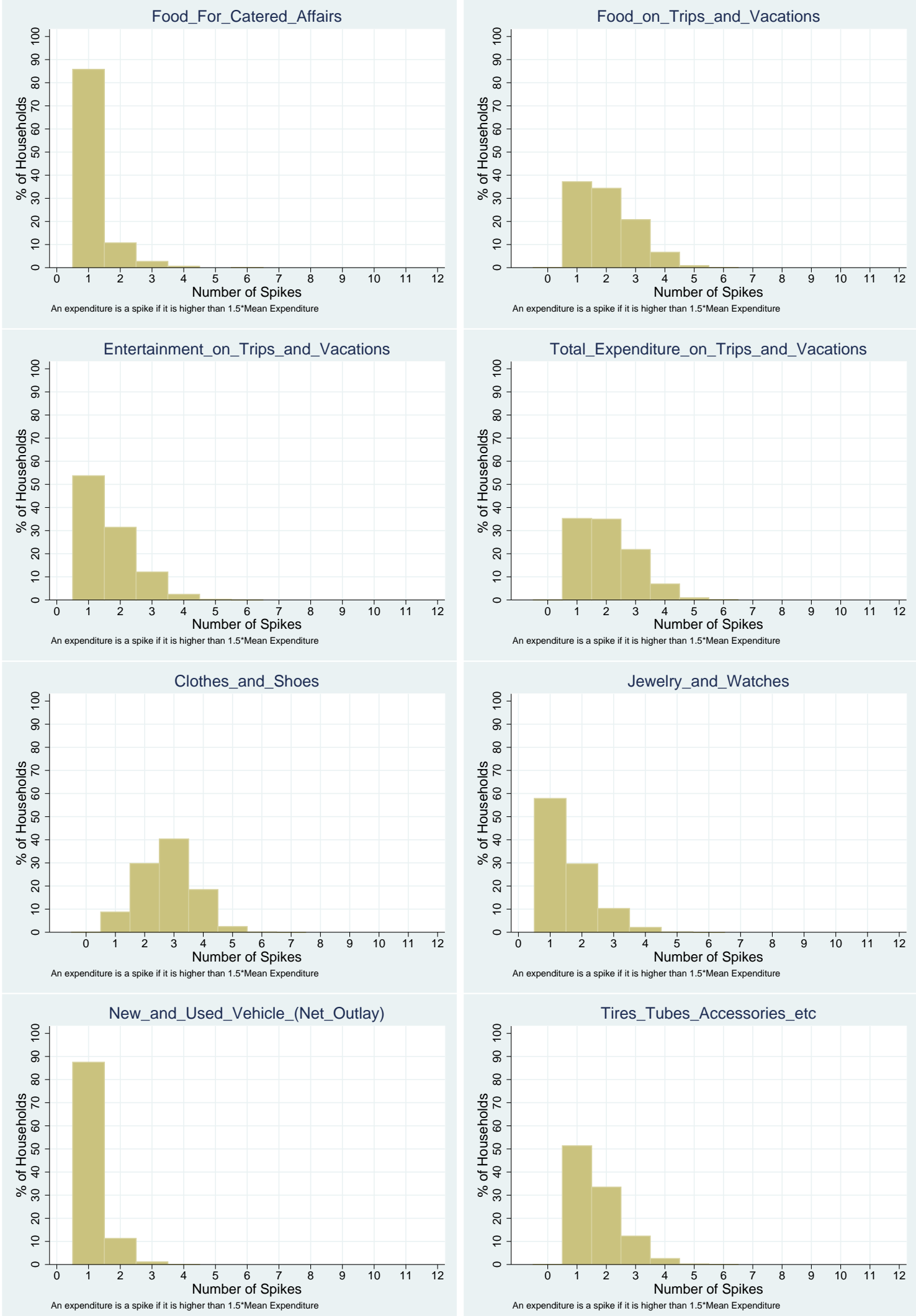
Figure 21:
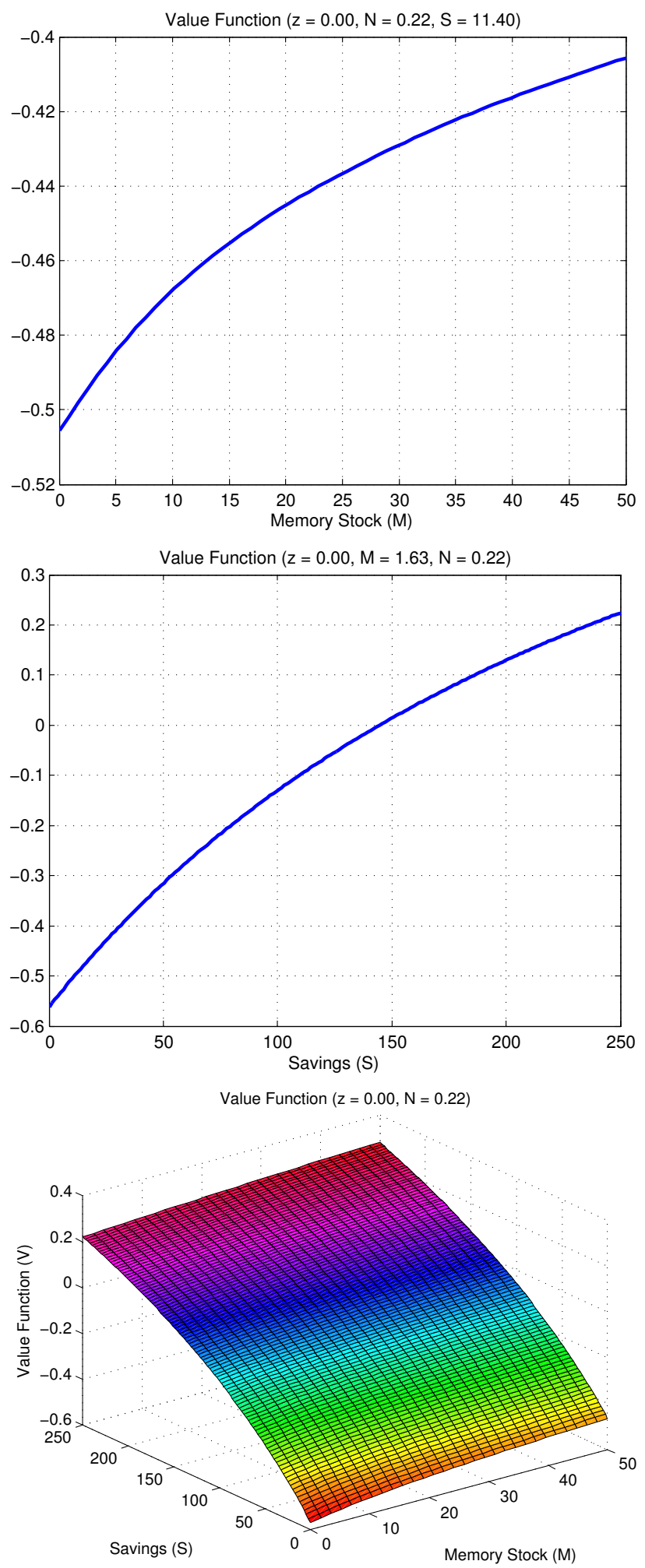